Supporting Information for

\title{
Loops Versus Branch Functionality in Model Click Hydrogels
}

Ken Kawamoto $^{1}$, Mingjiang Zhong ${ }^{1,2}$, Rui Wang ${ }^{2}$, Bradley D. Olsen ${ }^{2}$, Jeremiah A. Johnson ${ }^{1}$

${ }^{1}$ Department of Chemistry, Massachusetts Institute of Technology, 77 Massachusetts Avenue, Cambridge, MA 02139, U.S.A.

${ }^{2}$ Department of Chemical Engineering, Massachusetts Institute of Technology, 77 Massachusetts Avenue, Cambridge, MA 02139, U.S.A. 


\section{Contents}

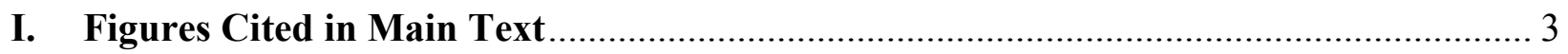

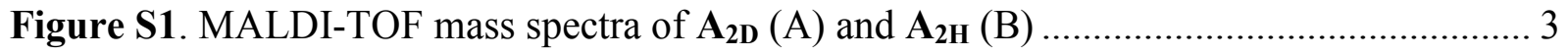

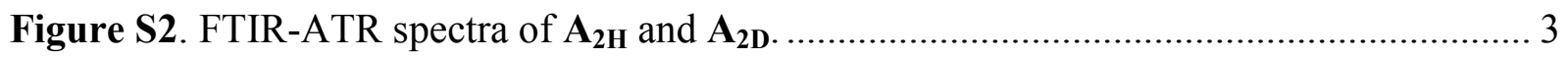

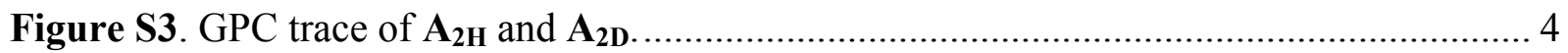

Figure S4. MALDI-TOF mass spectra of $\mathbf{A}_{\mathbf{2 C 5}}$ (A) $\mathbf{A}_{2 \mathbf{2 6}}$ (B) $\mathbf{A}_{\mathbf{2 H}},(\mathrm{C})$ and $\mathbf{A}_{2 \mathbf{D}},(\mathrm{D})$................ 4

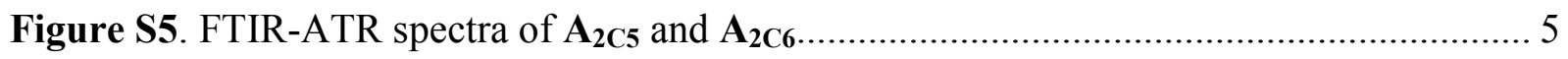

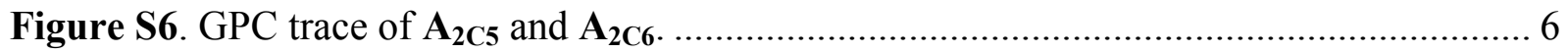

Figure S7. Representative FTIR-ATR spectrum of gel indicating the absence of azide and

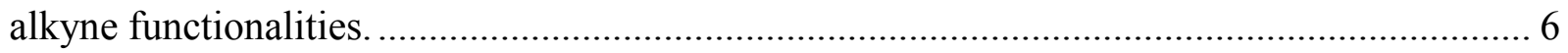

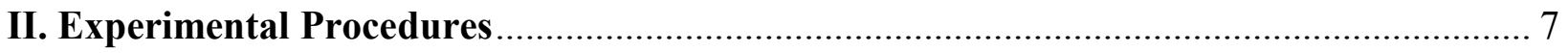

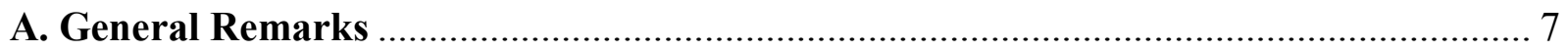

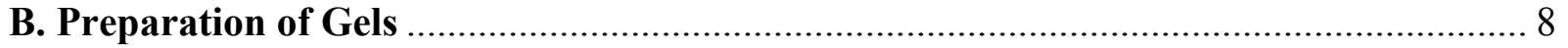

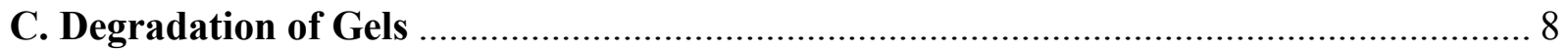

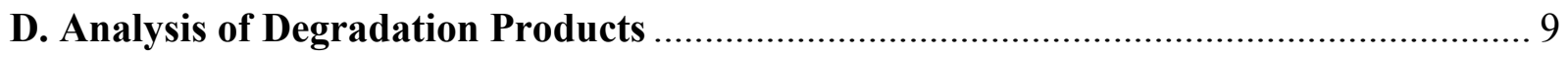

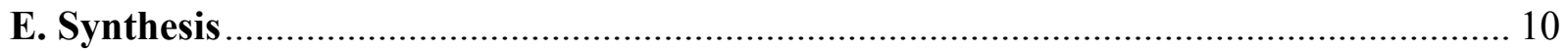

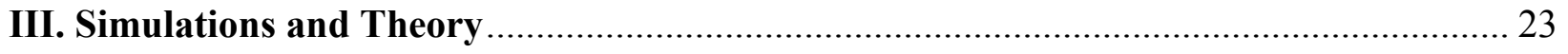

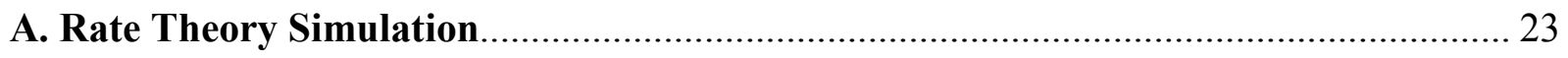

B. Monte Carlo Simulation ........................................................................................ 24

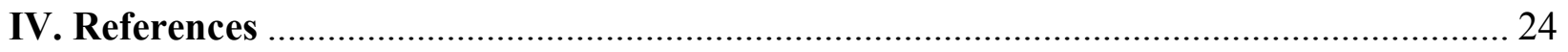

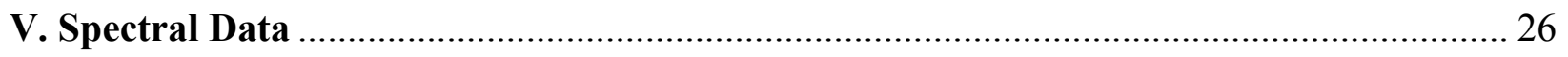

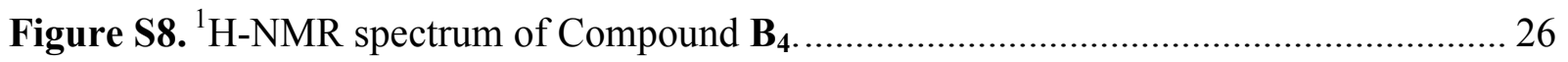

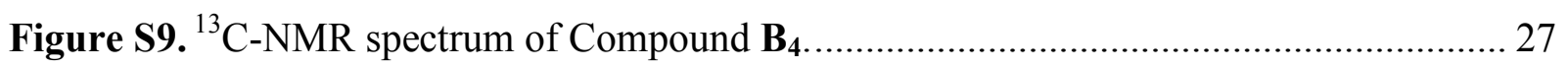

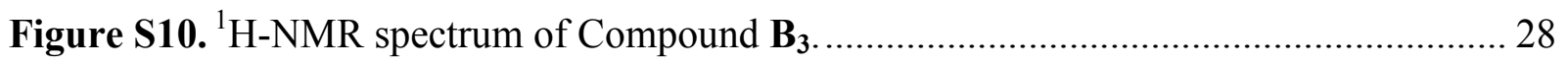

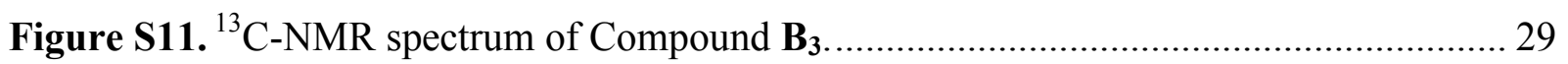

Figure S12. ${ }^{1} \mathrm{H}-\mathrm{NMR}$ spectrum of 2,2-ditrideutromethyl-5,5-dideutro-1,3-dioxane-4,6-dione

Figure S13. ${ }^{13}$ C-NMR spectrum of 2,2-ditrideutromethyl-5,5-dideutro-1,3-dioxane-4,6-dione 31

Figure S14. ${ }^{1} \mathrm{H}-\mathrm{NMR}$ spectrum of 2,2,5,5-tetramethyl-1,3-dioxane-4,6-dione ........................ 32

Figure S15. ${ }^{13} \mathrm{C}-\mathrm{NMR}$ spectrum of 2,2,5,5-tetramethyl-1,3-dioxane-4,6-dione...................... 33 
Figure S16. ${ }^{1}$ H-NMR spectrum of 2-((3-azidopropyl)carbamoyl)-2-(methyl-d3)propanoic3,3,3-d3 acid.

Figure S17. ${ }^{13} \mathrm{C}$-NMR spectrum of 2-((3-azidopropyl)carbamoyl)-2-(methyl-d3)propanoic3,3,3-d3 acid. 35

Figure S18. ${ }^{1}$ H-NMR spectrum of 3-((3-azidopropyl)amino)-2,2-dimethyl-3-oxopropanoic acid 36

Figure S19. ${ }^{13} \mathrm{C}$-NMR spectrum of 3-((3-azidopropyl)amino)-2,2-dimethyl-3-oxopropanoic acid

Figure S20. ${ }^{1} \mathrm{H}$ NMR spectrum of 3-azidopropan-1-amine as a solution in toluene .............. 38

Figure S21. ${ }^{1}$ H-NMR spectrum of 4-((5-azidopentyl)amino)-4-oxobutanoic acid ................. 39

Figure S22. ${ }^{13} \mathrm{C}-\mathrm{NMR}$ spectrum of $4-((5$-azidopentyl)amino)-4-oxobutanoic acid................ 40

Figure S23. ${ }^{1} \mathrm{H}-\mathrm{NMR}$ spectrum of 4-((6-azidohexyl)amino)-4-oxobutanoic acid ................. 41

Figure S24. ${ }^{13} \mathrm{C}-\mathrm{NMR}$ spectrum of 4-((6-azidohexyl)amino)-4-oxobutanoic acid................. 43

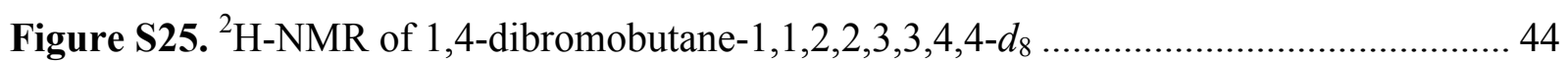

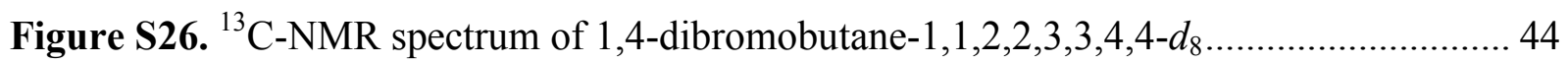

Figure S27. ${ }^{1} \mathrm{H}-\mathrm{NMR}$ spectrum of ethyl 6-bromo-2,2-dimethylhexanoate........................... 45

Figure S28. ${ }^{13} \mathrm{C}$-NMR spectrum of ethyl 6-bromo-2,2-dimethylhexanoate .......................... 46

Figure S29. ${ }^{1} \mathrm{H}-\mathrm{NMR}$ spectrum of ethyl 6-bromo-2,2-dimethylhexanoate-3,3,4,4,5,5,6,6- $d_{8} 47$

Figure S30. ${ }^{2} \mathrm{H}-\mathrm{NMR}$ spectrum of ethyl 6-bromo-2,2-dimethylhexanoate-3,3,4,4,5,5,6,6- $d_{8} 48$

Figure S31. ${ }^{13} \mathrm{C}$-NMR spectrum of ethyl 6-azido-2,2-dimethylhexanoate-3,3,4,4,5,5,6,6- $d_{8}$. 49

Figure S32. ${ }^{1} \mathrm{H}-\mathrm{NMR}$ spectrum of 6-azido-2,2-dimethylhexanoic acid .............................. 50

Figure S33. ${ }^{13} \mathrm{C}$-NMR spectrum of 6-azido-2,2-dimethylhexanoic acid .............................. 51

Figure S34. ${ }^{1} \mathrm{H}-\mathrm{NMR}$ spectrum of 6-azido-2,2-dimethylhexanoic-3,3,4,4,5,5,6,6- $d_{8}$ acid ..... 52

Figure S35. ${ }^{2} \mathrm{H}-\mathrm{NMR}$ spectrum of 6-azido-2,2-dimethylhexanoic-3,3,4,4,5,5,6,6- $d_{8}$ acid ..... 53

Figure S35. ${ }^{13} \mathrm{C}$-NMR spectrum of 6-azido-2,2-dimethylhexanoic-3,3,4,4,5,5,6,6- $d_{8}$ acid .... 54

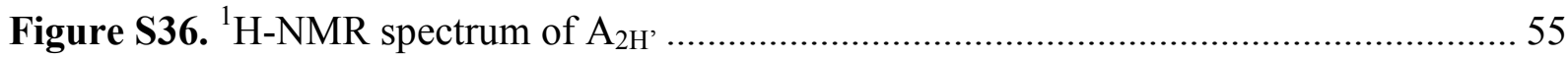

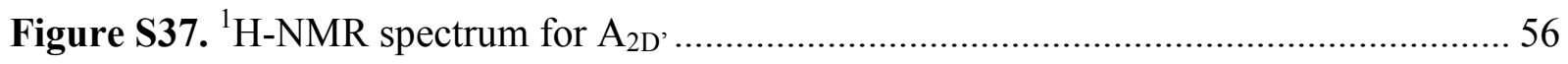




\section{Figures Cited in Main Text}

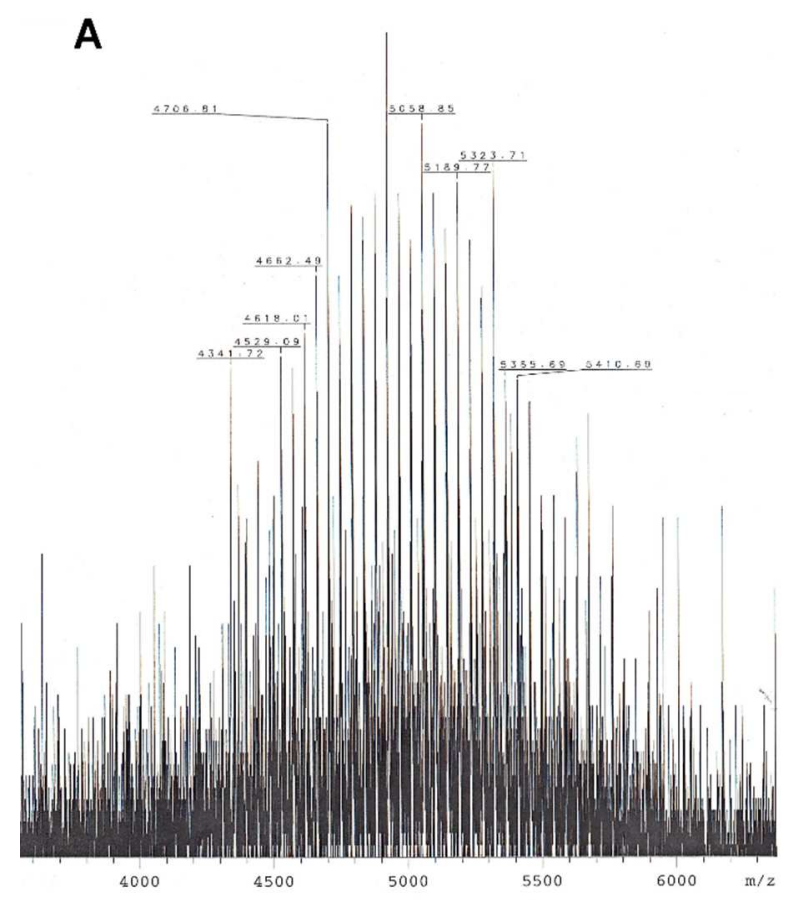

B

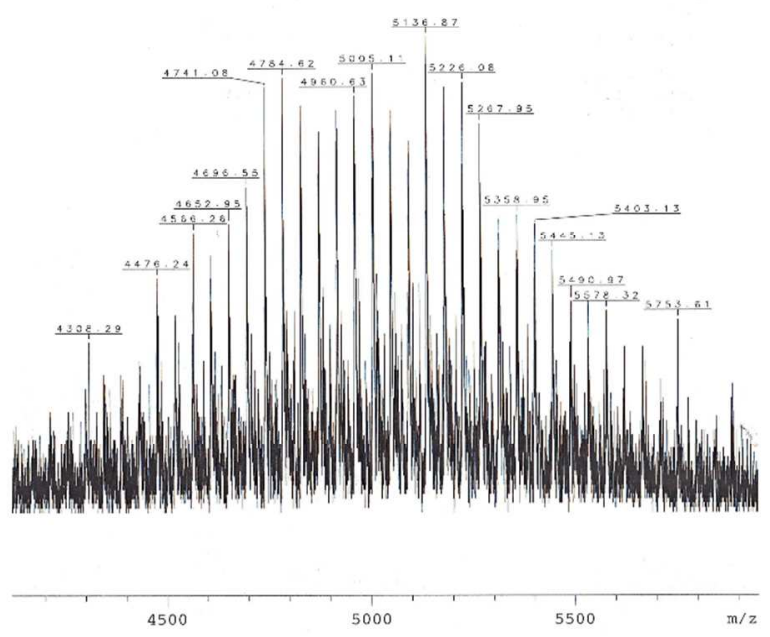

Figure S1. MALDI-TOF mass spectra of $\mathbf{A}_{2 \mathbf{D}}(\mathrm{A})$ and $\mathbf{A}_{2 \mathrm{H}}$ (B)

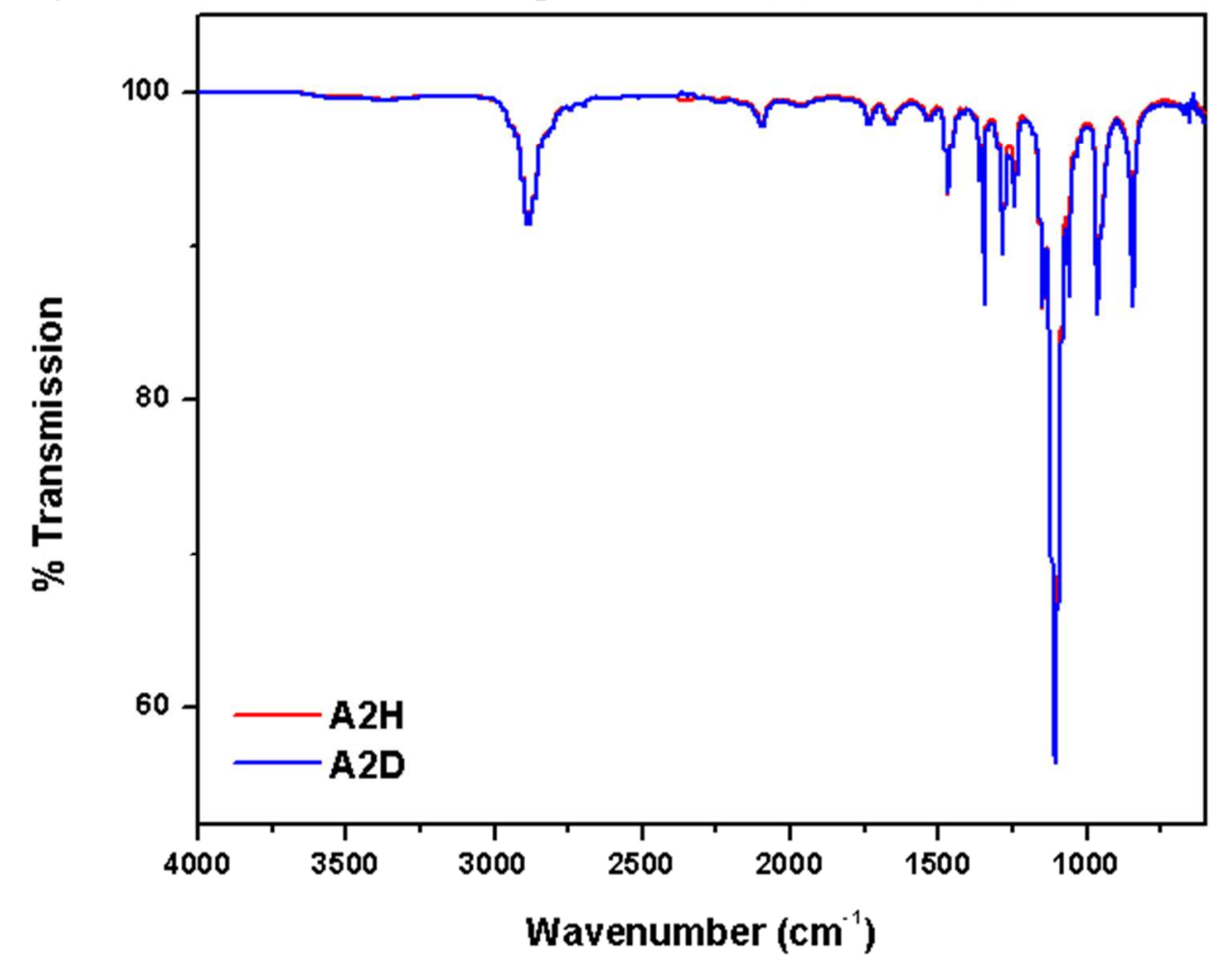

Figure S2. FTIR-ATR spectra of $\mathbf{A}_{\mathbf{2 H}}$ and $\mathbf{A}_{\mathbf{2 D}}$. 


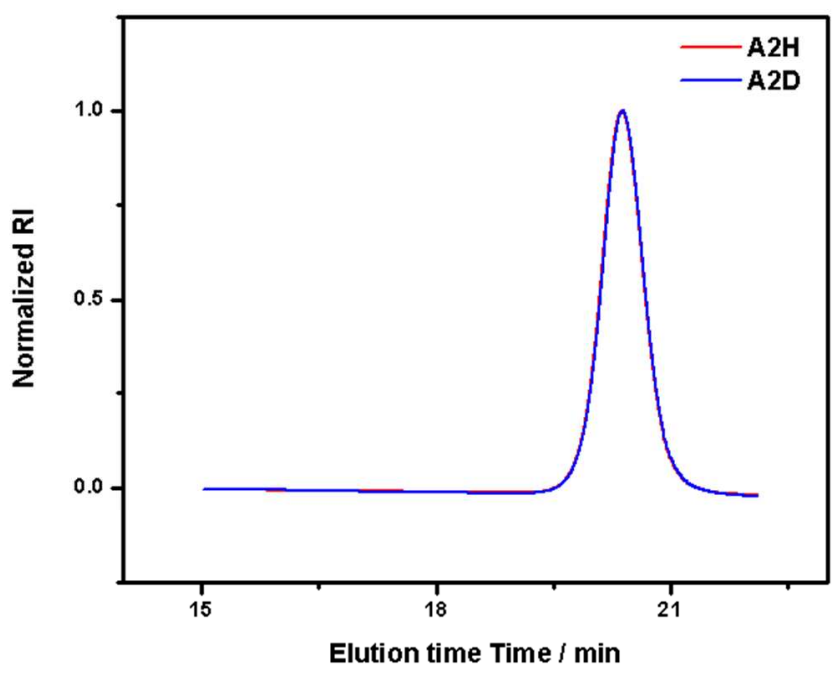

Figure S3. GPC traces of $\mathbf{A}_{2 H}$ and $\mathbf{A}_{2 D}$. RI = refractive index detector response.
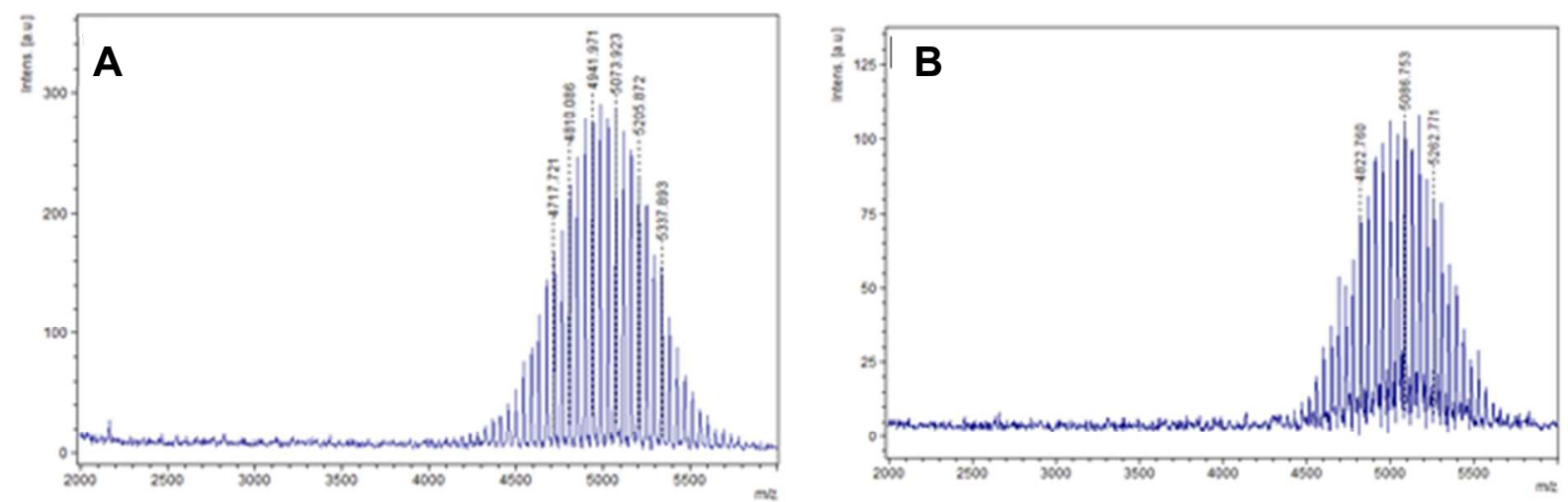

Figure S4. MALDI-TOF mass spectra of $\mathbf{A}_{2 \mathbf{H}},(\mathrm{A})$ and $\mathbf{A}_{2 \mathrm{D}},(\mathrm{B})$. 
A

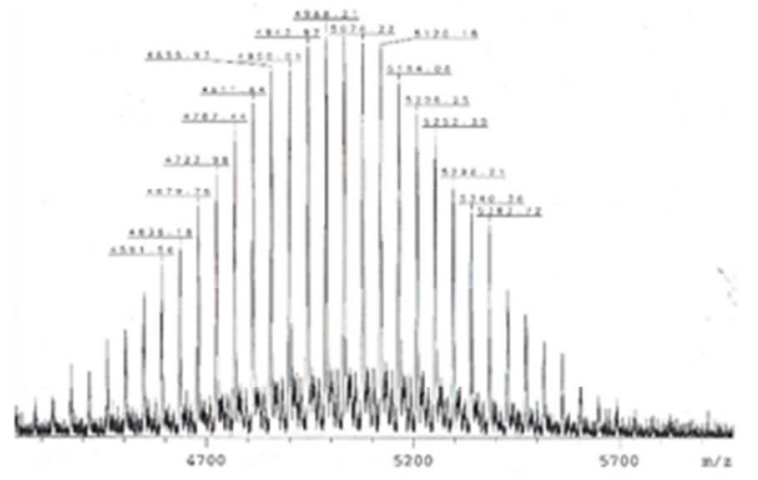

B

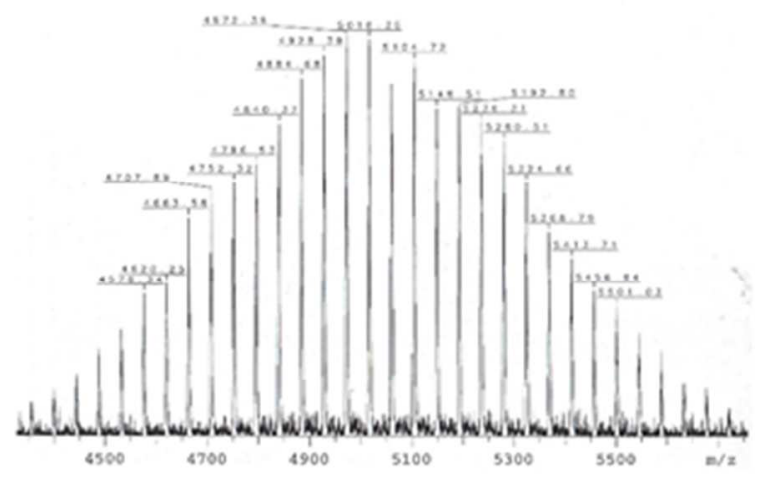

Figure S5. MALDI-TOF mass spectra of $\mathbf{A}_{2 \mathrm{C5}}$ (A) $\mathbf{A}_{2 \mathbf{2} 6}$ (B).

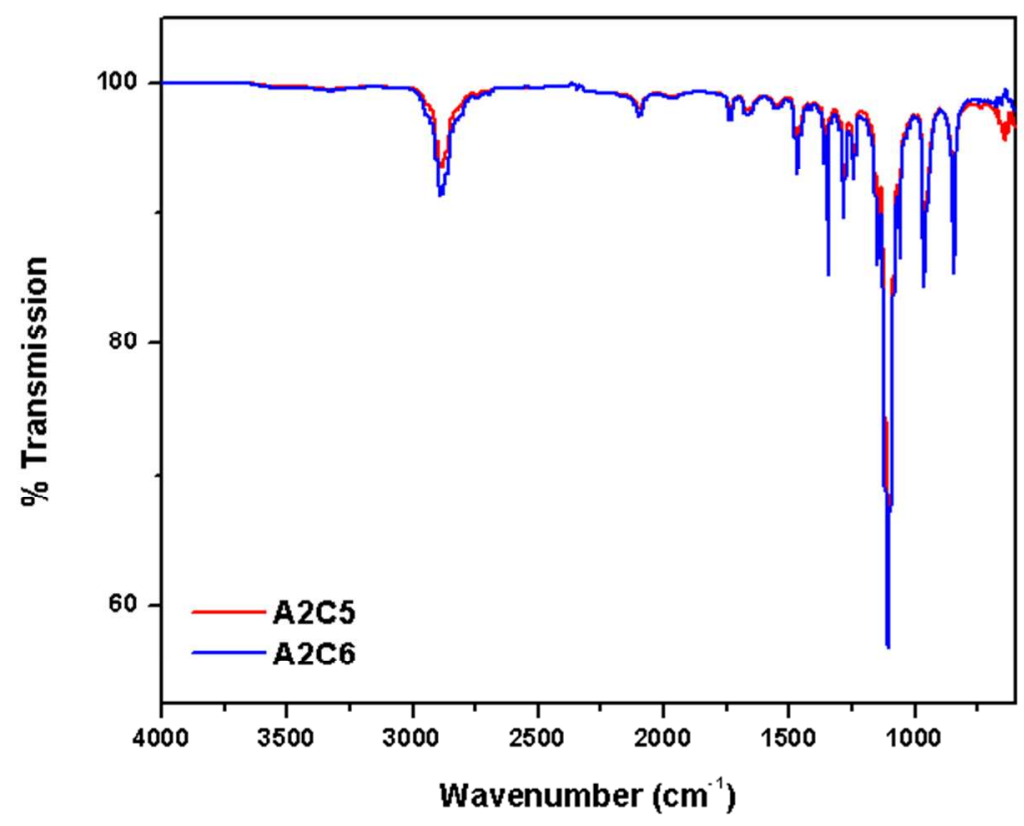

Figure S6. FTIR-ATR spectra of $\mathbf{A}_{2 \mathrm{C} 5}$ and $\mathbf{A}_{2 \mathrm{C} 6}$. 


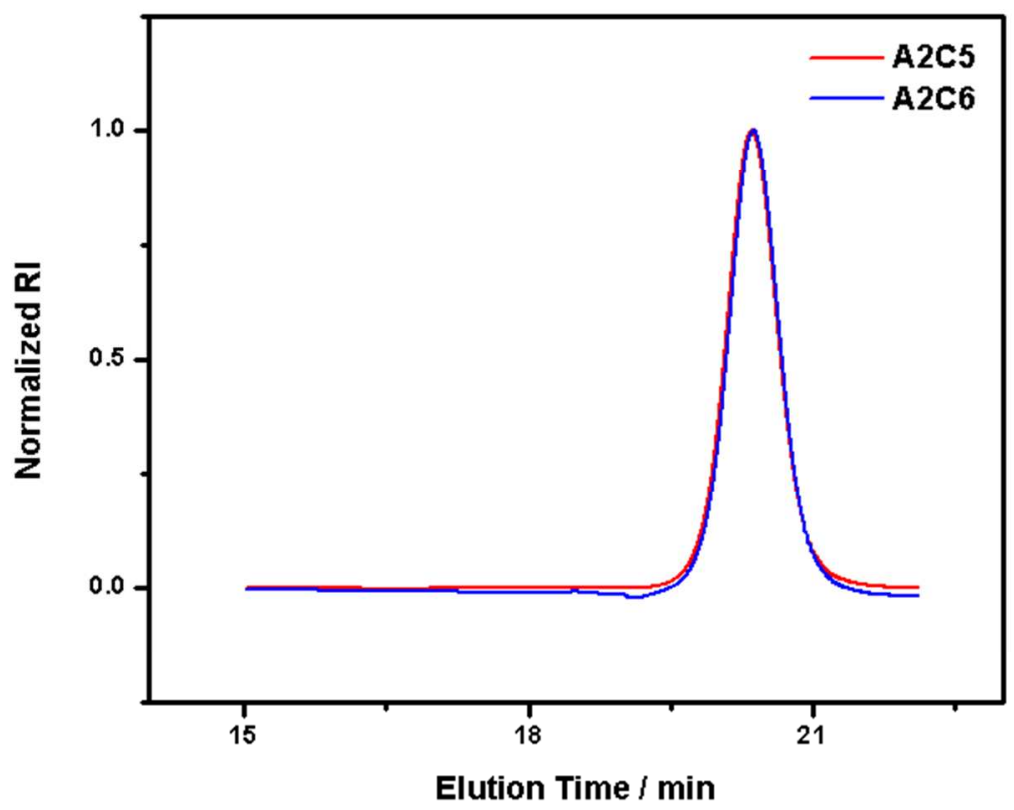

Figure S7. GPC traces of $\mathbf{A}_{2 \mathrm{C} 5}$ and $\mathbf{A}_{2 \mathbf{C 6}}$.

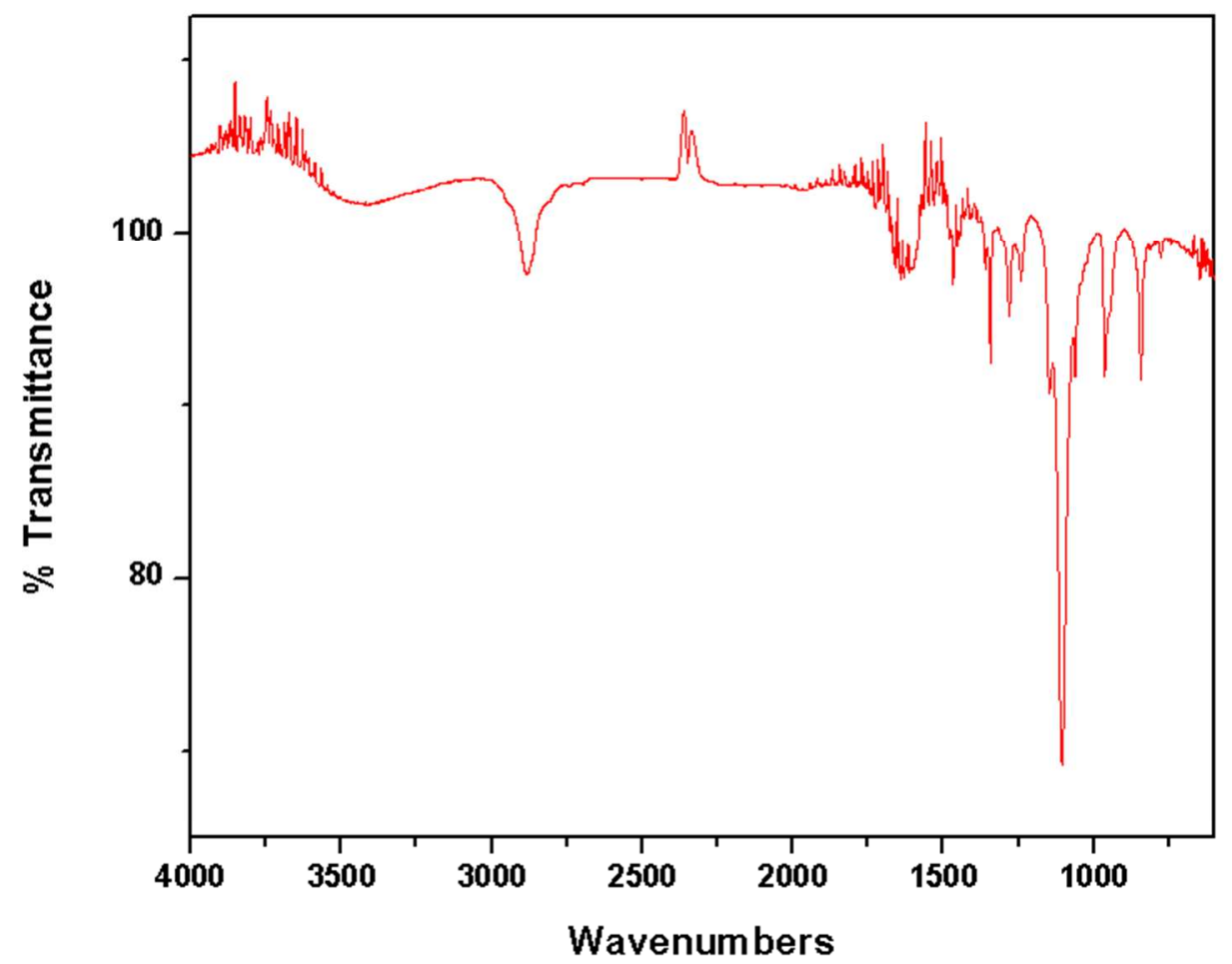

Figure S8. Representative FTIR-ATR spectrum of gel indicating the absence of azide and terminal alkyne functionalities. 


\section{Experimental Procedures}

\section{A. General Remarks}

All anhydrous and HPLC grade solvents were purchased from Sigma Aldrich or Alfa Aesar and used as supplied unless otherwise stated. Anhydrous, degassed dichloromethane (DCM) and tetrahydrofuran (THF) were used from a J.C. Meyer solvent purification system. HPLC grade DCM and THF were sparged vigorously with argon for at least one hour before being connected to the solvent purification system. All reagents were purchased from Sigma Aldrich or Alfa Aesar unless otherwise stated. All chromatography was performed on EMD Millipore silica gel 60, particle size $0.040-0.063 \mathrm{~mm}$ (230-400 mesh) on a Biotage ${ }^{\circledR}$ Isolera Prime ${ }^{\mathrm{TM}}$ flash purification system. Liquid chromatography/mass spectrometry (LC/MS) analysis was done on an Agilent Infinity 1260 stack with a diode array detector and a 6130 quadrupole mass spectrometer. A Phenomenex Luna $5 \mu \mathrm{m} \mathrm{C18,20 \times 2.0} \mathrm{mm} \mathrm{column} \mathrm{was} \mathrm{connected} \mathrm{in} \mathrm{series} \mathrm{to}$ an Advanced Materials Technology Halo C18, $2.7 \mu \mathrm{m}, 2.1 \times 30 \mathrm{~mm}$ column as a guard columncolumn, respectively, for the LC/MS. A mixture $0.1 \%$ acetic acid/MilliQ $\mathrm{H}_{2} \mathrm{O}$ and HPLC grade acetonitrile $(\mathrm{MeCN})$ were used as the mobile phase for the LC/MS. LC/MS data analysis was done on Agilent ChemStation. Gel Permeation Chromatography (GPC) was performed on an Agilent 1260 LC stack equipped with an Agilent multi-wavelength UV/vis detector, Wyatt TrEX refractive index detector, Wyatt DAWN EOS 18-angle light scattering detector, and two Shodex KD-806M GPC columns. The GPC system was set to $60{ }^{\circ} \mathrm{C}$ with a $1 \mathrm{~mL} / \mathrm{min}$ flow rate with $0.025 \mathrm{M} \mathrm{LiBr}$ in DMF. Fourier transform infrared attenuated total reflectance (FTIR-ATR) spectroscopy was performed on a Thermo Scientific Nicolet 6700 FT-IR equipped with a germanium ATR crystal.

${ }^{1} \mathrm{H}$ nuclear magnetic resonance $\left({ }^{1} \mathrm{H} \mathrm{NMR}\right)$ and ${ }^{13} \mathrm{C}$ nuclear magnetic resonance $\left({ }^{13} \mathrm{C} \mathrm{NMR}\right)$ spectra were acquired on $500 \mathrm{MHz}$ Varian INOVA or $600 \mathrm{MHz}$ Bruker AVANCE spectrometers. Spectra were calibrated by the residual solvent signal in deuterated solvents $\left(\mathrm{CDCl}_{3}\right)$, which were purchased from Cambridge Isotope Laboratories, Inc. NMR spectra were processed in MestReNova LITE 5.2.5. Matrix-assisted laser desorption/ionization time-of-flight (MALDITOF) analyses were collected on a Bruker OmniFlex instrument with a $337 \mathrm{~nm} \mathrm{~N}$ laser with a $0.1 \mathrm{~nm}$ spectral bandwidth. High resolution mass spectrometry (HRMS) was done on a Bruker Daltronics APEXIV 4.7 Tesla Fourier transform ion cyclotron resonance mass spectrometer (FTICR MS). 


\section{B. Preparation of Gels}

Gels were prepared using a stock solution of $\mathrm{A}_{2}$ macromer and $\mathrm{B}_{f}$ crosslinker. The mixture of $\mathrm{A}_{2}$ macromer was prepared by carefully weighing each component in an Erlenmeyer flask, dissolving in a minimal amount of ethyl acetate, and precipitating the mixture by dropwise addition to a stirring flask of cold diethyl ether. The crosslinker was carefully weighed in a vial on a balance, to which the correct stoichiometric equivalent of macromer was added. The dry mixture was brought into a glovebox.

For the catalyst, $\mathrm{CuBr}$ was prepared by dispersing commercial $\mathrm{CuBr}$, which contains some $\mathrm{Cu}(\mathrm{II})$, in water. A tenfold excess of $L$-ascorbic acid was added and the mixture was stirred for 15 minutes, after which the powder was almost completely white. The suspension was filtered using a medium fritted glass funnel and washed with copious amounts of deionized water. The white powder $(\mathrm{CuBr})$ was washed sequentially with glacial acetic acid and diethyl ether, dried under vacuum, and then brought into a glovebox. The $\mathrm{CuBr}$ was stored in a vial in the dark. $\mathrm{Me}_{6}$ TREN was transferred to a Schlenk flask, sparged with nitrogen for $6 \mathrm{~h}$, and then freezepump-thawed. The flask was brought into a glovebox under vacuum. $\mathrm{CuBr}$ was first weighed into a vial in the glovebox, and then suspended in acetonitrile. In a separate vial, 1.1 equivalents of $\mathrm{Me}_{6}$ TREN was dissolved in acetonitrile and transferred to the vial with $\mathrm{CuBr}$. The catalyst solution was vortexed until all of the $\mathrm{CuBr}$ was converted to the complex. A small amount of $\mathrm{Cu}(0)$ due to the disproportionation of $\mathrm{Cu}(\mathrm{I})$ was often observed as a fine brown powder for concentrated solutions. The presence of $\mathrm{Cu}(0)$ did not appear to affect any of the reactions.

For concentrated gels (total sample volumes $<300 \mu \mathrm{L}$ ), the reactions were prepared in $1.8 \mathrm{~mL}$ LC/MS vials (VWR: 46610-722) with $400 \mu \mathrm{L}$ inserts (VWR: 97047-024) or $12 \mathrm{~mm}$ x $32 \mathrm{~mm}$ vials with inserts (Thermo Scientific C4011-LV1). More dilute gels and soluble networks were prepared directly in $1.8 \mathrm{~mL}$ LC/MS vials or $2 \mathrm{~mL}$ screw-top vials (Agilent Technologies: 51834428).

Each sample was prepared in triplicate. All volumes were measured using a 20,100, or $1000 \mu \mathrm{L}$ micropipette. First, any acetonitrile in addition to the required macromer/crosslinker and catalyst stock solutions were added to the vials. Then, the appropriate amount of macromer/crosslinker stock solution was added to all samples. Finally, a stoichiometric amount of catalyst solution was added to the macromer/crosslinker solution and immediately vortexed. The vials were capped tightly and sealed in a secondary container to react overnight. Most gelations occurred within an hour, but all reactions were allowed to react for at least $24 \mathrm{~h}$ to ensure complete conversion.

\section{Degradation of Gels}

To degrade the networks, the samples were removed from the glovebox. The samples were then dissolved in $300 \mu \mathrm{L}$ of $1.5 \mathrm{M} \mathrm{KOH}$ in MilliQ $\mathrm{H}_{2} \mathrm{O}$ and vortexed. After about an hour, the reactions were quenched with $150 \mu \mathrm{L}$ of $1.5 \mathrm{M} \mathrm{H}_{2} \mathrm{SO}_{4}$. The samples were then analyzed via LC/MS. 


\section{Analysis of Degradation Products}

The degradation products were analyzed by LC/MS using the Single Ion Mode (SIM) on the MS. The masses of fully reacted junctions as well as incompletely reacted trifunctional junctions and bifunctional junctions were entered into the SIM mass series for tetrafunctional and trifunctional networks, respectively, to identify dangling chains that could result from incomplete conversion and/or off-stoichiometry error. The principal isotope peak for each degradation product was extracted in the "Extract Ion" feature of ChemStation, and quantified using the integration feature for each extracted ion.

Previously, the following equation was derived to relate the abundance of each junction with $p$ natural abundance labels, where $m$ is the maximum number of loops that can form for an $f$ functional crosslinker, $x$ is the ratio of natural abundance labels to labeled samples, and $n_{\lambda}$ is the average number of loops per junction. ${ }^{1-2}$

$$
N I(p)=m^{-m} \sum_{j=0}^{m}\left\langle n_{\lambda}\right\rangle^{j}\left(m-\left\langle n_{\lambda}\right\rangle\right)^{(m-j)} x^{p-j}(1-x)^{f-p-j} \sum_{k=0}^{j}\left(\begin{array}{l}
j \\
k
\end{array}\right)(1-x)^{k} x^{j-k}\left(\begin{array}{l}
f-2 j \\
p-2 k
\end{array}\right)
$$

For tetrafunctional networks, this equation simplifies to the following set of equations:

$$
\begin{aligned}
& {[1111]=x^{4}+x^{3} n_{\lambda 4}-x^{4} n_{\lambda 4}+\frac{1}{4} x^{2} n_{\lambda 4}^{2}-\frac{1}{2} x^{3} n_{\lambda 4}^{2}+\frac{1}{4} x^{4} n_{\lambda 4}^{2}} \\
& {[1112]=4 x^{3}-4 x^{4}+2 x^{2} n_{\lambda 4}-6 x^{3} n_{\lambda 4}+4 x^{4} n_{\lambda 4}-x^{2} n_{\lambda 4}^{2}+2 x^{3} n_{\lambda 4}^{2}-x^{4} n_{\lambda 4}^{2}} \\
& {[1122]=6 x^{2}-12 x^{3}+6 x^{4}+x n_{\lambda 4}-7 x^{2} n_{\lambda 4}+12 x^{3} n_{\lambda 4}-6 x^{4} n_{\lambda 4}+\frac{3}{2} x^{2} n_{\lambda 4}^{2}-3 x^{3} n_{\lambda 4}^{2}} \\
& +\frac{3}{2} x^{4} n_{\lambda 4}^{2} \\
& {[1222]=4 x-12 x^{2}+12 x^{3}-4 x^{4}-2 x n_{\lambda 4}+8 x^{2} n_{\lambda 4}-10 x^{3} n_{\lambda 4}+4 x^{4} n_{\lambda 4}-x^{2} n_{\lambda 4}^{2}} \\
& +2 x^{3} n_{\lambda 4}^{2}-x^{4} n_{\lambda 4}^{2} \\
& {[2222]=1-} \\
& \quad 4 x+6 x^{2}-4 x^{3}+x^{4}+x n_{\lambda 4}-3 x^{2} n_{\lambda 4}+3 x^{3} n_{\lambda 4}-x^{4} n_{\lambda 4}+\frac{1}{4} x^{2} n_{\lambda 4}^{2}-\frac{1}{2} x^{3} n_{\lambda 4}^{2} \\
& \quad+\frac{1}{4} x^{4} n_{\lambda 4}^{2}
\end{aligned}
$$

To determine the number of loops in a given sample, we solve for $n_{\imath}$ using the ratio of $[1111] /[1112]$. This value yields the average number of loops at a tetrafunctional junction. 


\section{E. Synthesis}

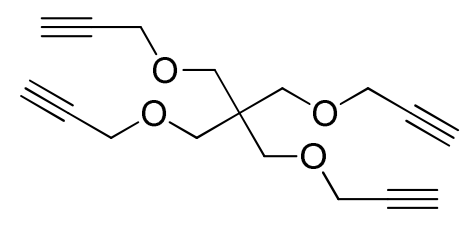

Compound $B_{4}$ : 3-(3-(prop-2-yn-1-yloxy)-2,2-bis((prop-2-yn-1-yloxy)methyl)propoxy)prop1-yne

To a $100 \mathrm{~mL}$ round bottom flask was added $1 \mathrm{~g}(7.3 \mathrm{mmol})$ of pentaerythritol and $6.2 \mathrm{~g}$ (40 mmol) of potassium hydroxide. Then, $12.5 \mathrm{~mL}$ of DMF was added and the suspension was cooled to $5{ }^{\circ} \mathrm{C}$. An $80 \%$ solution of propargyl bromide in toluene was added $(8.2 \mathrm{~mL}, 8.73 \mathrm{~g}$, $73.4 \mathrm{mmol}$ ), and the solution was heated to $40{ }^{\circ} \mathrm{C}$, and after which 5 minutes the solution turned black. After $2.5 \mathrm{~h}$, an additional $4 \mathrm{~mL}$ of propargyl bromide solution was added to the mixture. The reaction was stirred for $18 \mathrm{~h}$, after which the reaction was cooled to room temperature and water was added. The aqueous solution was extracted with diethyl ether three times and the combined organic layers were washed with brine. The organic fraction was then dried over sodium sulfate, filtered, and concentrated. The crude material was chromatographed on silica gel, using a 5\% ethyl acetate/hexanes $\rightarrow 32 \%$ ethyl acetate/hexanes gradient. The fractions containing the product were collected, concentrated, and then redissolved in approximately $2 \mathrm{~mL}$ of warm $25 \%$ ethyl acetate/hexane solution. The solution was stirred gently and small portions of hexanes were added while allowing the solution to cool. The product precipitated as a white powder, which was then collected to afford $279 \mathrm{mg}$ of the desired product in $13 \%$ yield. The compound can also be recrystallized from a warm mixture of $15 \%$ ethyl acetate/hexanes.

HRMS $(m / z)$ calculated for $\mathrm{C}_{17} \mathrm{H}_{20} \mathrm{O}_{4}{ }^{+}: 289.1434$; found: 289.1429

${ }^{1} \mathrm{H}-\mathrm{NMR}\left(500 \mathrm{MHz}, \mathrm{CDCl}_{3}\right) \delta: 4.12(8 \mathrm{H}, \mathrm{d}, 2.45 \mathrm{~Hz}), 3.52(8 \mathrm{H}, \mathrm{s}), 2.40(2.5 \mathrm{H}, \mathrm{t}, 2.40 \mathrm{~Hz})$

${ }^{13} \mathrm{C}-\mathrm{NMR}\left(125 \mathrm{MHz}, \mathrm{CDCl}_{3}\right) \delta: 80.23,74.31,69.21,58.92,44.95$

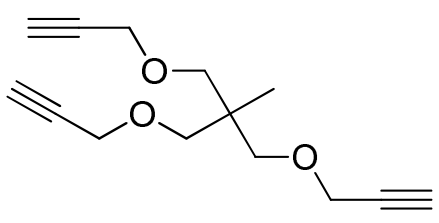

\section{Compound $\quad B_{3}: \quad 3-(2-m e t h y l-3-(p r o p-2-y n-1-y l o x y)-2-((p r o p-2-y n-1-$ yloxy)methyl)propoxy)prop-1-yne}

To a flame dried, $100 \mathrm{~mL}$ round bottom flask was added $1.0 \mathrm{~g}(8.3 \mathrm{mmol})$ of 1,1,1tris(hydroxymethyl)ethane and $3.98 \mathrm{~g}$ of potassium hydroxide $(71 \mathrm{mmol})$. The flask was evacuated and backfilled with $\mathrm{N}_{2}$ three times, and then suspended in $11 \mathrm{~mL}$ of anhydrous DMSO. 
The suspension was cooled to $0{ }^{\circ} \mathrm{C}$. Then, $2.9 \mathrm{~mL}$ of a $80 \%$ propargyl bromide solution in toluene $(25.9 \mathrm{mmol})$ was added dropwise, after which the solution turned dark brown. The flask was stirred under $\mathrm{N}_{2}$ and allowed to warm to room temperature overnight. The next day, the reaction was diluted with $120 \mathrm{~mL}$ of water. The mixture was extracted three times with a 1:1 solution of diethyl ether/ethyl acetate. The combined organic layers were washed successively with water twice and brine twice. The organic fraction was dried over sodium sulfate, filtered, and concentrated. The crude material was chromatographed on silica gel using 9:1 hexane/ethyl acetate as the eluent. The fraction containing the product were collected and concentrated to afford $1.12 \mathrm{~g}$ in $58 \%$ yield.

${ }^{1} \mathrm{H}-\mathrm{NMR}\left(500 \mathrm{MHz}, \mathrm{CDCl}_{3}\right) \delta: 4.12(6 \mathrm{H}, \mathrm{d}, 2.37 \mathrm{~Hz}), 3.39(6 \mathrm{H}, \mathrm{s}), 2.40(3 \mathrm{H}, \mathrm{t}, 2.35 \mathrm{~Hz}), 0.97$ $(3 \mathrm{H}, \mathrm{s})$

${ }^{13} \mathrm{C}-\mathrm{NMR}\left(125 \mathrm{MHz}, \mathrm{CDCl}_{3}\right) \delta: 80.28,74.25,72.89,58.86,40.52,17.54$

HRMS (m/z) calculated for C14H18O3+: 251.1278; found 251.1278

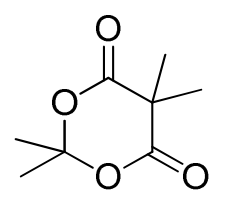

\section{2,2,5,5-tetramethyl-1,3-dioxane-4,6-dione}

To a flame-dried $250 \mathrm{~mL}$ round bottom flask was added $9.1 \mathrm{~g}(39.3 \mathrm{mmol})$ of $\mathrm{Ag}_{2} \mathrm{O}$. The flask was evacuated and backfilled with nitrogen three times. The $\mathrm{Ag}_{2} \mathrm{O}$ was then suspended in $50 \mathrm{~mL}$ of acetonitrile and $7.4 \mathrm{~mL}(16.3 \mathrm{~g}, 114.5 \mathrm{mmol})$ of MeI was added to the flask, after which the reaction was cooled to $0{ }^{\circ} \mathrm{C}$. In a separate vial, $5 \mathrm{~g}(34.7 \mathrm{mmol})$ of Meldrum's acid was dissolved in $20 \mathrm{~mL}$ of acetonitrile and added dropwise to the flask. The reaction was allowed to stir overnight, during which time a yellow precipitate formed. The next day, the reaction was filtered over Celite 545 in a Büchner funnel, which was washed with acetonitrile. The filtrate was concentrated and then chromatographed on silica, using $15 \%$ ethyl acetate/hexanes as the eluent. The fractions containing the product were collected and concentrated, affording $4.88 \mathrm{~g}$ of the desired product in $81 \%$ yield.

${ }^{1} \mathrm{H}-\mathrm{NMR}\left(500 \mathrm{MHz}, \mathrm{CDCl}_{3}\right) \delta: 1.75(6 \mathrm{H}, \mathrm{s}), 1.65(6 \mathrm{H}, \mathrm{s})$

${ }^{13} \mathrm{C}-\mathrm{NMR}\left(125 \mathrm{MHz}, \mathrm{CDCl}_{3}\right) \delta: 171.12$ 104.86, 44.71, 29.00, 25.75

HRMS $(\mathrm{m} / \mathrm{z})$ calculated for $\mathrm{C}_{8} \mathrm{H}_{13} \mathrm{O}_{4}{ }^{+}: 173.0808$; found: 173.0815 


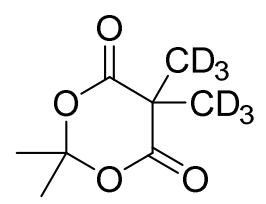

\section{2,2-ditrideutromethyl-5,5-dideutro-1,3-dioxane-4,6-dione}

This isotopologue was synthesized in the same manner as its natural isotope analogue. The desired product was isolated as a crystalline solid. $76 \%$ yield.

${ }^{1} \mathrm{H}-\mathrm{NMR}\left(500 \mathrm{MHz}, \mathrm{CDCl}_{3}\right) \delta: 1.75(6 \mathrm{H}, \mathrm{s})$

${ }^{13} \mathrm{C}-\mathrm{NMR}\left(125 \mathrm{MHz}, \mathrm{CDCl}_{3}\right) \delta: 171.15,104.86,44.35,29.00$. N.B. the resonance for the deuterated carbons is absent due to the lack of dipolar relaxation and NOE enhancement, which result from the lack of protons.

HRMS $(m / z)$ calculated for $\mathrm{C}_{5} \mathrm{O}_{4} \mathrm{H}_{3} \mathrm{D}_{6}{ }^{+}: 139.0872$; found: 139.0871 . N.B. the molecular ion was not found; compound was found to ionize as the malonic acid due to the temperature of the drying gas.

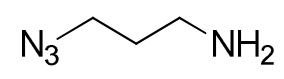

\section{3-azidopropan-1-amine}

To a $250 \mathrm{~mL}$ round bottom flask was added $10.2 \mathrm{~g}(78.5 \mathrm{mmol})$ of 2-chloropropylamine $\cdot \mathrm{HCl}$, $25.5 \mathrm{~g} \mathrm{NaN}_{3}(392 \mathrm{mmol}$ ), and a catalytic amount of $\mathrm{KI}$ (approximately $50 \mathrm{mg}$ ). The mixture was dissolved in $78 \mathrm{~mL}$ of MilliQ $\mathrm{H}_{2} \mathrm{O}$, and a reflux condenser was connected to the flask. The mixture was heated to $90{ }^{\circ} \mathrm{C}$. After three days, the reaction was cooled to room temperature and then cooled on an ice bath. Sodium hydroxide pellets were added to the stirring solution until the $\mathrm{pH}$ was adjusted to 14 . The aqueous solution was then saturated with sodium chloride. The aqueous mixture was transferred to a separatory funnel and extracted with toluene four times. The combined organic fractions were dried over sodium sulfate, filtered, and concentrated. Special care was taken so that the solution was not concentrated to dryness. The product was isolated as a $2.19 \mathrm{M}$ solution in toluene $(24.5 \mathrm{~mL}, 53.7 \mathrm{mmol}, 68 \%)$. Note: Though this compound has been reported several times in the literature, and we have not experienced any issues during the synthesis, isolation, or use of this compound, one should always be aware of the potential toxicity and explosion hazards associated with small organic azides.

${ }^{1} \mathrm{H}-\mathrm{NMR}\left(500 \mathrm{MHz}, \mathrm{CDCl}_{3}\right.$, as a solution in toluene) $\delta: 3.40(2 \mathrm{H}, \mathrm{t}, 6.68 \mathrm{~Hz}), 2.83(2 \mathrm{H}, \mathrm{t}, 6.78$ $\mathrm{Hz}), 1.75(2 \mathrm{H}, \mathrm{p}, 6.79 \mathrm{~Hz}, 6.73 \mathrm{~Hz})$ 


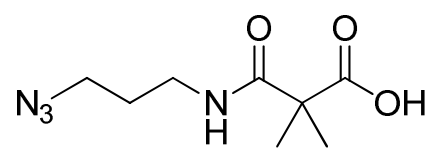

\section{3-((3-azidopropyl)amino)-2,2-dimethyl-3-oxopropanoic acid}

The synthesis of this compound was based on a literature procedure. ${ }^{3}$ To a dry $100 \mathrm{~mL}$ round bottom flask was added $1.95 \mathrm{~g}$ (11.4 mmol) of 2,2,5,5-tetramethyl-1,3-dioxane-4,6-dione. The flask was evacuated and backfilled with $\mathrm{N}_{2}$ three times. Then, $10.1 \mathrm{~mL}$ of $N, N-$ diisopropylethylamine was added to the flask via syringe to form a suspension. A solution of 3azidopropan-1-amine in toluene $(5.8 \mathrm{~mL}, 12.5 \mathrm{mmol})$ was added to the flask and the mixture was allowed to stir overnight under $\mathrm{N}_{2}$ at room temperature. The next day, the reaction was quenched by cooling the mixture on ice and adding $1 \mathrm{~N} \mathrm{HCl}$ until the $\mathrm{pH}$ was 0 . The aqueous mixture was extracted with ethyl acetate three times. The combined organic layers were dried over sodium sulfate, filtered, and concentrated. The product was isolated as a white solid (1.23 g, 51\% yield).

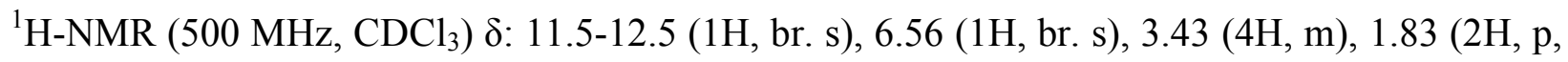
$6.56 \mathrm{~Hz}), 1.54(6 \mathrm{H}, \mathrm{s})$

${ }^{13} \mathrm{C}-\mathrm{NMR}\left(125 \mathrm{MHz}, \mathrm{CDCl}_{3}\right) \delta: 177.85,174.15,49.63,49.26,38.10,28.43,24.02$

HRMS ( $m / z)$ calculated for $\mathrm{C}_{8} \mathrm{H}_{14} \mathrm{~N}_{4} \mathrm{O}_{3}: 215.1139$; found: 215.1130

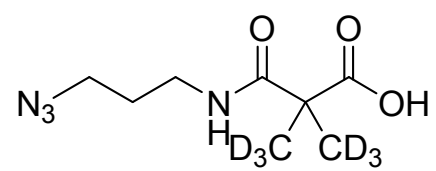

\section{2-((3-azidopropyl)carbamoyl)-2-(methyl-d3)propanoic-3,3,3-d3 acid}

The isotopologue was synthesized in the same manner as the natural isotopologue.

${ }^{1} \mathrm{H}-\mathrm{NMR}\left(500 \mathrm{MHz}, \mathrm{CDCl}_{3}\right) \delta: 11.47$ (1H, br. s), $6.84(1 \mathrm{H}$, br. s), $3.38(4 \mathrm{H}, \mathrm{m}), 1.81(2 \mathrm{H}, \mathrm{p}$, $6.59)$

${ }^{13} \mathrm{C}-\mathrm{NMR}\left(125 \mathrm{MHz}, \mathrm{CDCl}_{3}\right) \delta: 177.73,174.24,49.65,48.83,38.10,28.44$. N.B. the resonance for the deuterated carbons is absent due to the lack of dipolar relaxation and NOE enhancement, which result from the lack of protons.

HRMS $(m / z)$ calculated for $\mathrm{C}_{8} \mathrm{H}_{9} \mathrm{D}_{6} \mathrm{~N}_{4} \mathrm{O}_{3}{ }^{+}: 221.1515$; found: 221.1508 


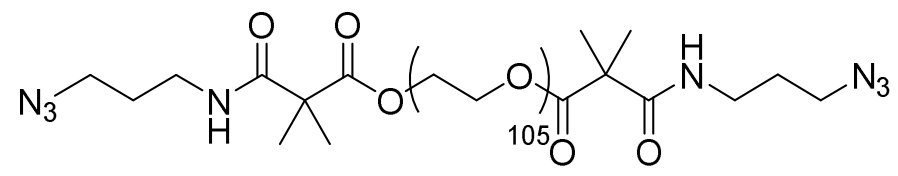

\section{Compound $\mathrm{A}_{2 \mathrm{H}}$}

To a flame-dried $100 \mathrm{~mL}$ round bottomed flask was added $282 \mathrm{mg}(1.3 \mathrm{mmol})$ of 3-((3azidopropyl)amino)-2,2-dimethyl-3-oxopropanoic acid, $505 \mathrm{mg}(2.6 \mathrm{mmol})$ of $\mathrm{EDC} \cdot \mathrm{HCl}, 116$ $\mathrm{mg}(1.8 \mathrm{mmol})$ of 4-dimethylamino pyridine, and $1.01 \mathrm{~g}(0.27 \mathrm{mmol})$ of poly(ethylene glycol) $\left(M_{\mathrm{n}}: 4600 \mathrm{Da}\right)$. The flask was evacuated and backfilled with nitrogen three times, after which 93 $\mathrm{mL}$ of dry dichloromethane (DCM) was added via syringe. The reaction was stirred under nitrogen overnight at room temperature. Then, the reaction was diluted with DCM and washed with water twice and then brine twice. The organic layer was collected and dried over sodium sulfate. The crude product was filtered, concentrated, and dried to remove residual DCM. The product was then redissolved in a minimal amount of ethyl acetate and precipitated by dropwise addition into a stirring flask of cold diethyl ether. The product was collected and dried to afford $1.06 \mathrm{~g}$ of the title compound in $96 \%$ yield. ${ }^{1} \mathrm{H}-\mathrm{NMR}$, FT-IR ATR, GPC, and MALDI-TOF data are shown above in Part I of the Supporting Information.

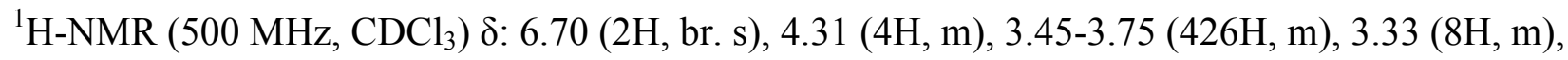
$1.79(4 \mathrm{H}, \mathrm{p}, 6.86 \mathrm{~Hz}), 1.45(12 \mathrm{H}, \mathrm{s})$

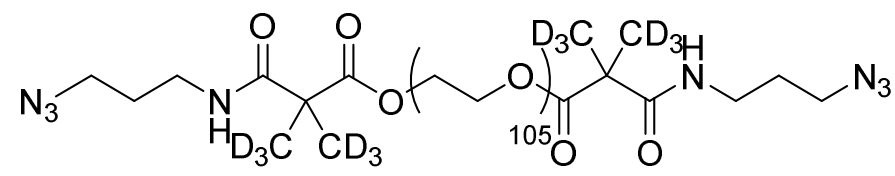

\section{Compound $A_{2 D}$}

Compound $\mathbf{A}_{2 \mathbf{D}}$ was synthesized analogously to $\mathbf{A}_{\mathbf{2 H}}$, with the exception of using 2-((3azidopropyl)carbamoyl)-2-(methyl-d3)propanoic-3,3,3-d3 acid as the carboxylic acid. ${ }^{1} \mathrm{H}-\mathrm{NMR}$, FTIR-ATR, GPC, and MALDI-TOF data are shown above in Part I of the Supporting Information.

${ }^{1} \mathrm{H}-\mathrm{NMR}\left(500 \mathrm{MHz}, \mathrm{CDCl}_{3}\right) \delta: 6.70(2 \mathrm{H}$, br. s), $4.31(4 \mathrm{H}, \mathrm{m}), 3.45-3.75(424 \mathrm{H}, \mathrm{m}), 3.33(8 \mathrm{H}, \mathrm{m})$, $1.79(4 \mathrm{H}, \mathrm{p}, 6.86 \mathrm{~Hz})$<smiles>NCCCCCCCN</smiles> 


\section{6-azidohexan-1-amine}

This compound was synthesized according to literature procedure. ${ }^{4}$

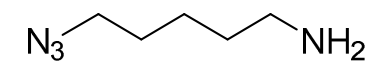

\section{5-azidopentan-1-amine}

This compound was synthesized according to literature procedure. ${ }^{4}$

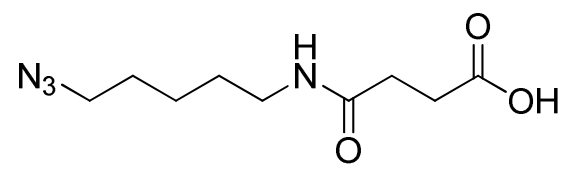

\section{4-((5-azidopentyl)amino)-4-oxobutanoic acid}

To a flame-dried $40 \mathrm{~mL}$ vial was added $584 \mathrm{mg}(5.6 \mathrm{mmol})$ of succinic anhydride. The vial was evacuated and backfilled with $\mathrm{N}_{2}$ three times. The succinic anhydride was then dissolved in 12 $\mathrm{mL}$ of dry THF. In a separate vial, $792 \mathrm{mg}$ (6.2 mmol) of 5-azidopentan-1-amine was dissolved in $10 \mathrm{~mL}$ of THF. The solution was added to the solution of succinic anhydride via syringe. The vial was then lowered into an oil bath preheated to $80{ }^{\circ} \mathrm{C}$ for 20 minutes. The solution was cooled to room temperature and chromatographed on silica gel, using a $0 \% \rightarrow 10 \% \mathrm{MeOH} / \mathrm{DCM}$ gradient. The fractions containing the product were collected. If any triphenylphosphine oxide from the previous step was detected by ${ }^{1} \mathrm{H}-\mathrm{NMR}$ after this step, the product was purified by dissolving the product in saturated sodium bicarbonate solution, washing with DCM thrice, acidifying the solution, and extracted with ethyl acetate. $68 \%$ yield.

${ }^{1} \mathrm{H}-\mathrm{NMR}\left(500 \mathrm{MHz}, \mathrm{CDCl}_{3}\right) \delta: 10-11.5$ (1H, br. s), $6.16(1 \mathrm{H}$, br. t, $5.37 \mathrm{~Hz}), 3.26(4 \mathrm{H}, \mathrm{m}), 2.69$ $(2 \mathrm{H}, \mathrm{t}, 6.40 \mathrm{~Hz}), 2.59(2 \mathrm{H}, \mathrm{t}, 6.40 \mathrm{~Hz}), 1.60(2 \mathrm{H}, \mathrm{m}), 1.52(2 \mathrm{H}, \mathrm{m}), 1.39(2 \mathrm{H}, \mathrm{m})$

${ }^{13} \mathrm{C}-\mathrm{NMR}\left(125 \mathrm{MHz}, \mathrm{CDCl}_{3}\right) \delta: 176.78,172.58,51.43,39.76,30.92,30.00,29.18,28.65,24.15$

HRMS $(m / z)$ calculated for $\mathrm{C}_{9} \mathrm{H}_{16} \mathrm{~N}_{4} \mathrm{O}_{3}{ }^{+}: 229.1295$; found: 229.1290<smiles>NCCCCCCNC(=O)CCC(=O)O</smiles>

\section{4-((6-azidohexyl)amino)-4-oxobutanoic acid}


To a flame-dried $40 \mathrm{~mL}$ vial was added $600 \mathrm{mg}(5.8 \mathrm{mmol})$ of succinic anhydride. The vial was evacuated and backfilled with $\mathrm{N}_{2}$ three times. The succinic anhydride was then dissolved in 12 $\mathrm{mL}$ of dry THF. In a separate vial, $920 \mathrm{mg}(6.3 \mathrm{mmol})$ of 6-azidohexan-1-amine was dissolved in $10 \mathrm{~mL}$ of THF. The solution was added to the solution of succinic anhydride via syringe. The vial was then lowered into an oil bath preheated to $80{ }^{\circ} \mathrm{C}$ for 20 minutes. The solution was cooled to room temperature. Then $1 \mathrm{~N} \mathrm{HCl}$ was added to the solution and the mixture was extracted three times with ethyl acetate. The combined organic layers were dried over magnesium sulfate, filtered, and concentrated. The crude mixture was chromatographed on silica gel, using a $0 \% \rightarrow 10 \% \mathrm{MeOH} / \mathrm{DCM}$ gradient. The fractions containing the product were collected to afford $1.13 \mathrm{~g}$ of the desired product in $74 \%$ yield.

${ }^{1} \mathrm{H}-\mathrm{NMR}\left(500 \mathrm{MHz}, \mathrm{CDCl}_{3}\right) \delta: 10-11.5$ (1H, br. s), $5.80(1 \mathrm{H}$, br. s), $3.27(4 \mathrm{H}, \mathrm{m}), 2.71(2 \mathrm{H}, \mathrm{t}$, $5.96 \mathrm{~Hz}), 2.51(2 \mathrm{H}, \mathrm{t}, 5.88 \mathrm{~Hz}), 1.60(2 \mathrm{H}, \mathrm{m}), 1.52(2 \mathrm{H}, \mathrm{m}), 1.37(4 \mathrm{H}, \mathrm{m})$

${ }^{13} \mathrm{C}-\mathrm{NMR}\left(125 \mathrm{MHz}, \mathrm{CDCl}_{3}\right) \delta: 176.42,172.5,51.52,39.90,30.95,30.06,29.54,28.90,26.56$

HRMS $(m / z)$ calculated for $\mathrm{C}_{10} \mathrm{H}_{18} \mathrm{~N}_{4} \mathrm{O}_{3}{ }^{+}: 243.1452$; found: 243.1449

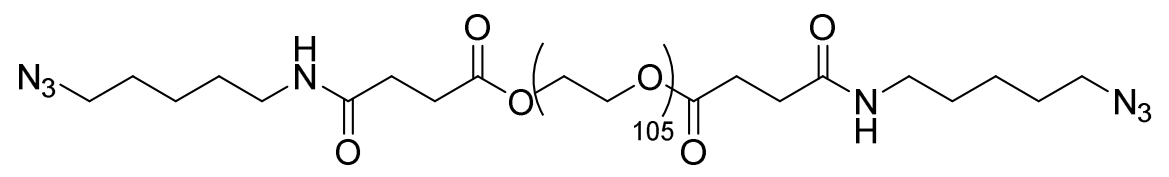

\section{Compound $\mathrm{A}_{2 \mathrm{C} 5}$}

To a flame dried $100 \mathrm{~mL}$ round bottomed flask was added $598 \mathrm{mg}(2.62 \mathrm{mmol})$ of 4-((5azidopentyl)amino)-4-oxobutanoic acid, $795.3 \mathrm{mg}(4.16 \mathrm{mmol})$ of $\mathrm{EDC} \cdot \mathrm{HCl}, 47 \mathrm{mg}(0.39 \mathrm{mmol})$ of 4-dimethylamino pyridine, and $1.56 \mathrm{~g}(0.34 \mathrm{mmol})$ of poly(ethylene glycol) $\left(M_{\mathrm{n}}: 4600 \mathrm{Da}\right)$. The flask was evacuated and backfilled with nitrogen three times. Then, $17 \mathrm{~mL}$ of dry DCM was added via syringe. After stirring at room temperature and under nitrogen overnight, the reaction was diluted with DCM. The reaction mixture was washed with deionized water twice, then brine twice. The organic layer was dried with sodium sulfate, then filtered. The product was then redissolved in a minimal amount of ethyl acetate and precipitated from a stirring flask of cold diethyl ether. The product was collected and dried to afford $1.358 \mathrm{~g}$ of the title compound in $80 \%$ yield. ${ }^{1}$ H-NMR, FTIR-ATR, GPC, and MALDI-TOF data are shown above in Part I of the Supporting Information.

${ }^{1} \mathrm{H}-\mathrm{NMR}\left(500 \mathrm{MHz}, \mathrm{CDCl}_{3}\right)$ 8: $5.91(2 \mathrm{H}, \mathrm{s}), 4.19(4 \mathrm{H}, \mathrm{m}), 3.41-3.83(402 \mathrm{H}, \mathrm{m}), 3.21(8 \mathrm{H}, \mathrm{m})$, $2.66(4 \mathrm{H}, \mathrm{t}, 6.76 \mathrm{~Hz} 0,2.42(4 \mathrm{H}, \mathrm{t}, 6.76 \mathrm{H}), 1.57(4 \mathrm{H}, \mathrm{m}), 1.49(4 \mathrm{H}, \mathrm{m}), 1.36(4 \mathrm{H}, \mathrm{m})$ 
<smiles>CCOC(=O)CCC(=O)NCCCCCCNC(=O)CCC(=O)OCCOC(C)(C)O</smiles>

\section{Compound $\mathrm{A}_{2 \mathrm{C} 6}$}

Compound $\mathbf{A}_{2 \mathbf{C 6}}$ was synthesized analogously to $\mathbf{A}_{2 \mathrm{C5}}$, with the difference of using 4-((6azidohexyl)amino)-4-oxobutanoic acid as the carboxylic acid. 79.8\% yield. ${ }^{1} \mathrm{H}-\mathrm{NMR}$, FTIRATR, GPC, and MALDI-TOF data are shown above in Part I of the Supporting Information.

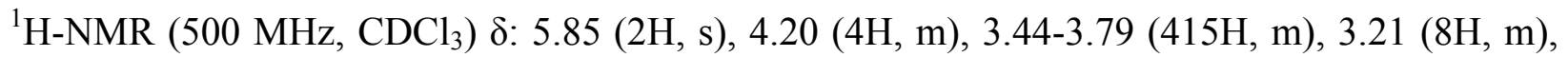
$2.67(4 \mathrm{H}, \mathrm{t}, 6.88 \mathrm{~Hz}), 2.42(4 \mathrm{H}, \mathrm{t}, 6.88 \mathrm{~Hz}), 1.56(4 \mathrm{H}, \mathrm{m}), 1.47(4 \mathrm{H}, \mathrm{m}), 1.33(8 \mathrm{H}, \mathrm{m})$<smiles>[2H]C([2H])(Br)C([2H])([2H])C([2H])([2H])C([2H])([2H])Br</smiles>

\section{1,4-dibromobutane-1,1,2,2,3,3,4,4- $d_{8}$}

This procedure was adapted from a literature preparation. ${ }^{5}$ To a $250 \mathrm{~mL}$ round bottom flask was added $38 \mathrm{~mL}$ of $48 \%$ aqueous $\mathrm{HBr}$ and cooled on an ice/water bath. Then, $8.1 \mathrm{~mL}$ of concentrated $\mathrm{H}_{2} \mathrm{SO}_{4}$ was added dropwise, followed by $10 \mathrm{~g}$ of THF- $d_{8}$ (Cambridge Isotope Laboratories, $10 \mathrm{~g}$ ampoule). A second portion $(13.5 \mathrm{~mL})$ of concentrated $\mathrm{H}_{2} \mathrm{SO}_{4}$ was added dropwise, after which the reaction mixture was heated to $110^{\circ} \mathrm{C}$. As the reaction proceeded, the immiscible product formed and the mixture became biphasic. After $6.5 \mathrm{~h}$, the reaction mixture was cooled until it was warm to the touch and poured into $75 \mathrm{~mL}$ of ice/water. The mixture was carefully extracted with hexane three times. The organic layers were combined and washed sequentially with water once, saturated sodium bicarbonate solution twice, and water again. The organic layer was dried over magnesium sulfate, filtered, and concentrated on a rotary evaporator. There is minimal product loss on a rotary evaporator with a typical vacuum pump. The compound was transferred to a $100 \mathrm{~mL}$ round bottom flask and was distilled over a short path distillation head under vacuum. The product was collected on a dry ice/isopropanol bath. $26.6 \mathrm{~g}$, $95 \%$ yield

${ }^{2} \mathrm{H}-\mathrm{NMR}\left(76.8 \mathrm{MHz}^{\mathrm{CDCl}}{ }_{3}\right) \delta: 3.43(4 \mathrm{H}, \mathrm{s}), 2.01(4 \mathrm{H}, \mathrm{s})$

${ }^{13} \mathrm{C}-\mathrm{NMR}\left(125 \mathrm{MHz}, \mathrm{CDCl}_{3}\right)$ $\delta: 32.08$ (p), $29.91(\mathrm{p})$ 


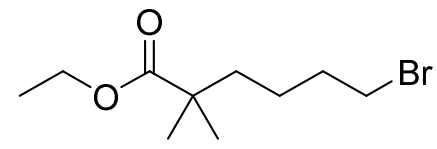

ethyl 6-bromo-2,2-dimethylhexanoate

The preparation of this compound was adapted from a literature procedure. ${ }^{6}$ To a flame-dried, two-neck $250 \mathrm{~mL}$ round bottom flask was added $6.34 \mathrm{~mL}(44.9 \mathrm{mmol})$ of diisopropylamine, followed by $60 \mathrm{~mL}$ of dry tetrahydrofuran. The vessel was cooled to $-78{ }^{\circ} \mathrm{C}$ with a dry ice isopropanol bath, after which $16.5 \mathrm{~mL}(41.1 \mathrm{mmol})$ of $2.5 \mathrm{M} n$-BuLi in hexane was added dropwise via syringe. Then, $5 \mathrm{~mL}(37.4 \mathrm{mmol})$ of ethyl isobutyrate dissolved in $20 \mathrm{~mL}$ of THF was added dropwise to the LDA. After 30 minutes, the reaction was allowed to warm to $-40{ }^{\circ} \mathrm{C}$ with a dry ice acetonitrile bath, and $6.7 \mathrm{~mL}(56.1 \mathrm{mmol})$ of 1,4-dibromobutane was added in one shot via syringe. The reaction was allowed to warm to room temperature. Next, the majority of THF was removed on a rotary evaporator, and water was added to the reaction mixture. The organic layer was extracted three times with diethyl ether in a separatory funnel, dried over $\mathrm{Na}_{2} \mathrm{SO}_{4}$, filtered, and evaporated. The crude material was chromatographed on silica with a gradient of $0 \rightarrow 5 \%$ ethyl acetate in hexanes to separate the product from the bis-alkylated side product. The product was isolated in $63 \%(5.93 \mathrm{~g})$ yield as a clear oil.

HRMS ( $m / z$ ) calculated for $\mathrm{C}_{10} \mathrm{H}_{20} \mathrm{BrO}_{2}^{+}: 251.0641$; found: 251.0644

${ }^{1} \mathrm{H}-\mathrm{NMR}\left(500 \mathrm{MHz}, \mathrm{CDCl}_{3}\right)$ ): $4.11(2 \mathrm{H}, \mathrm{q}, 7.30 \mathrm{~Hz}), 3.40(2 \mathrm{H}, \mathrm{t}, 7.30 \mathrm{~Hz}), 1.83(2 \mathrm{H}, \mathrm{p}, 7.30$ $\mathrm{Hz}), 1.51-1.54(2 \mathrm{H}, \mathrm{m}), 1.32-1.41(2 \mathrm{H}, \mathrm{m}), 1.25(3 \mathrm{H}, \mathrm{t}, 7.30 \mathrm{~Hz}), 1.16(6 \mathrm{H}, \mathrm{s})$

${ }^{13} \mathrm{C}-\mathrm{NMR}\left(125 \mathrm{MHz}, \mathrm{CDCl}_{3}\right)$ ): 177.97, 60.51, 42.27, 39.83, 33.76, 33.30, 25.32, 23.79, 14.46<smiles>[2H]C([2H])(Br)C([2H])([2H])C([2H])([2H])C([2H])([2H])C([2H])(C)C(=O)OCC</smiles>

ethyl 6-bromo-2,2-dimethylhexanoate-3,3,4,4,5,5,6,6- $d_{8}$ 
This product was synthesized analogously to the natural isotope compound; 1,4-dibromobutane$1,1,2,2,3,3,4,4-d_{8}$ was used instead of 1,4 dibromobutane. The product was isolated in $62 \%$ yield as a clear oil.

HRMS $(m / z)$ calculated for $\mathrm{C}_{10} \mathrm{H}_{12} \mathrm{D}_{8} \mathrm{BrO}_{2}^{+}: 259.1143$; found: 259.1148

${ }^{1} \mathrm{H}-\mathrm{NMR}\left(500 \mathrm{MHz}, \mathrm{CDCl}_{3}\right) \delta: 4.11(2 \mathrm{H}, \mathrm{q}, 7.21 \mathrm{~Hz}), 1.25(3 \mathrm{H}, \mathrm{t}, 7.21 \mathrm{~Hz}), 1.15(6 \mathrm{H}, \mathrm{s})$

${ }^{2} \mathrm{H}-\mathrm{NMR}\left(76.8 \mathrm{MHz}, \mathrm{CDCl}_{3}\right)$ ): 3.37(2H, s), $1.78(2 \mathrm{H}, \mathrm{s}), 1.48(2 \mathrm{H}, \mathrm{s}), 1.32(2 \mathrm{H}, \mathrm{s})$

${ }^{13} \mathrm{C}$-NMR $\left(125 \mathrm{MHz}, \mathrm{CDCl}_{3}\right) \delta: 177.98,60.48,42.08,25.25,14.45 \mathrm{~N} . \mathrm{B}$. the resonance for the deuterated carbons is absent due to the lack of dipolar relaxation and NOE enhancement, which result from the lack of protons.

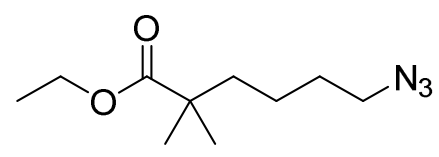

\section{ethyl 6-azido-2,2-dimethylhexanoate}

To a flame dried, $100 \mathrm{~mL}$ round bottom flask was added $1.75 \mathrm{~g}(7 \mathrm{mmol})$ of ethyl 8-bromo-2,2dimethyloctanoate and $819 \mathrm{mg}(12.6 \mathrm{mmol})$ of sodium azide. The flask was evacuated and backfilled with nitrogen three times. The mixture was suspended in $10 \mathrm{~mL}$ of $N, N$ dimethylformamide and heated to $60{ }^{\circ} \mathrm{C}$ overnight. The reaction mixture was cooled to room temperature, diluted with $50 \mathrm{~mL}$ of water, and extracted with diethyl ether three times. The organic layers were combined and washed with water and brine, then dried over $\mathrm{Na}_{2} \mathrm{SO}_{4}$, filtered, and concentrated on a rotary evaporator. The crude product was chromatographed on silica using a gradient of $20 \rightarrow 80 \%$ DCM in hexanes. The product was isolated in $89 \%$ yield $(1.33 \mathrm{~g})$ as a slightly yellow oil that was slightly volatile (some product loss was observed under vacuum for prolonged periods of time).

${ }^{1} \mathrm{H}-\mathrm{NMR}\left(500 \mathrm{MHz}, \mathrm{CDCl}_{3}\right) \delta: 4.11(2 \mathrm{H}, \mathrm{q}, 7.20 \mathrm{~Hz}), 3.26(2 \mathrm{H}, \mathrm{t}, 6.91), 1.50-1.61(4 \mathrm{H}, \mathrm{m})$, $1.27-1.34(2 \mathrm{H}, \mathrm{m}), 1.25(3 \mathrm{H}, \mathrm{t}, 7.20), 1.16(6 \mathrm{H}, \mathrm{s})$

${ }^{13} \mathrm{C}-\mathrm{NMR}\left(125 \mathrm{MHz}, \mathrm{CDCl}_{3}\right)$ ): 177.98, 60.51, 51.43, 42.28, 40.29, 29.47, 25.32, 22.38, 14.44 


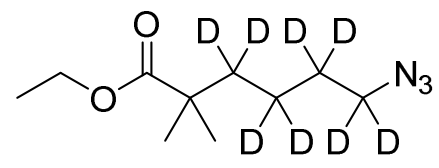

ethyl 6-azido-2,2-dimethylhexanoate-3,3,4,4,5,5,6,6- $d_{8}$

This product was synthesized analogously to the natural isotope compound; ethyl 6-bromo-2,2dimethylhexanoate-3,3,4,4,5,5,6,6- $d_{8}$ was used as the starting material. The product was isolated in $98 \%$ yield $(2.11 \mathrm{~g})$ as a slightly yellow oil and was also slightly volatile.

HRMS $(m / z)$ calculated for $\mathrm{C}_{10} \mathrm{H}_{12} \mathrm{D}_{8} \mathrm{~N}_{3} \mathrm{O}_{2}{ }^{+}: 222.2052$; found: 222.2055

${ }^{1} \mathrm{H}-\mathrm{NMR}\left(500 \mathrm{MHz}, \mathrm{CDCl}_{3}\right) \delta: 4.10(2 \mathrm{H}, \mathrm{q}, 7.13), 1.23(3 \mathrm{H}, \mathrm{t}, 7.12), 1.14(6 \mathrm{H}, \mathrm{s})$

${ }^{2} \mathrm{H}-\mathrm{NMR}\left(76.8 \mathrm{MHz}, \mathrm{CDCl}_{3}\right)$ 8: $3.22(2 \mathrm{H}, \mathrm{s}), 1.48-1.53(4 \mathrm{H}, \mathrm{m}), 1.25(2 \mathrm{H})$

${ }^{13} \mathrm{C}$-NMR $\left(125 \mathrm{MHz}, \mathrm{CDCl}_{3}\right) \delta: 177.89,60.39,42.03,25.17,14.34$ N.B. the resonance for the deuterated carbons is absent due to the lack of dipolar relaxation and NOE enhancement, which result from the lack of protons.<smiles>CC(C)(CCCCN)C(=O)O</smiles>

\section{6-azido-2,2-dimethylhexanoic acid}

To a $100 \mathrm{~mL}$ round bottom flask was transferred $5 \mathrm{~g}(23 \mathrm{mmol})$ of ethyl 6-azido-2,2dimethylhexanoate using $11 \mathrm{~mL}$ of EtOH. Then, $3.9 \mathrm{~g}(70 \mathrm{mmol})$ of $\mathrm{KOH}$ pellets were dissolved in $11 \mathrm{~mL}$ of water and added to the round bottom flask with starting material. A reflux condenser 
was fixed to the flask and the mixture was heated to $60{ }^{\circ} \mathrm{C}$ until TLC indicated the complete absence of the starting material. The mixture turned orange over the course of the reaction. The reaction was cooled to room temperature, and most of the ethanol was removed on a rotary evaporator. The mixture was then diluted with water, acidified to $\mathrm{pH} 1$ with $1 \mathrm{M} \mathrm{HCl}$, and then extracted with dichloromethane three times. The combined organic layers were dried over $\mathrm{MgSO}_{4}$, filtered, and concentrated on a rotary evaporator. The crude product was chromatographed on silica using a $0 \rightarrow 15 \%$ ethyl acetate in hexanes gradient, and the product was isolated in $95 \%$ yield $(4.03 \mathrm{~g})$ as a yellow oil.

HRMS $(m / z)$ calculated for $\mathrm{C}_{8} \mathrm{H}_{16} \mathrm{~N}_{3} \mathrm{O}_{2}^{+}: 186.1237$; found:186.1242

${ }^{1} \mathrm{H}-\mathrm{NMR}\left(500 \mathrm{MHz}, \mathrm{CDCl}_{3}\right) \delta: 3.28(2 \mathrm{H}, \mathrm{t}, 7.00), 1.54-1.64(4 \mathrm{H}, \mathrm{m}), 1.32-1.40(2 \mathrm{H}, \mathrm{m}), 1.20$ $(6 \mathrm{H}, \mathrm{s})$

${ }^{13} \mathrm{C}-\mathrm{NMR}\left(125 \mathrm{MHz}, \mathrm{CDCl}_{3}\right)$ ): 184.94, 51.43, 42.29, 40.04, 29.47, 25.11, 22.34<smiles>[2H]C([2H])(N)C([2H])([2H])C([2H])([2H])C([2H])([2H])C([2H])(C)C(=O)O</smiles>

6-azido-2,2-dimethylhexanoic-3,3,4,4,5,5,6,6- $d_{8}$ acid

This compound was synthesized analogously to the natural isotope compound; ethyl 6-azido-2,2dimethylhexanoate- $3,3,4,4,5,5,6,6-d_{8}$ was used as the starting material. The compound was isolated as a yellow oil in $96 \%$ yield $(1.47 \mathrm{~g})$.

HRMS ( $m / z)$ calculated for $\mathrm{C}_{8} \mathrm{H}_{8} \mathrm{D}_{8} \mathrm{~N}_{3} \mathrm{O}_{2}^{+}:$194.1739; found:194.1744

${ }^{1} \mathrm{H}-\mathrm{NMR}\left(500 \mathrm{MHz}, \mathrm{CDCl}_{3}\right) \delta: 1.21$

${ }^{2} \mathrm{H}-\mathrm{NMR}\left(76.8 \mathrm{MHz}, \mathrm{CDCl}_{3}\right) \delta: 3.26(2 \mathrm{H}, \mathrm{s}), 1.56(4 \mathrm{H}, \mathrm{s}), 1.33(2 \mathrm{H})$

${ }^{13} \mathrm{C}-\mathrm{NMR}\left(125 \mathrm{MHz}, \mathrm{CDCl}_{3}\right)$ 8: 185.18, 50.52 (p), 42.07, 38.94 (p), 28.21 (p), 24.98, 21.10 (p) N.B. the resonance for the deuterated carbons are normally not detectable, but were observed for this compound due to the high sample concentration 


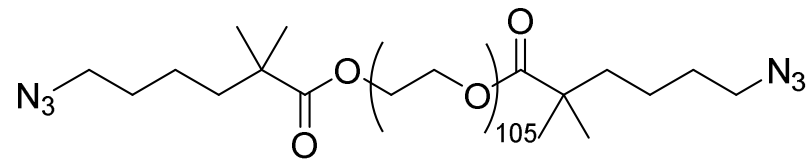

$\mathbf{A}_{2}{ }^{\prime}$

To a dry $100 \mathrm{~mL}$ round bottom flask was added $669.7 \mathrm{mg}(3.62 \mathrm{mmol})$ of 6-azido-2,2dimethylhexanoic acid, $2.78 \mathrm{~g}(0.60 \mathrm{mmol})$ of PEG 4600, $1.43 \mathrm{~g}(7.24 \mathrm{mmol})$ of $\mathrm{EDC} \cdot \mathrm{HCl}$, and $382 \mathrm{mg}$ (3.1 mmol)of DMAP. The flask was evacuated and backfilled with nitrogen three times, and then dissolved in $\mathrm{x} \mathrm{mL}$ of dry DCM. After stirring the mixture overnight at room temperature, reaction mixture was washed with water twice, brine twice, and then dried over $\mathrm{Na}_{2} \mathrm{SO}_{4}$. The organic layer was filtered and concentrated on a rotary evaporator. The crude product was redissolved in a minimal amount of ethyl acetate with gentle heating, and precipitated by dropwise addition to a stirring flask of cold diethyl ether. The product was collected on a Büchner funnel, dried, and collected as a white powder. $89 \%$ yield (2.62 g).

${ }^{1} \mathrm{H}-\mathrm{NMR}\left(500 \mathrm{MHz}, \mathrm{CDCl}_{3}\right) \delta: 4.20(4 \mathrm{H}, \mathrm{m}), 3.55-3.73(427 \mathrm{H}, \mathrm{m}), 3.25(4 \mathrm{H}, \mathrm{m}, 6.84 \mathrm{~Hz}), 1.50-$ $1.60(8 \mathrm{H}, \mathrm{m}), 1.26-1.33(4 \mathrm{H}, \mathrm{m}), 1.16(12 \mathrm{H}, \mathrm{s})$

$\mathbf{A}_{2 \mathrm{D}}$

This compound was synthesized analogously to the natural isotope compound; 6-azido-2,2dimethylhexanoic- $3,3,4,4,5,5,6,6-d_{8}$ acid was used as the starting material. This compound was isolated as a white powder in $87 \%$ yield $(2.16 \mathrm{~g})$.

${ }^{1} \mathrm{H}-\mathrm{NMR}\left(500 \mathrm{MHz}, \mathrm{CDCl}_{3}\right) \delta: 4.20(4 \mathrm{H}, \mathrm{m}), 3.55-3.73(427 \mathrm{H}, \mathrm{m}), 1.16(12 \mathrm{H}, \mathrm{s})$ 


\section{Simulations and Theory}

\section{A. Rate Theory Simulation}

The following 23 species were considered as unique species in the reaction.<smiles>[B]C([B])([B])[B]</smiles><smiles>[B]C([B])([B])C=CC([B])([B])[B]</smiles><smiles>[B]C([B])([B])C(C)C</smiles><smiles>[B]C(C)C([B])([B])[B]</smiles><smiles>[B]C([B])([B])C(C)C</smiles><smiles>[B]C12CCC1C2</smiles><smiles>CCCC(Br)(CC)CC</smiles><smiles>[B]C([B])([CH])C(C)C</smiles>

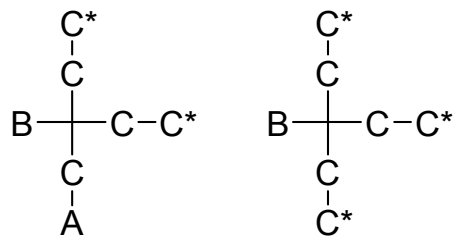<smiles>C1CC12CC2</smiles><smiles>[CH]C1CCC1</smiles><smiles>CCC(C)(C)C(C)C</smiles><smiles>CCC(C)(C)C1CCCC1</smiles><smiles>[CH]C([CH])C([CH])(C)C</smiles><smiles>[CH]C([CH])([CH])C(C)(C)C</smiles><smiles>[CH]C([CH])C([CH])([CH])CC</smiles><smiles>CC1CC1C1(C)CC1</smiles><smiles>[CH]C1(C#C)CCC1</smiles><smiles>CCC1(CC)CCC1</smiles><smiles>C1CC2(C1)CC2</smiles>

For reactive groups belonging to different species, the reaction rate for forming the bridge is given by

$$
R_{i j, \text { bridge }}=k_{\mathrm{AB}}\left[\mathrm{A}_{i}\right]\left[\mathrm{B}_{j}\right]
$$

where $k_{A B}$ is the second order rate constant, and $\left[\mathrm{A}_{i}\right]$ and $\left[\mathrm{B}_{j}\right]$ are the concentrations of $\mathrm{A}$ and $\mathrm{B}$ functional groups on species $i$ and $j$, respectively. For groups belonging to the same species $i$, the reaction rate for forming the intramolecular loop is given by 


$$
R_{i, \text { loop }}=k_{A B} \frac{N_{\mathrm{A} i}}{N_{\mathrm{av}}}\left(\frac{3}{2 \pi<r^{2}>}\right)^{3 / 2}\left[\mathrm{~B}_{j}\right]
$$

where $N_{\mathrm{A} i}$ is the number of A reactive groups attached to the specie $i$, and $N_{\mathrm{av}}$ is Avogadro's number. $\left\langle r^{2}\right\rangle$ is the mean square end-to-end distance of the polymer that is used as a fitting parameter. Based on these reaction rates, a series of rate equations for the production and consumption of each species was created, from which the product distribution was determined. Rate theory simulation was conducted using the fourth order Runge-Kutta-Fehlberg method in MATLAB.

\section{B. Monte Carlo Simulation}

The Monte Carlo simulation is following the general algorithm developed by Stepto. Based on the desired concentration, $N_{0}$ A and $N_{0}$ B groups are initially put in the system of volume $V$. At each step, a pair of unreacted A-B groups is selected with a probability $P_{a b}$ reflecting the connectivity between these two groups,

$$
P_{a b}=\frac{\frac{1}{V}+\left(\frac{3}{2 \pi<r^{2}>d_{a b}}\right)^{3 / 2}}{\sum_{i j}\left[\frac{1}{V}+\left(\frac{3}{2 \pi<r^{2}>d_{i j}}\right)^{3 / 2}\right]}
$$

where the summations are taken over all unreacted A-B pairs. $d_{i j}$ is the distance (defined by the minimum number of $\mathrm{A}_{2}$ chains) between $\mathrm{A}$ group $i$ and $\mathrm{B}$ group $j . d_{i j}=\infty$ the groups are not

connected. The term $\left(\frac{3}{2 \pi<r^{2}>d_{i j}}\right)^{3 / 2}$ comes from the statistics of flexible Gaussian chains for closing loops.

The topology of the entire network is updated after the selected A-B pair reacts: the distance between all the groups that are connected to these reacted A and B groups are recalculated. The process repeat until full conversion is achieved. The fraction of primary loops is recorded according to the number of adjacent A groups (two A groups belonging to the same polymer chain) share the same junction. 10 simulations each were run at various concentrations with $N_{0}=$ 15000 to estimate the average primary loop fraction.

\section{References}

(1) Zhou, H.; Jiyeon, W.; Cok, A. M.; Wang, M.; Olsen, B. D.; Johnson, J. A. Proceedings of the National Academy of Sciences of the United States of America 2012, 109, 19119. 
(2) Zhou, H.; Schön, E.-M.; Wang, M.; Glassman, M. J.; Liu, J.; Zhong, M.; Díaz Díaz, D.; Olsen, B. D.; Johnson, J. A. Journal of the American Chemical Society 2014, 136, 9464. 2006.

(3) Flohr, A.; Jakob-Roetne, R.; Wostl, W. U.S. Patent US2006/122168 A1, June 8,

(4) Lin, H.-Y.; Snider, B. B. The Journal of Organic Chemistry 2012, 77, 4832.

(5) Ya-Ting, Y.; Bing-Qin, Y.; Min, L.; Wei, N; Zhen-Huan, L. Synn. Comm. 2008, 38(4):530-536.

(6) Dasseaux, J. H.; Oniciu, C.D. U.S. Patent US2004/192771, Sept. 30, 2004. 


\section{Spectral Data}

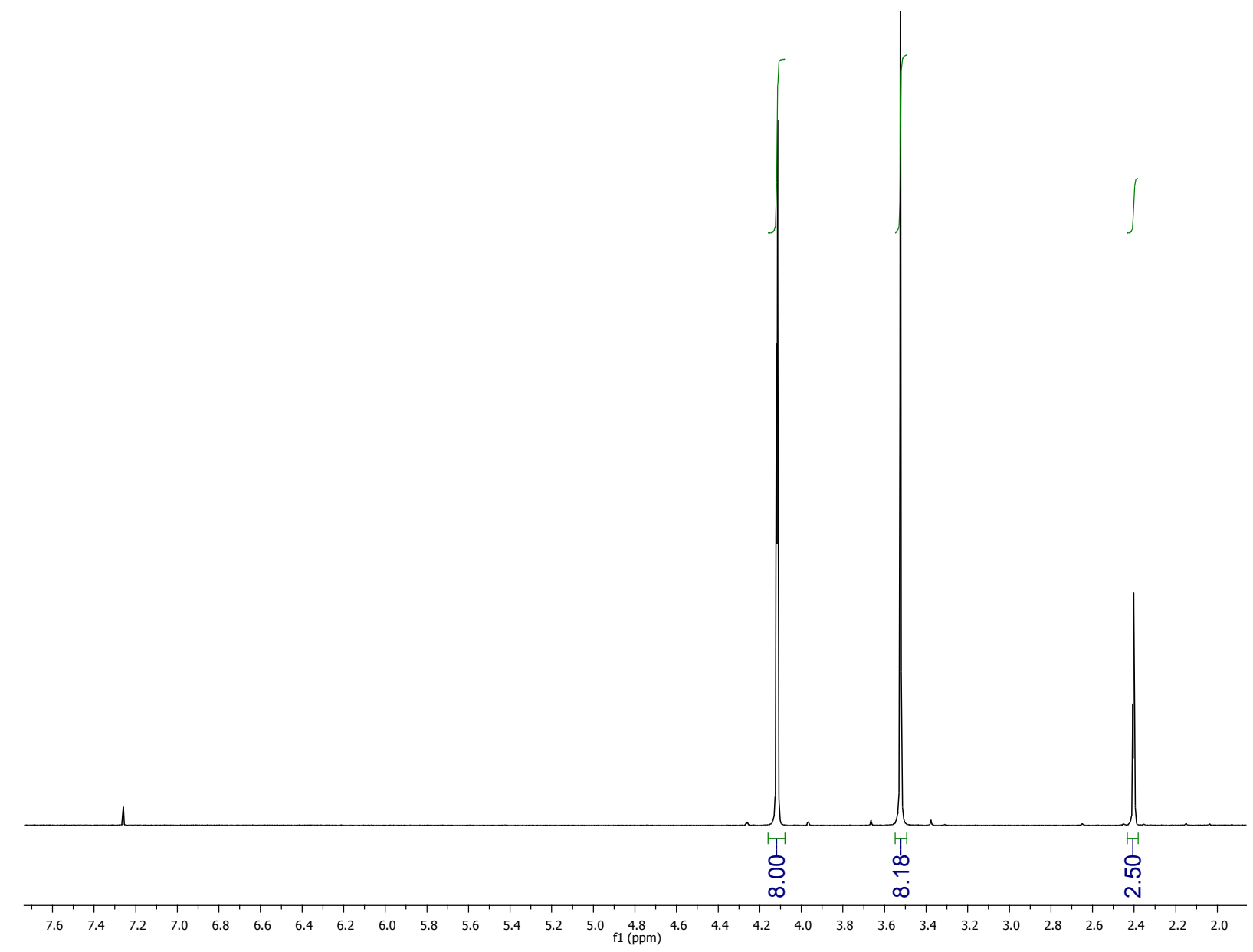

Figure S8. ${ }^{1} \mathrm{H}-\mathrm{NMR}$ spectrum of Compound $\mathbf{B}_{\mathbf{4}}$. 


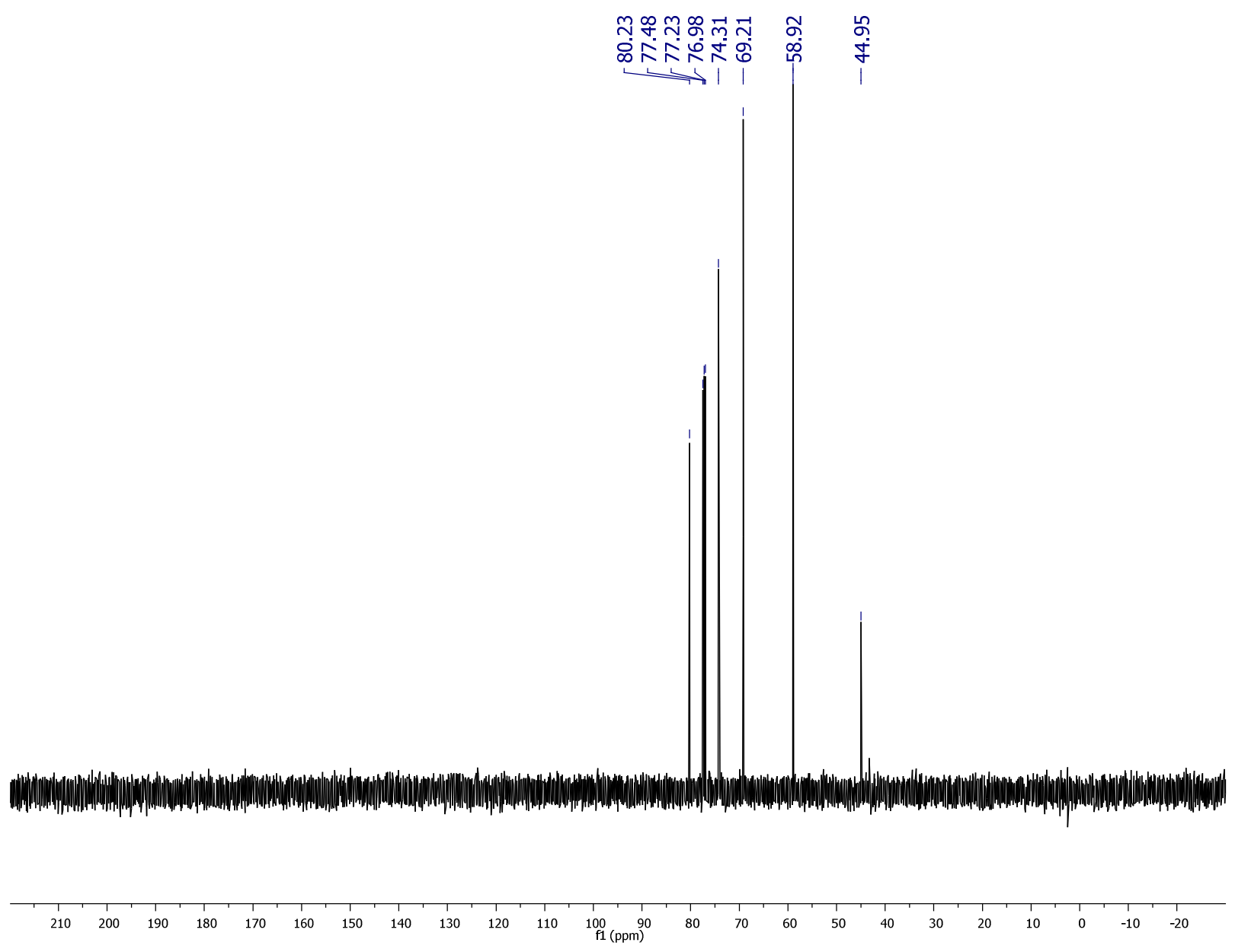

Figure S9. ${ }^{13} \mathrm{C}-\mathrm{NMR}$ spectrum of Compound $\mathbf{B}_{\mathbf{4}}$. 


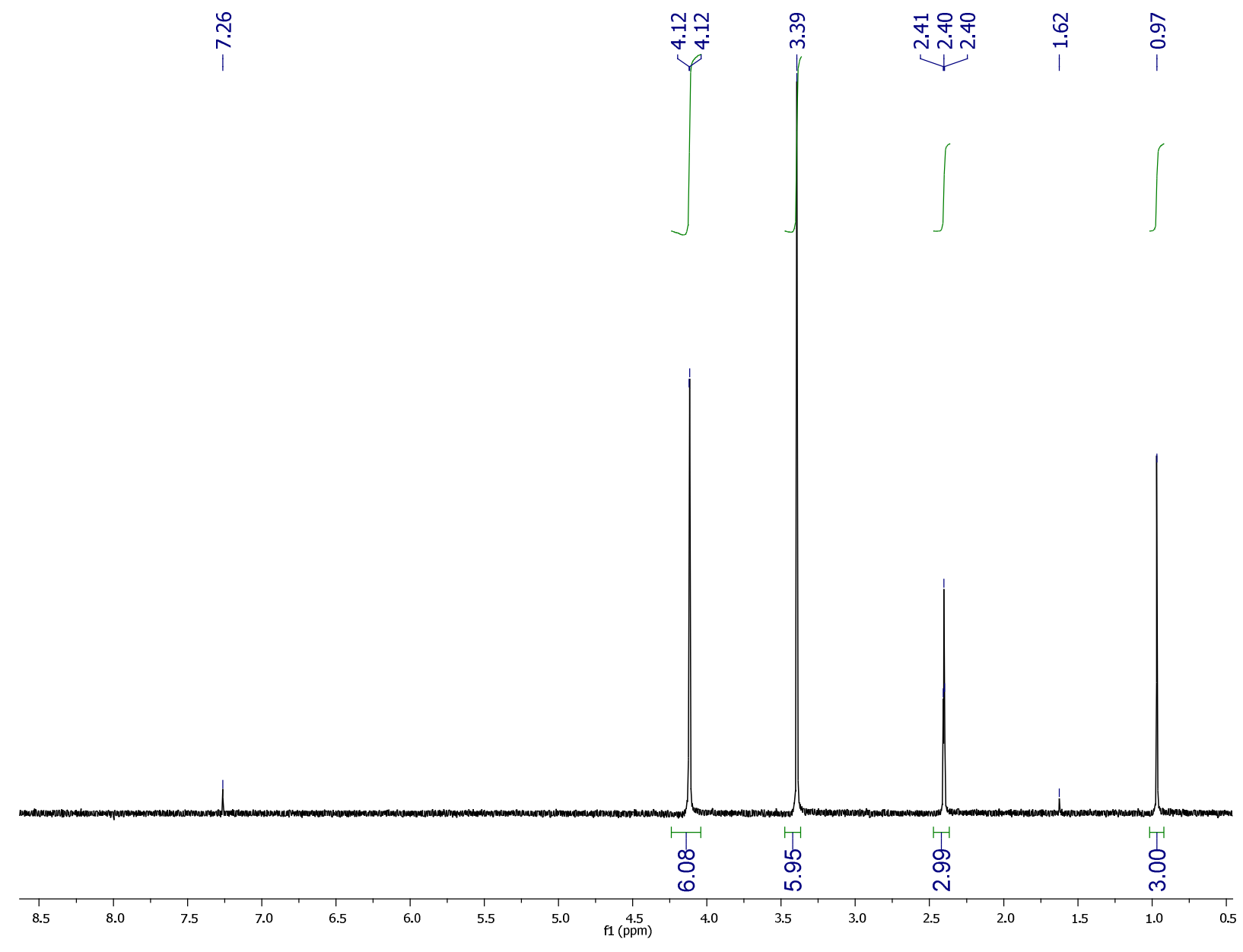

Figure S10. ${ }^{1} \mathrm{H}-\mathrm{NMR}$ spectrum of Compound $\mathbf{B}_{\mathbf{3}}$. 

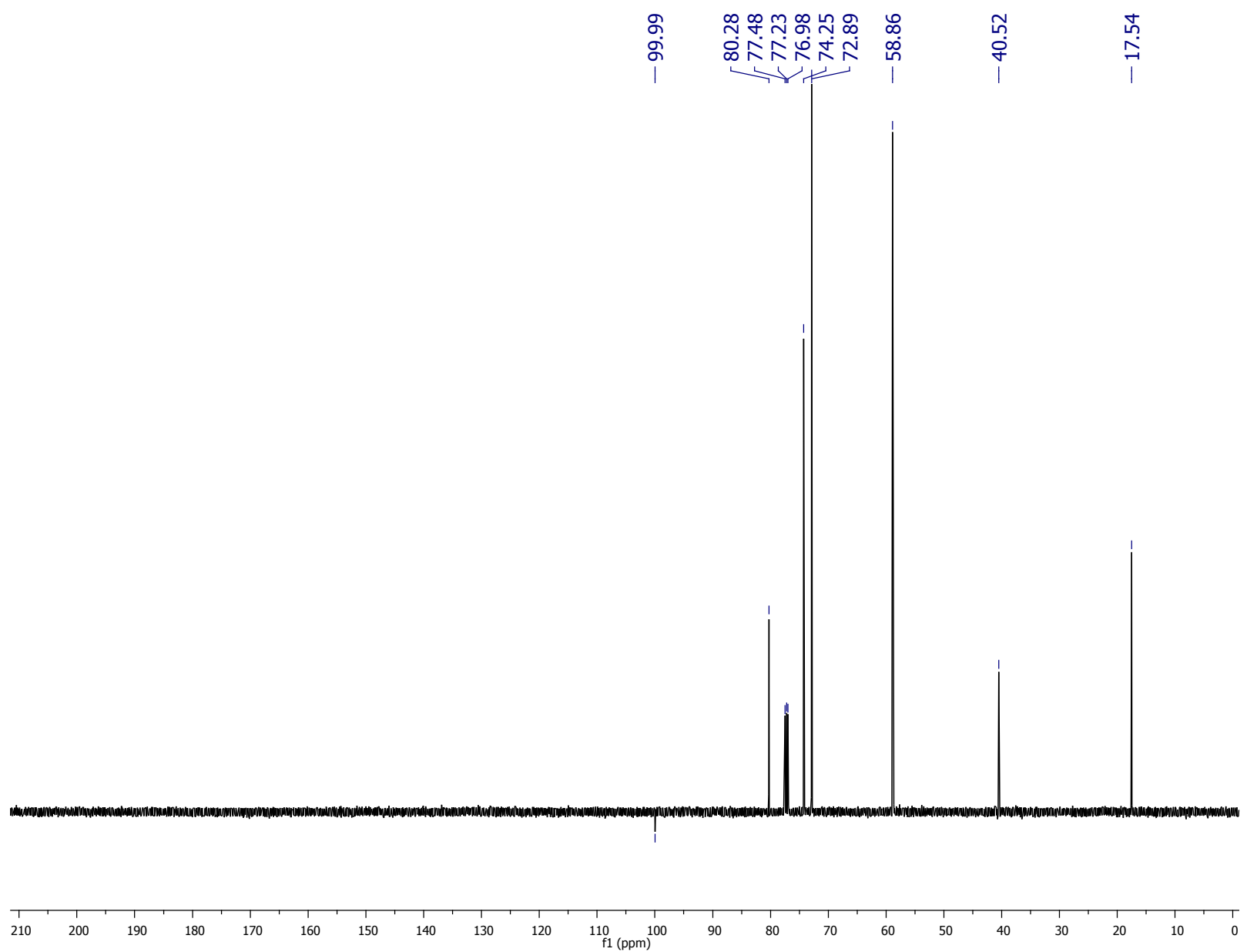

Figure S11. ${ }^{13} \mathrm{C}-\mathrm{NMR}$ spectrum of Compound $\mathbf{B}_{\mathbf{3}}$. 


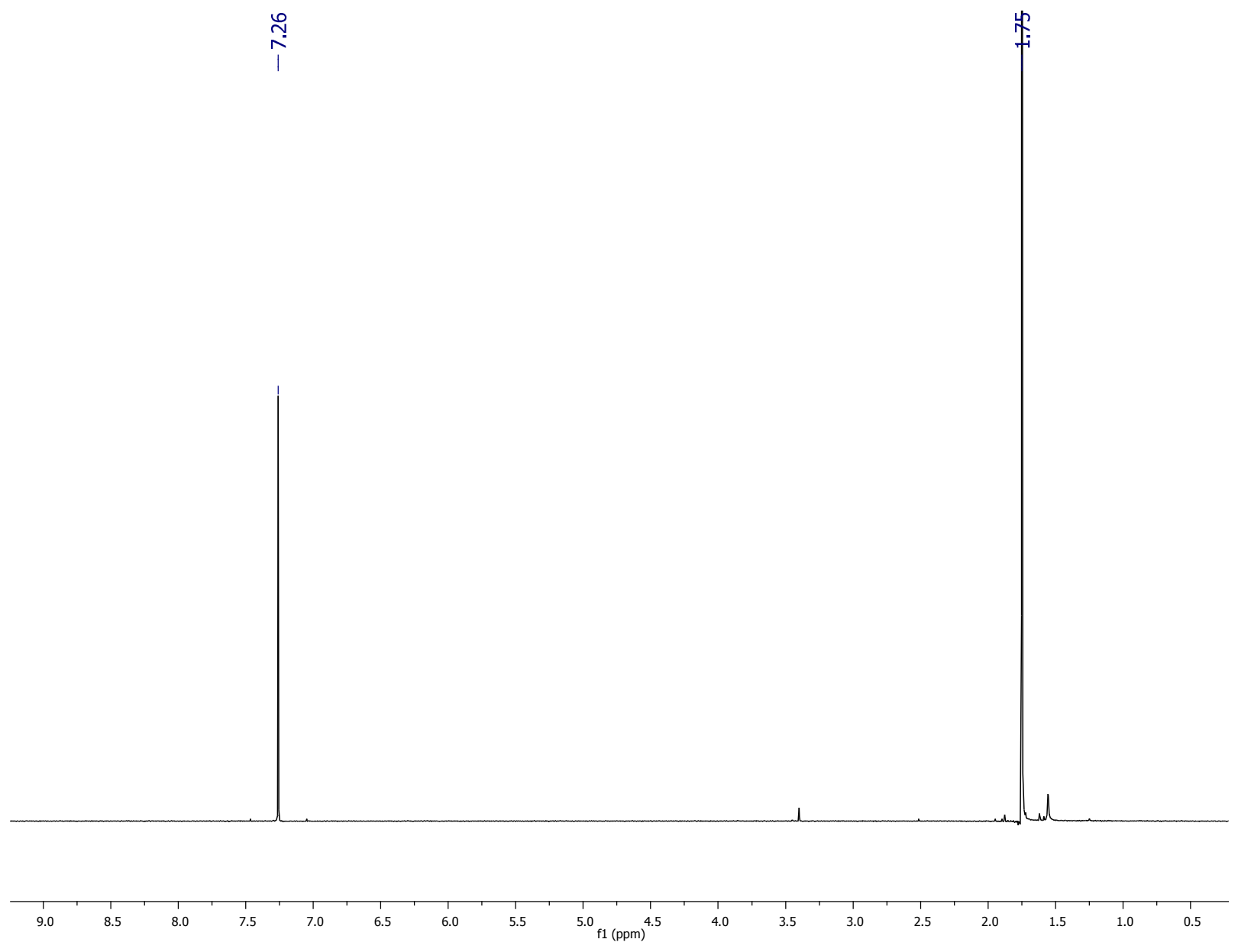

Figure S12. ${ }^{1} \mathrm{H}-\mathrm{NMR}$ spectrum of 2,2-ditrideutromethyl-5,5-dideutro-1,3-dioxane-4,6-dione 


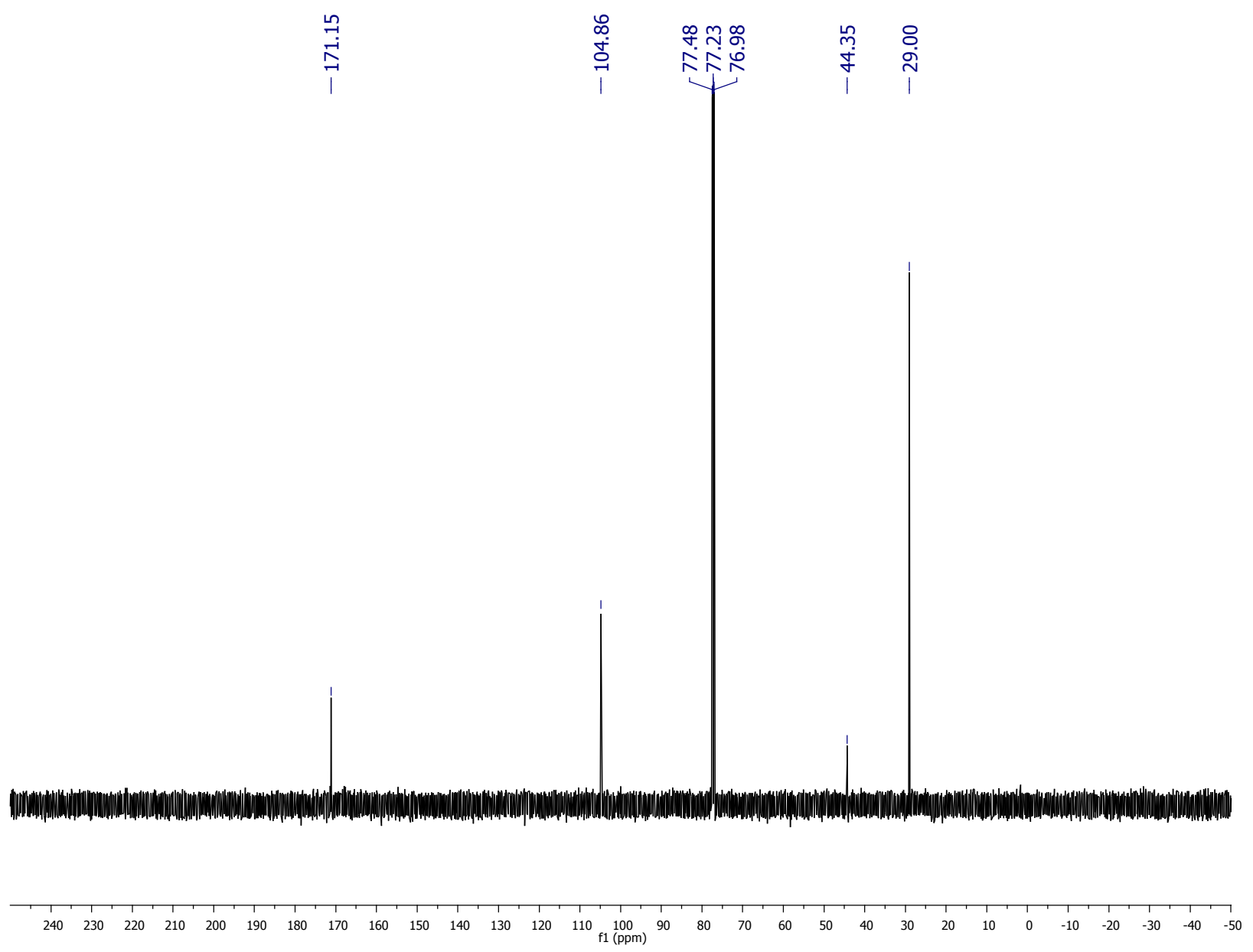

Figure S13. ${ }^{13} \mathrm{C}-\mathrm{NMR}$ spectrum of 2,2-ditrideutromethyl-5,5-dideutro-1,3-dioxane-4,6-dione 


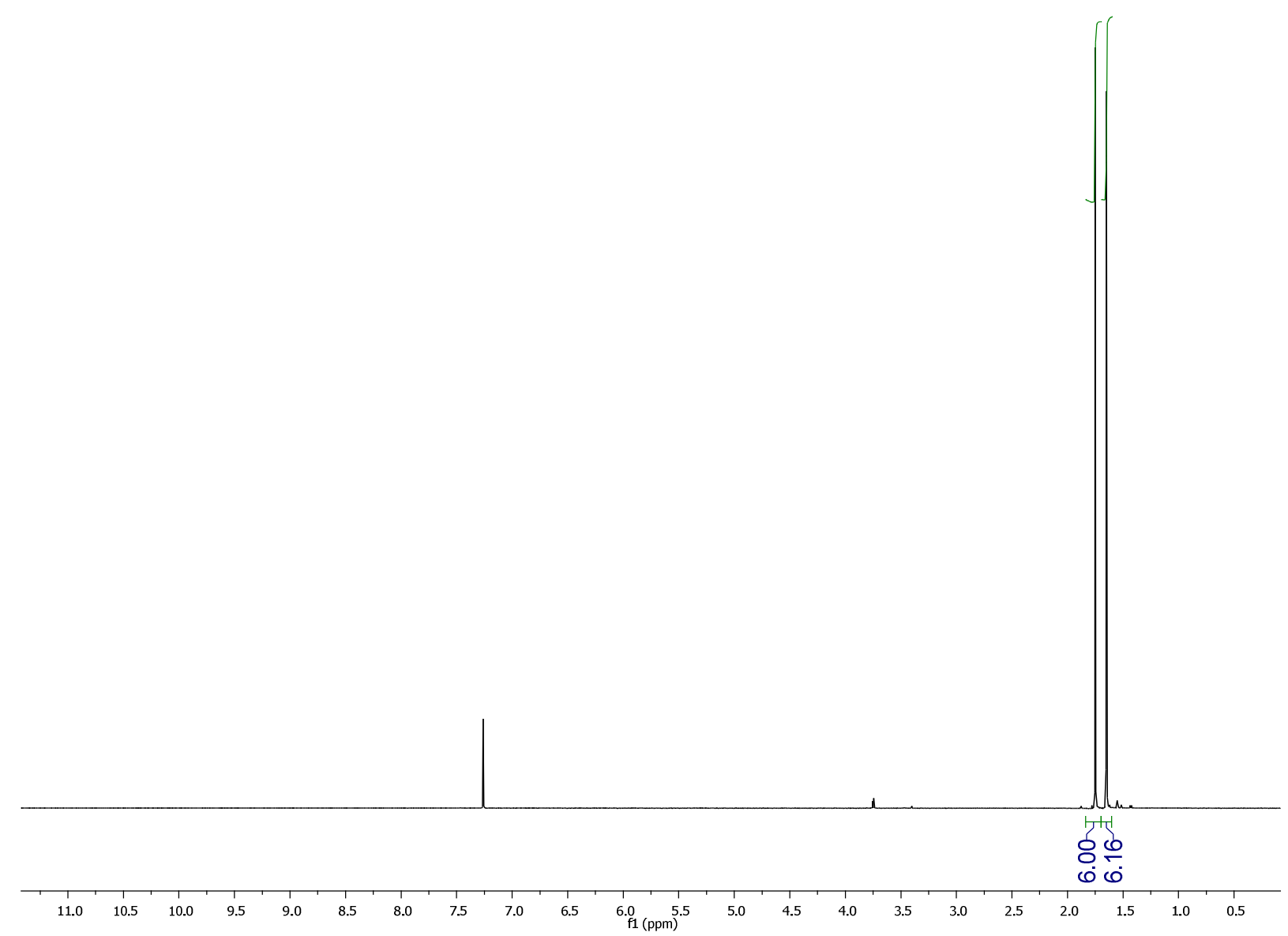

Figure S14. ${ }^{1} \mathrm{H}-\mathrm{NMR}$ spectrum of 2,2,5,5-tetramethyl-1,3-dioxane-4,6-dione 


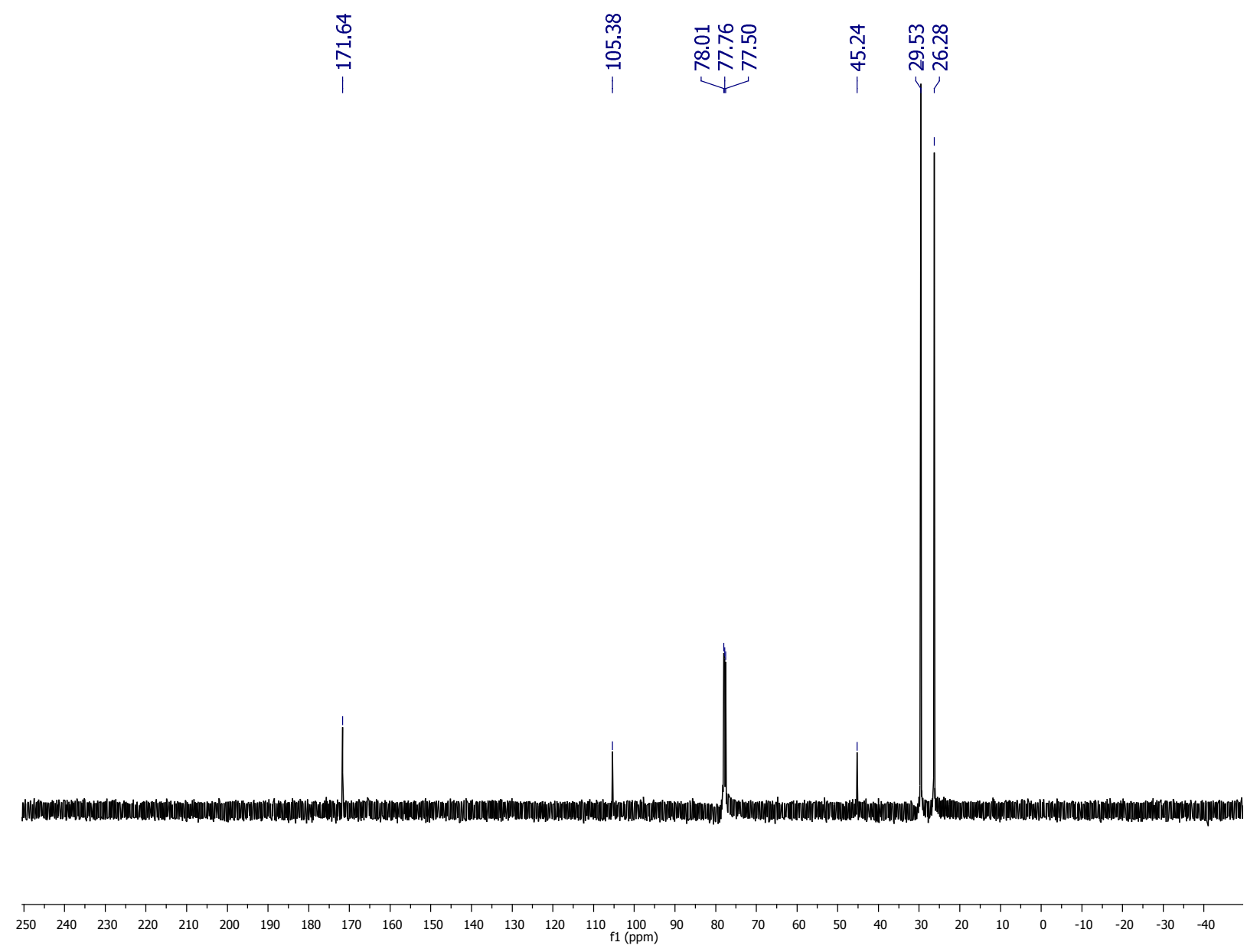

Figure S15. ${ }^{13} \mathrm{C}-\mathrm{NMR}$ spectrum of 2,2,5,5-tetramethyl-1,3-dioxane-4,6-dione. 


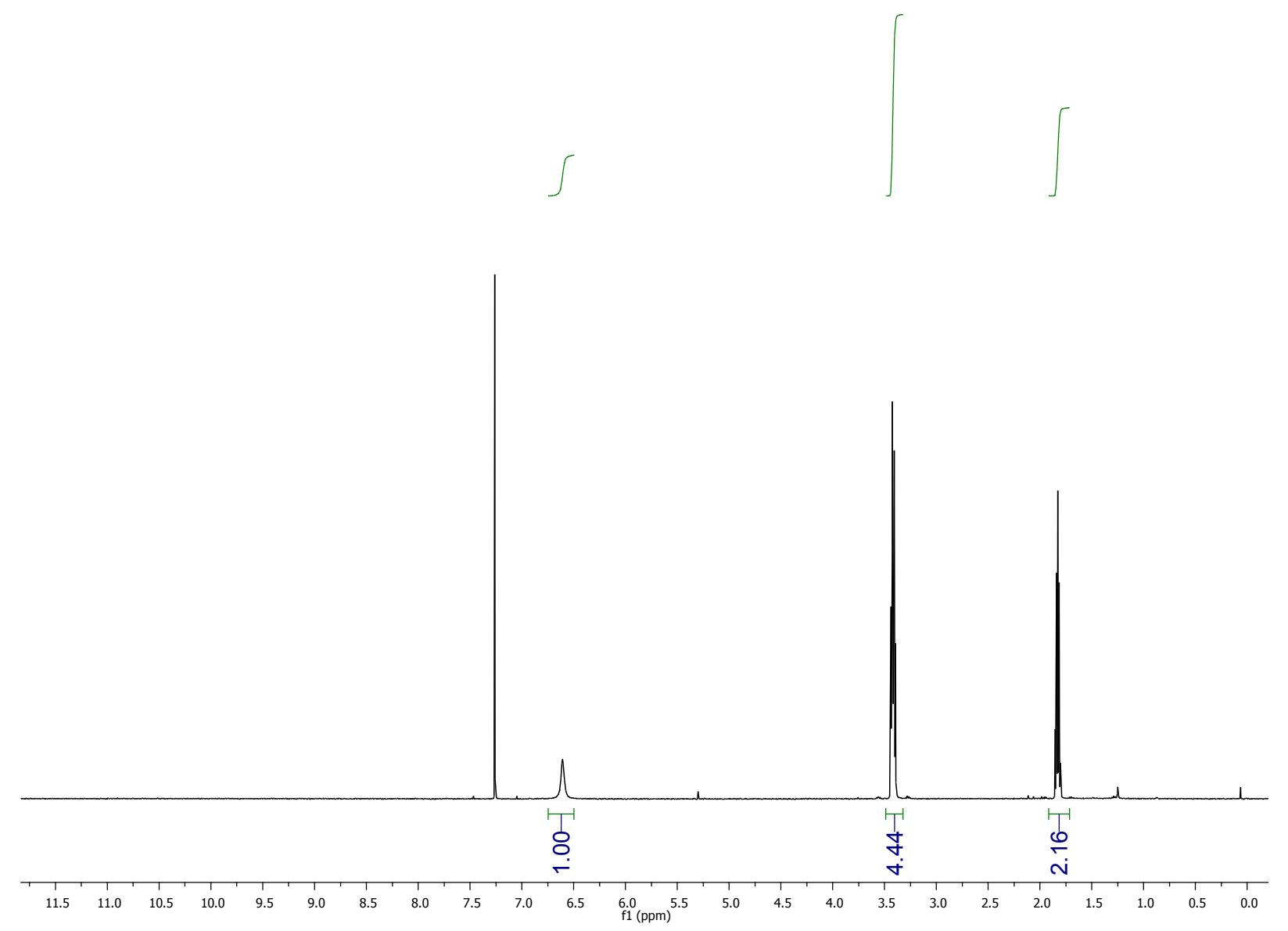

Figure S16. ${ }^{1}$ H-NMR spectrum of 2-((3-azidopropyl)carbamoyl)-2-(methyl-d3)propanoic-3,3,3d3 acid. 


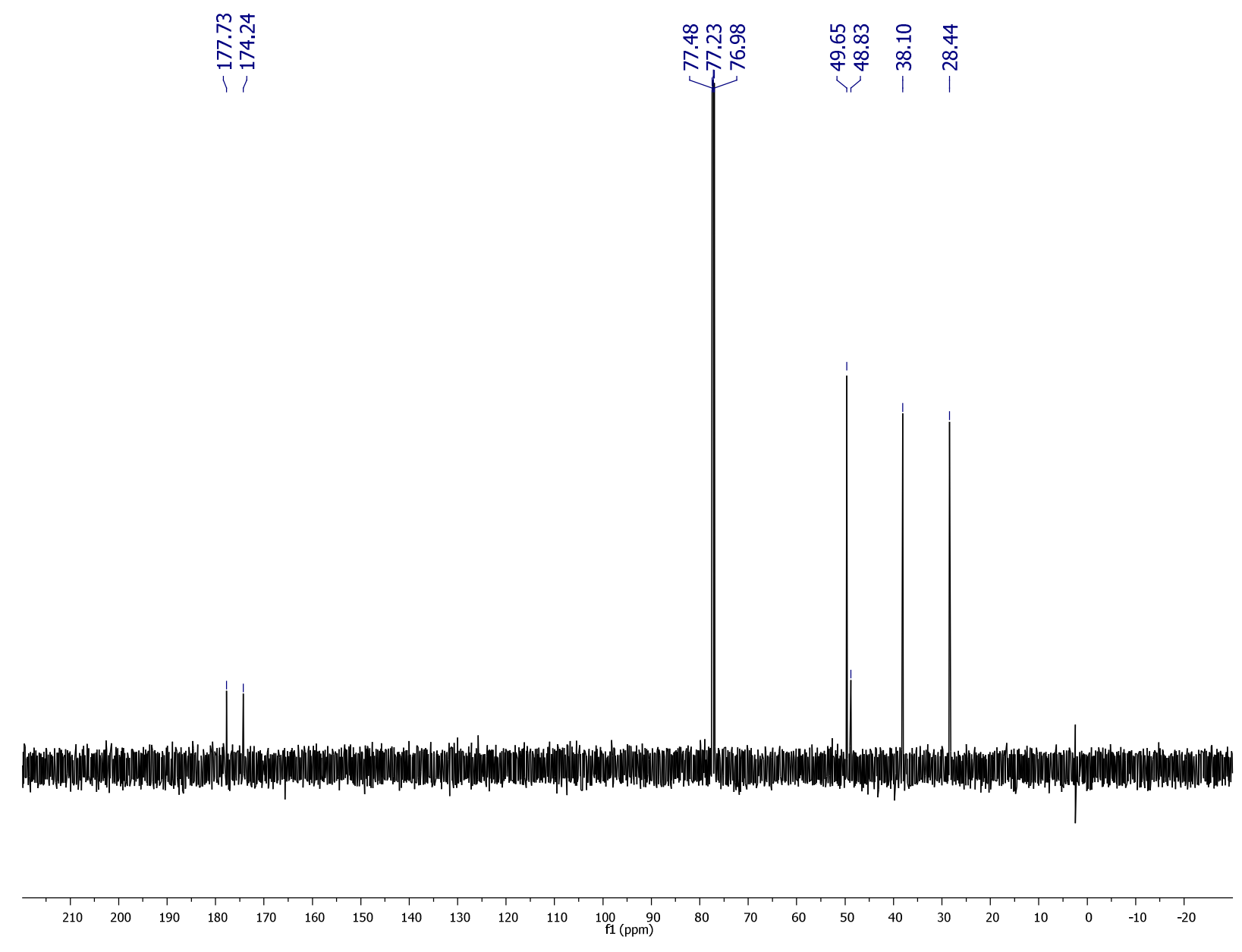

Figure S17. ${ }^{13} \mathrm{C}-\mathrm{NMR}$ spectrum of 2-((3-azidopropyl)carbamoyl)-2-(methyl-d3)propanoic-3,3,3d3 acid 


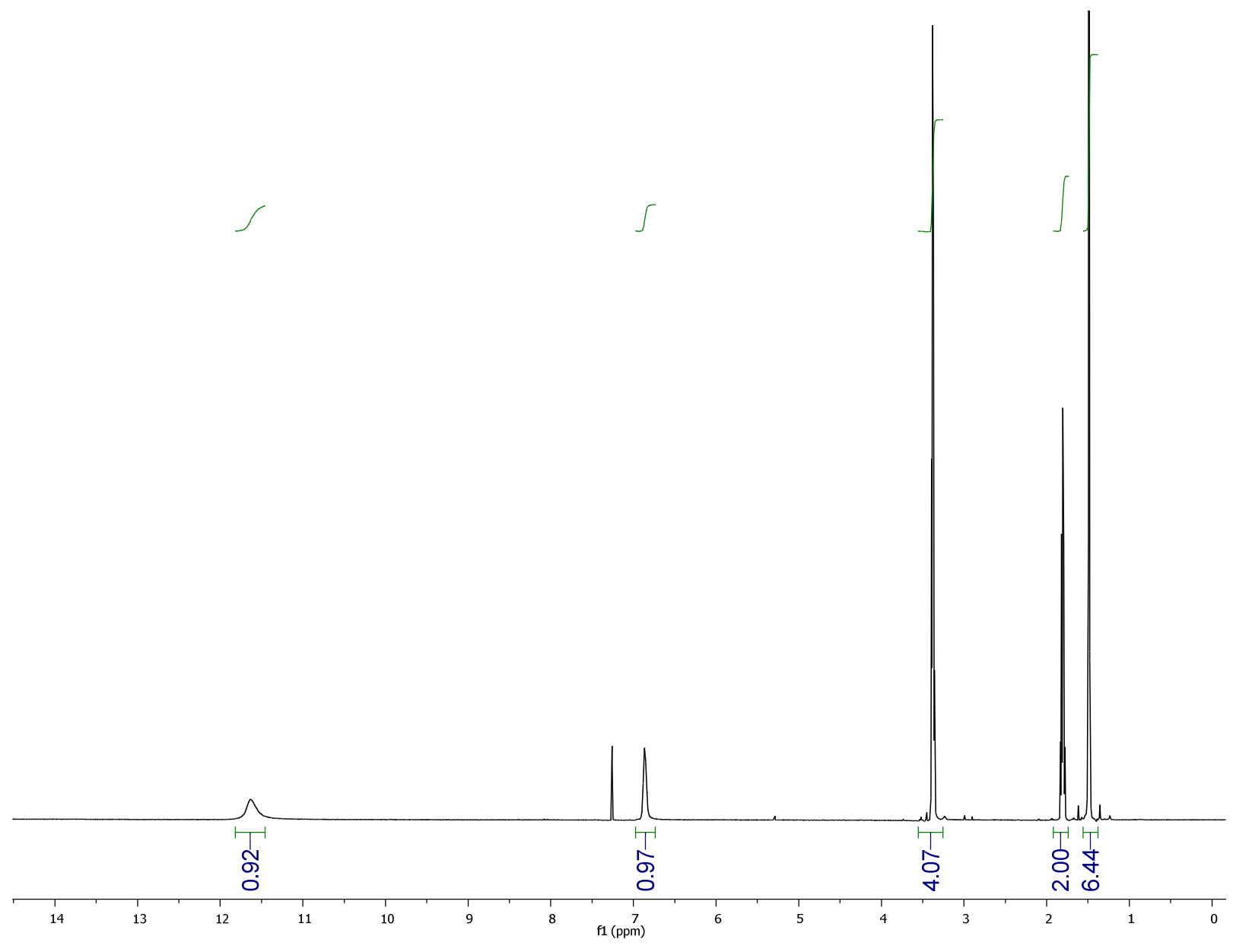

Figure S18. ${ }^{1}$ H-NMR spectrum of 3-((3-azidopropyl)amino)-2,2-dimethyl-3-oxopropanoic acid 


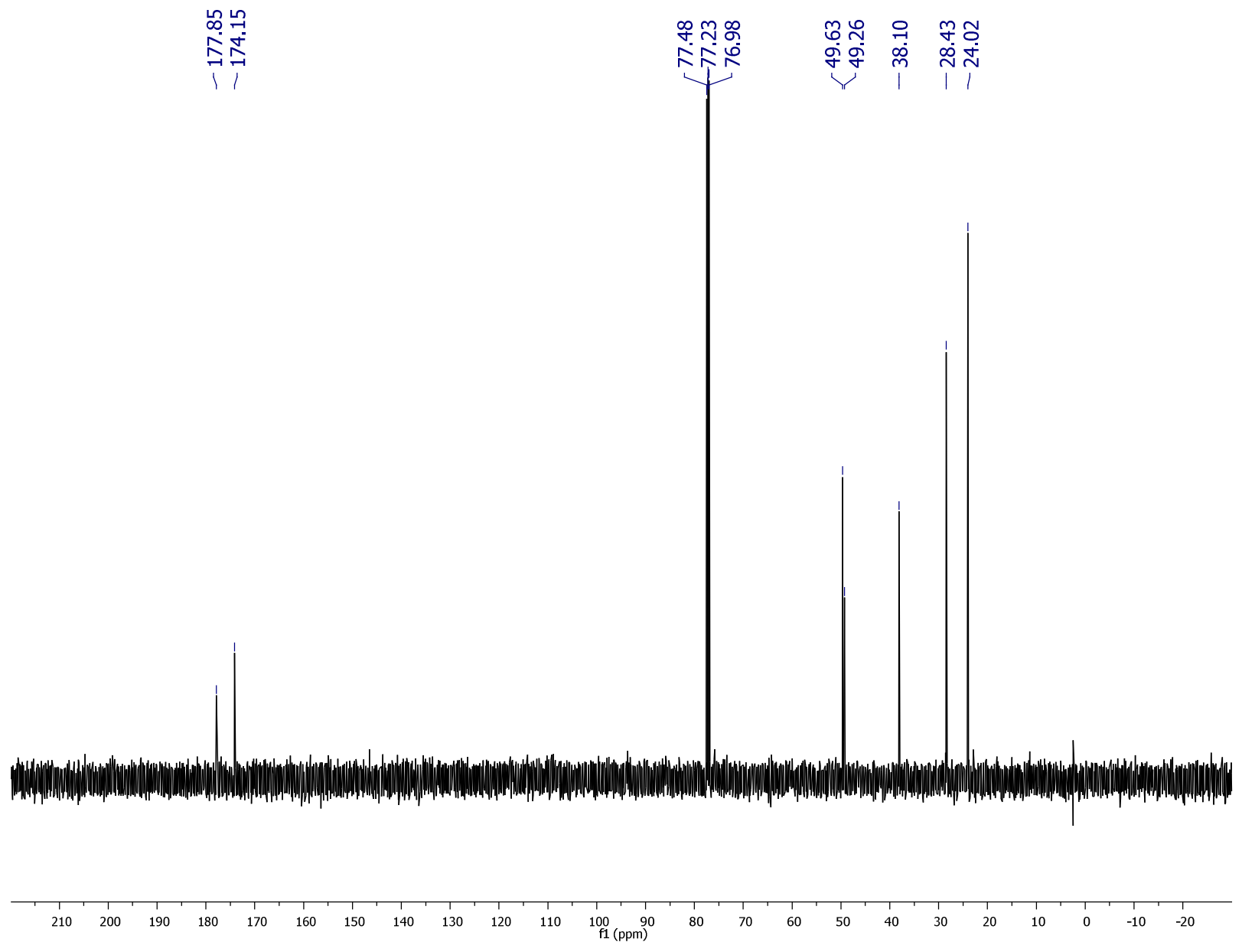

Figure S19. ${ }^{13} \mathrm{C}$-NMR spectrum of 3-((3-azidopropyl)amino)-2,2-dimethyl-3-oxopropanoic acid 


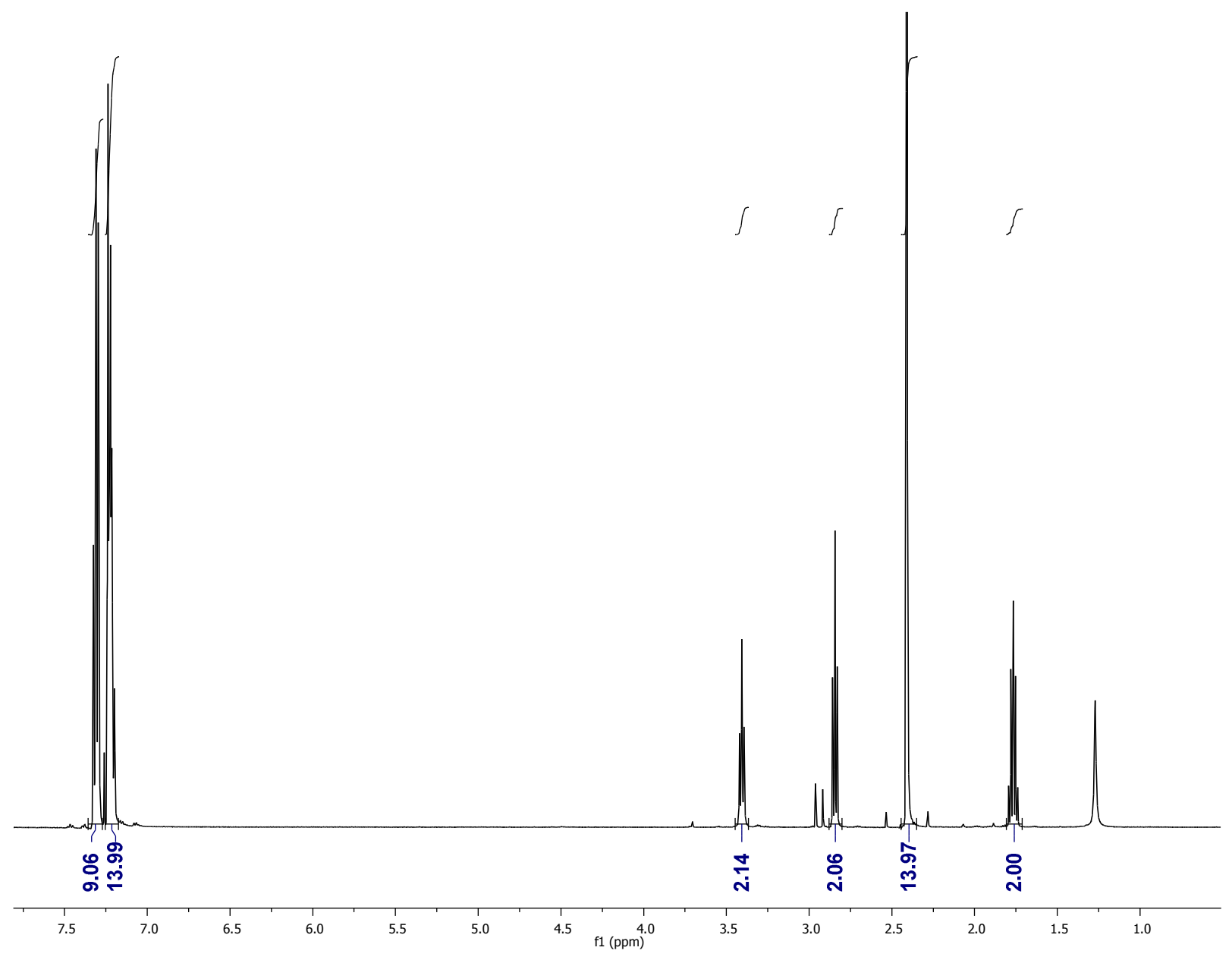

Figure S20. ${ }^{1} \mathrm{H}$ NMR spectrum of 3-azidopropan-1-amine as a solution in toluene 


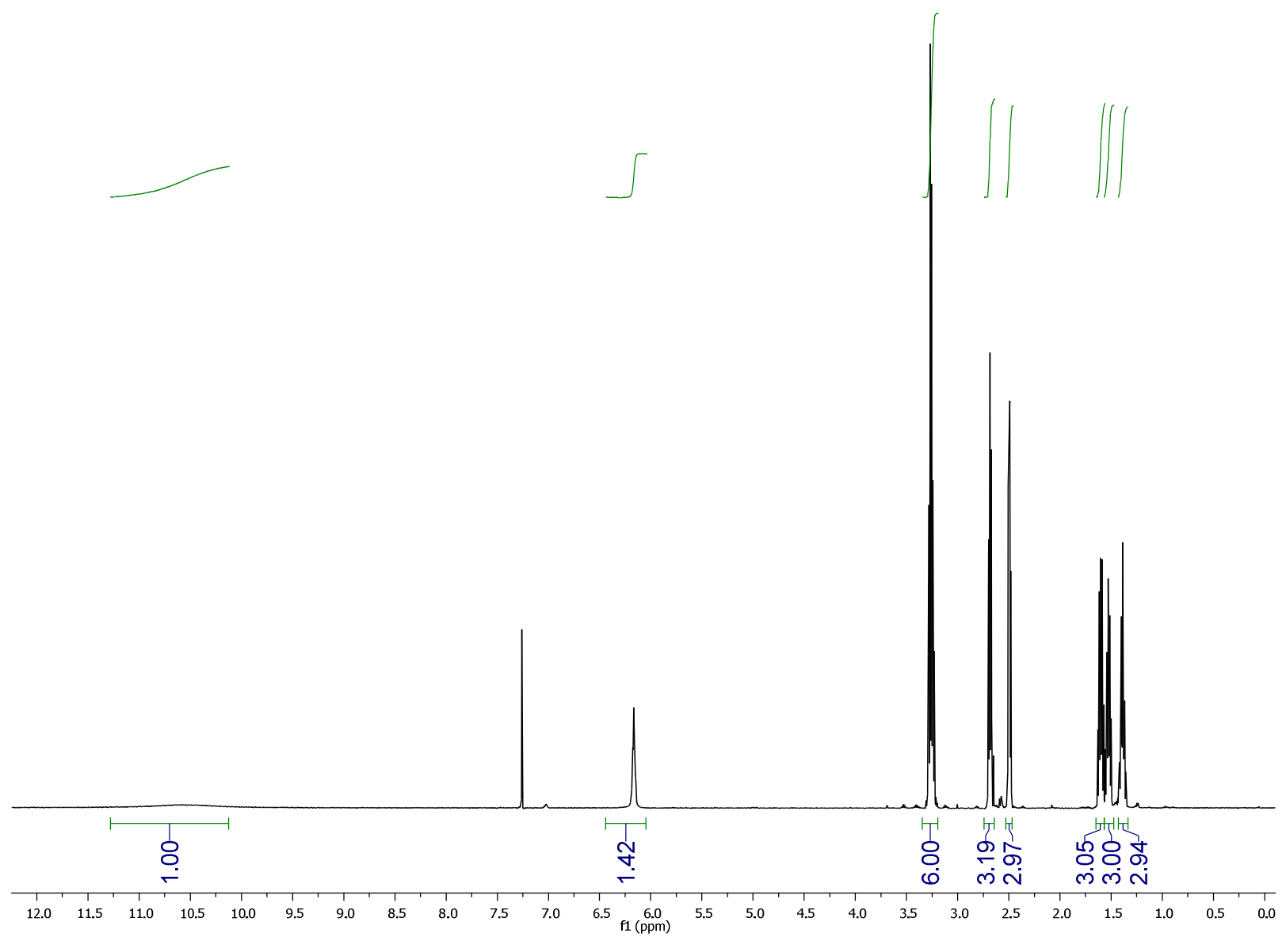

Figure S21. ${ }^{1} \mathrm{H}-\mathrm{NMR}$ spectrum of 4-((5-azidopentyl)amino)-4-oxobutanoic acid 


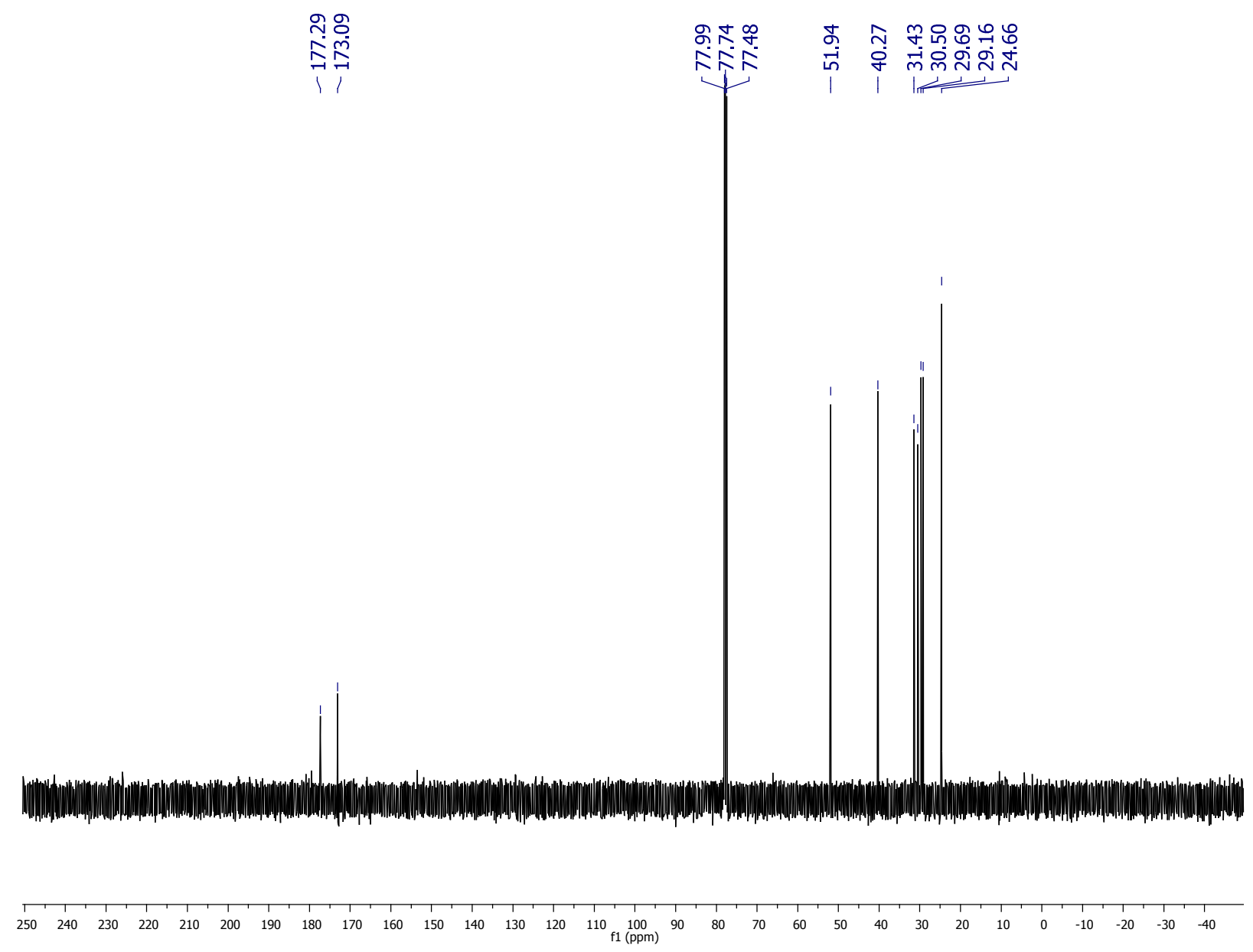

Figure S22. ${ }^{13} \mathrm{C}$-NMR spectrum of 4-((5-azidopentyl)amino)-4-oxobutanoic acid 


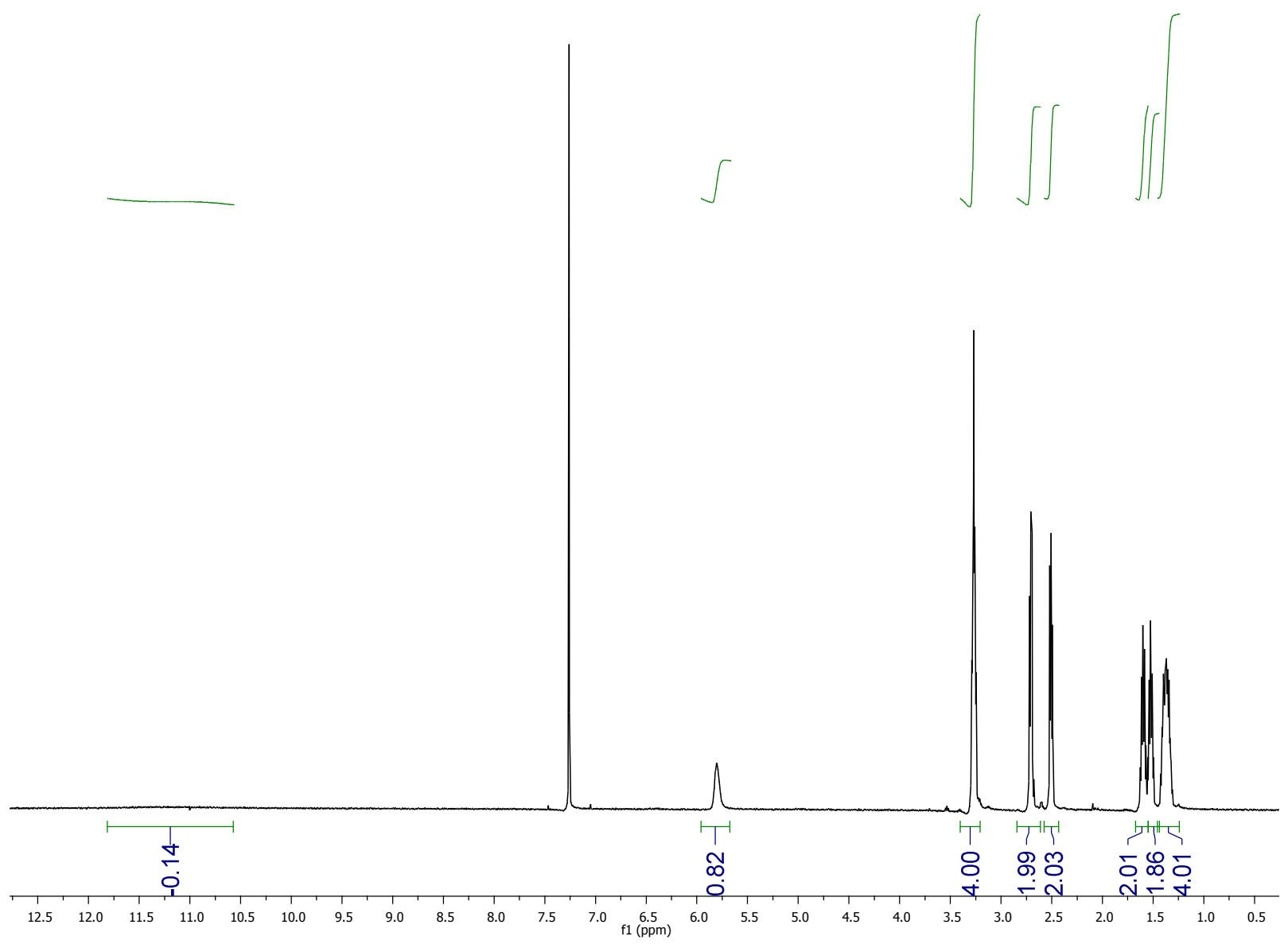

Figure S23. ${ }^{1}$ H-NMR spectrum of 4-((6-azidohexyl)amino)-4-oxobutanoic acid 


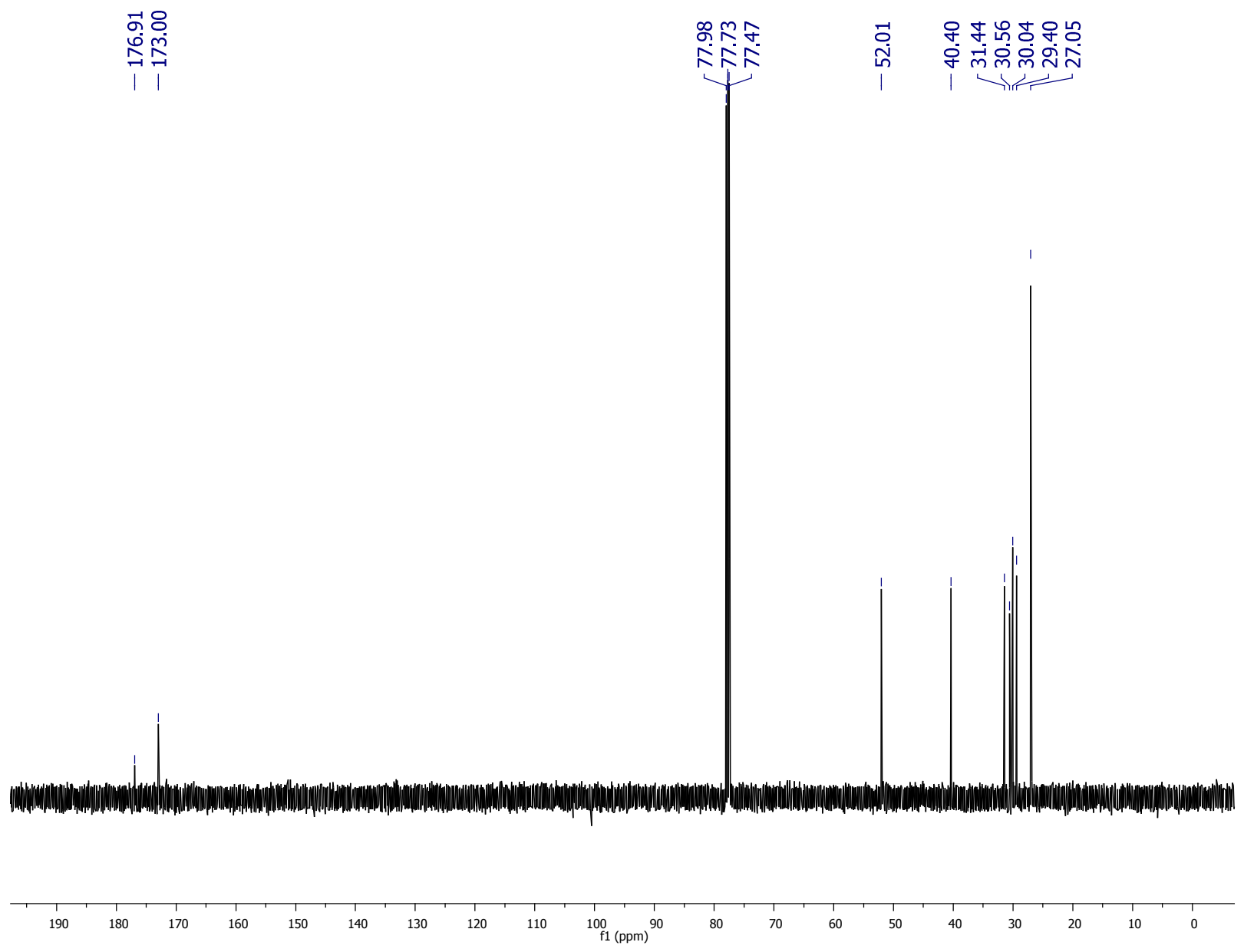


Figure S24. ${ }^{13} \mathrm{C}$-NMR spectrum of 4-((6-azidohexyl)amino)-4-oxobutanoic acid

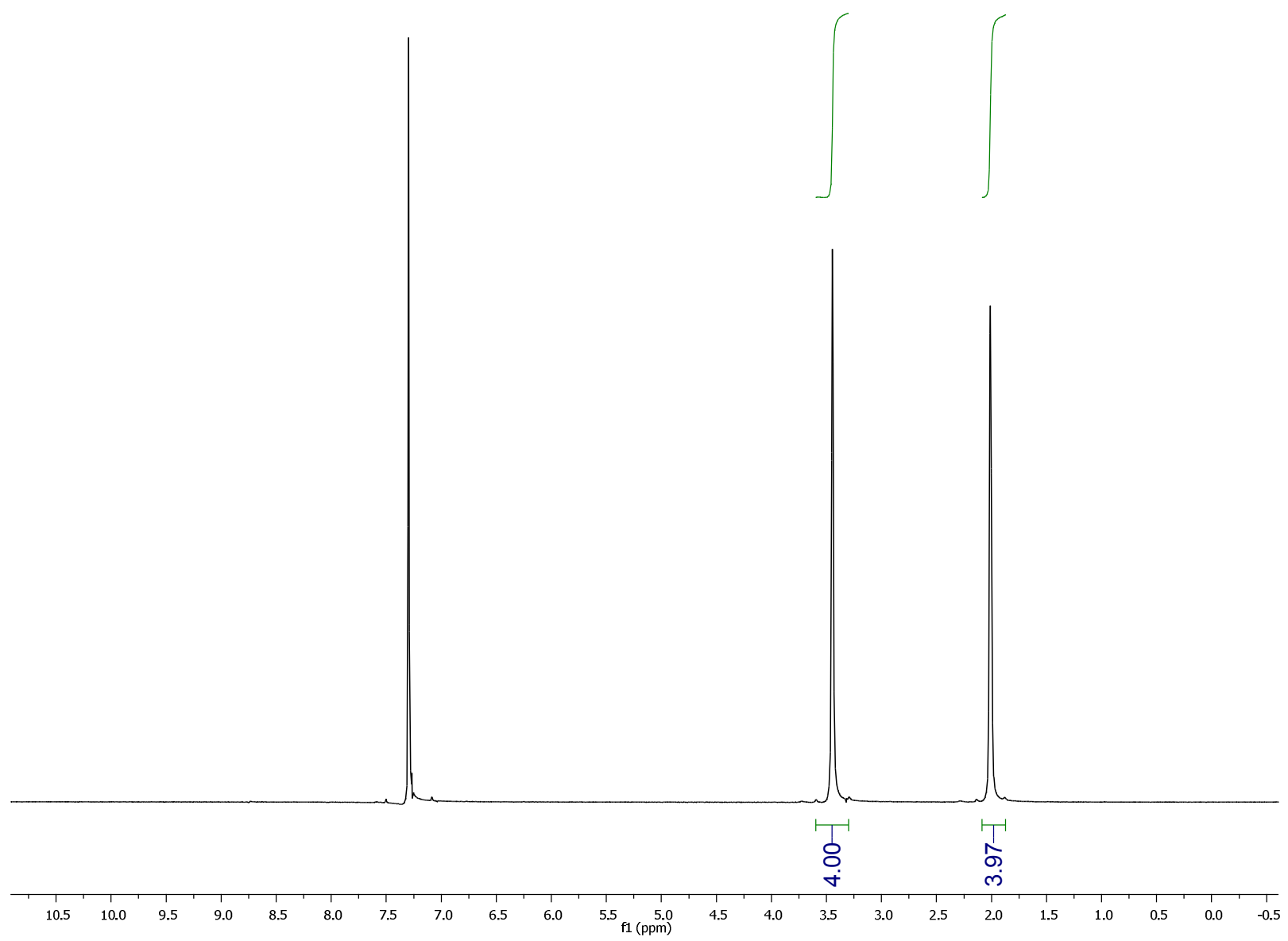


Figure S25. ${ }^{2} \mathrm{H}-\mathrm{NMR}$ of 1,4-dibromobutane-1,1,2,2,3,3,4,4- $d_{8}$

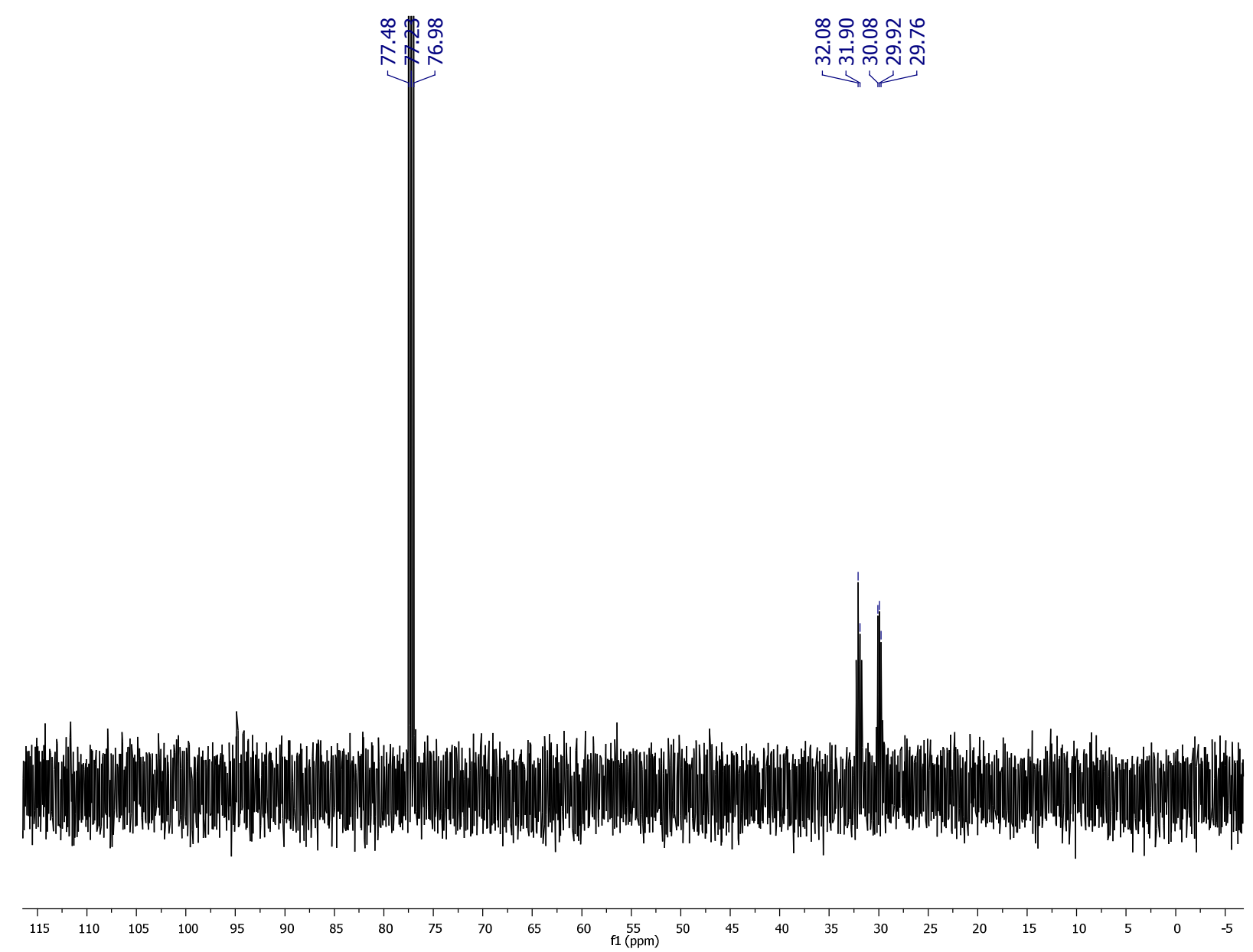

Figure S26. ${ }^{13} \mathrm{C}$-NMR spectrum of 1,4-dibromobutane-1,1,2,2,3,3,4,4-d $d_{8}$ 


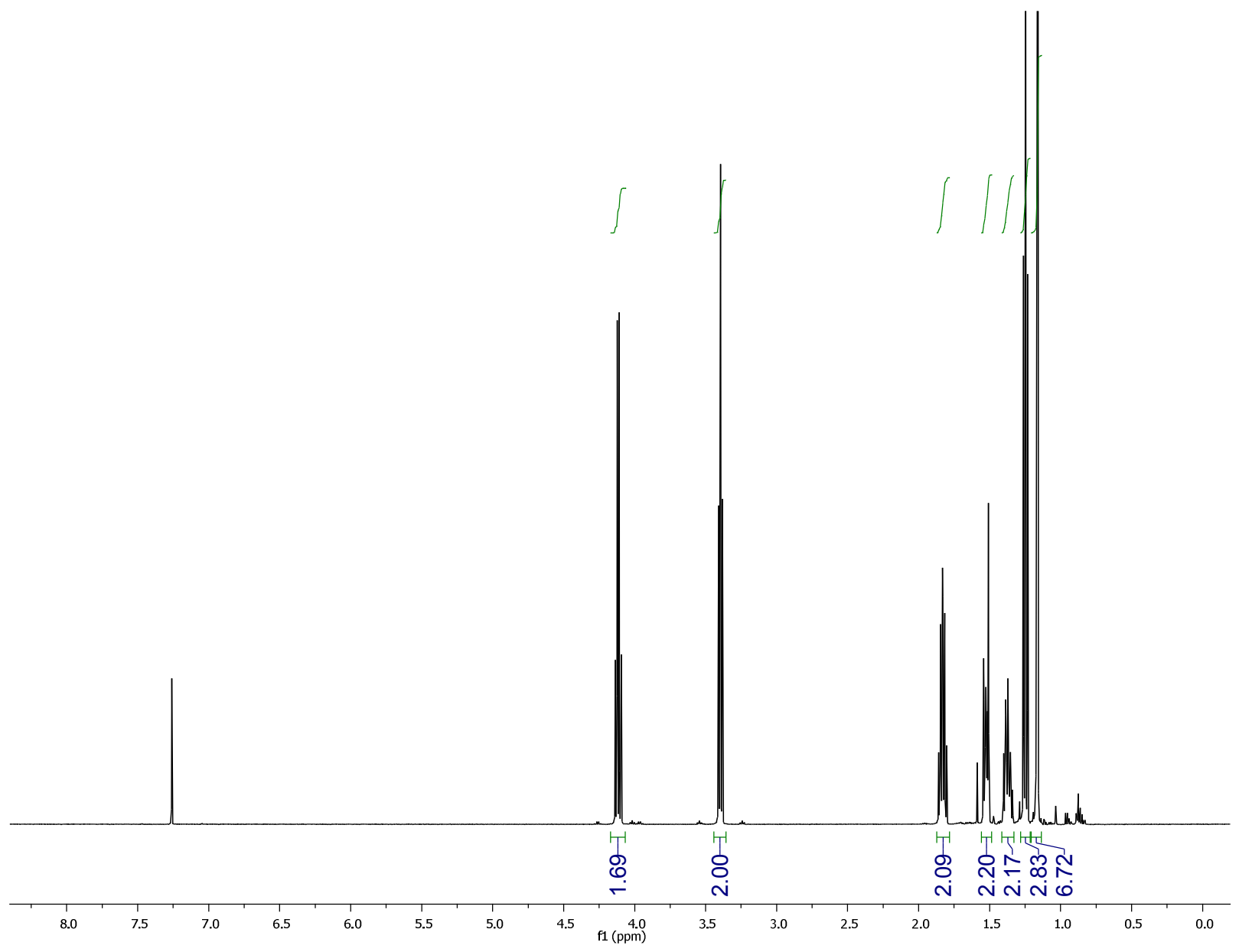

Figure S27. ${ }^{1}$ H-NMR spectrum of ethyl 6-bromo-2,2-dimethylhexanoate 


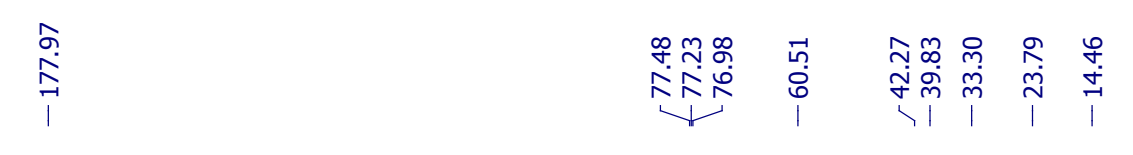

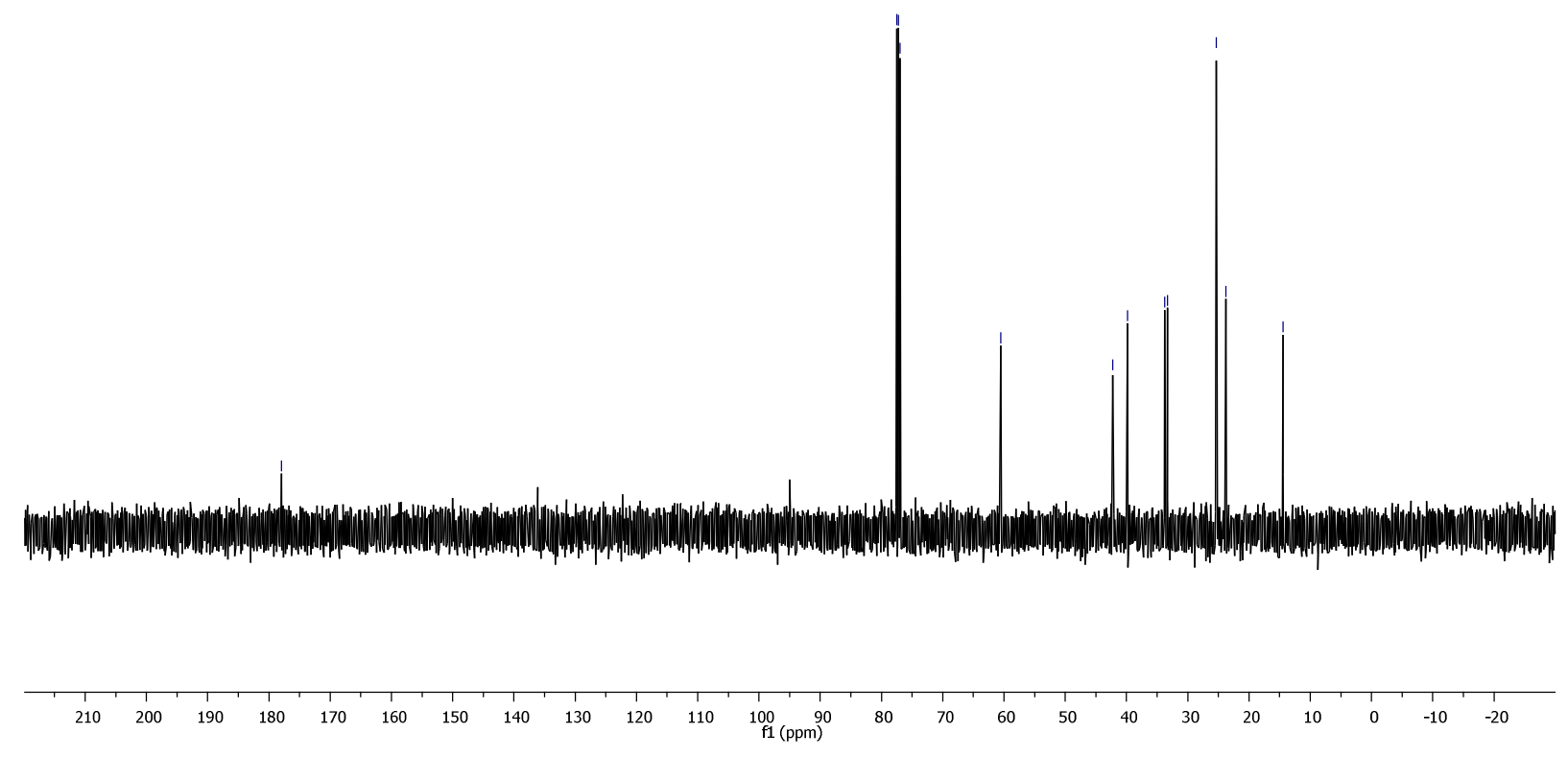

Figure S28. ${ }^{13} \mathrm{C}-\mathrm{NMR}$ spectrum of ethyl 6-bromo-2,2-dimethylhexanoate 


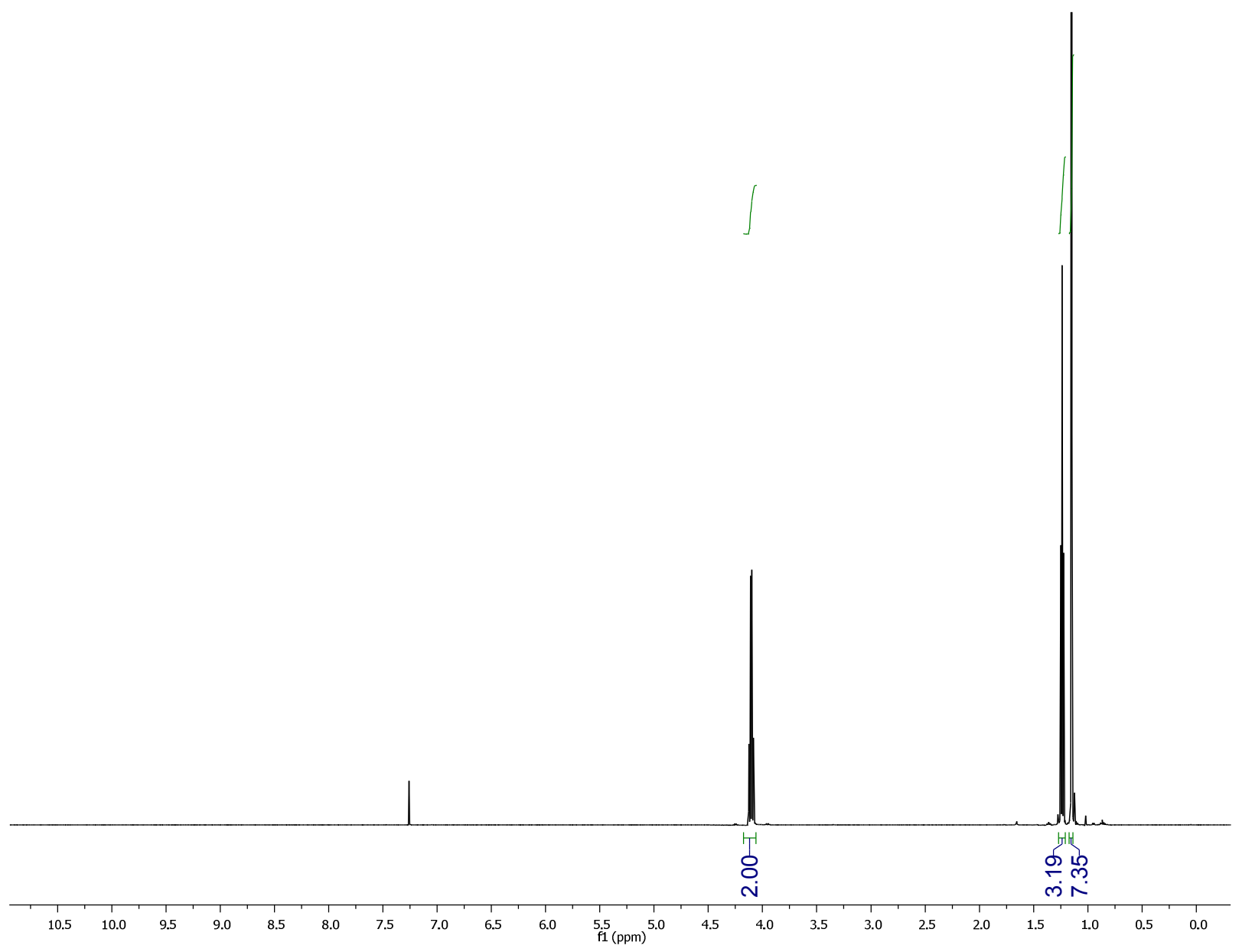

Figure S29. ${ }^{1}$ H-NMR spectrum of ethyl 6-bromo-2,2-dimethylhexanoate-3,3,4,4,5,5,6,6- $d_{8}$ 


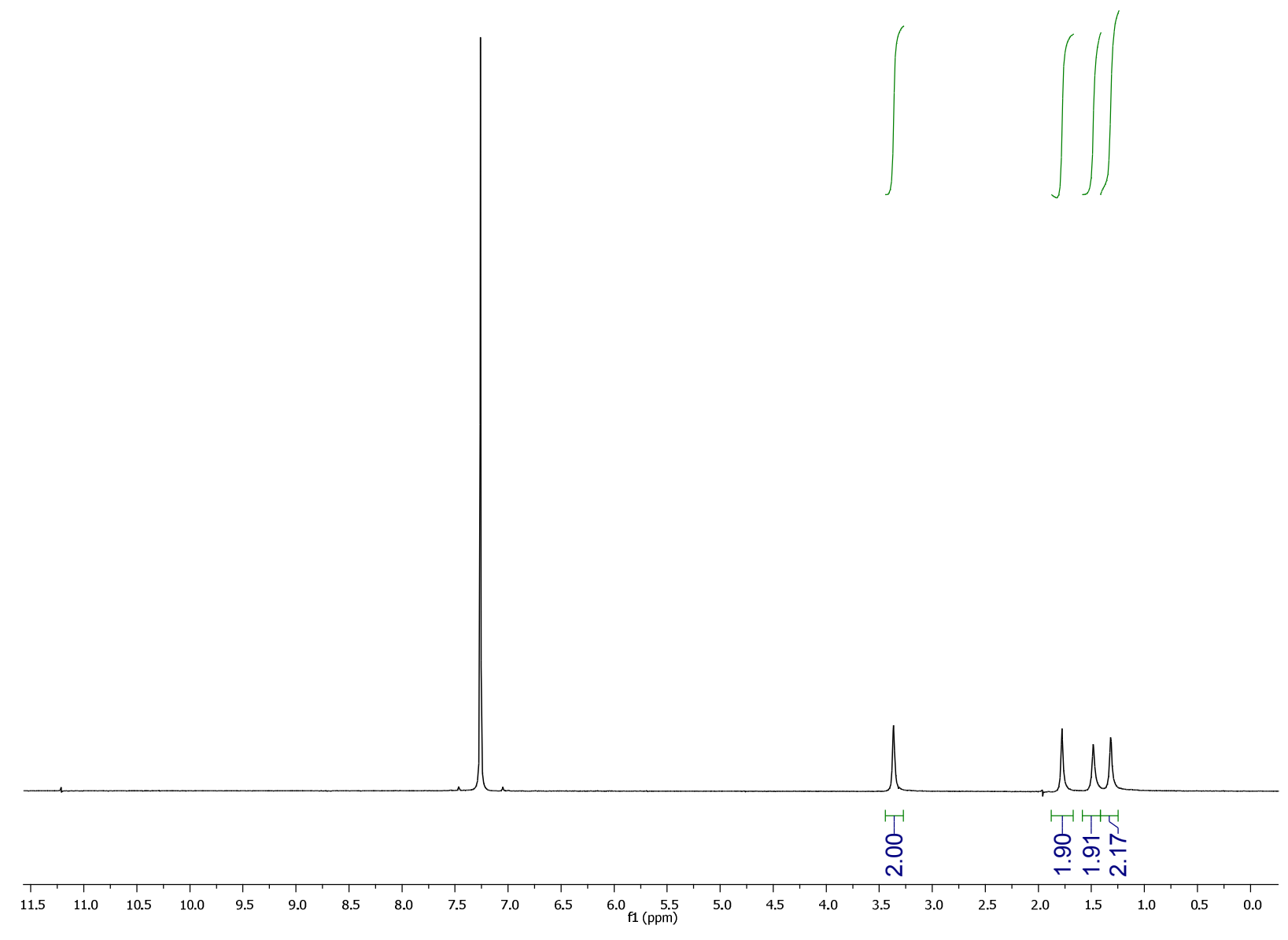

Figure S30. ${ }^{2} \mathrm{H}-\mathrm{NMR}$ spectrum of ethyl 6-bromo-2,2-dimethylhexanoate-3,3,4,4,5,5,6,6- $d_{8}$ 


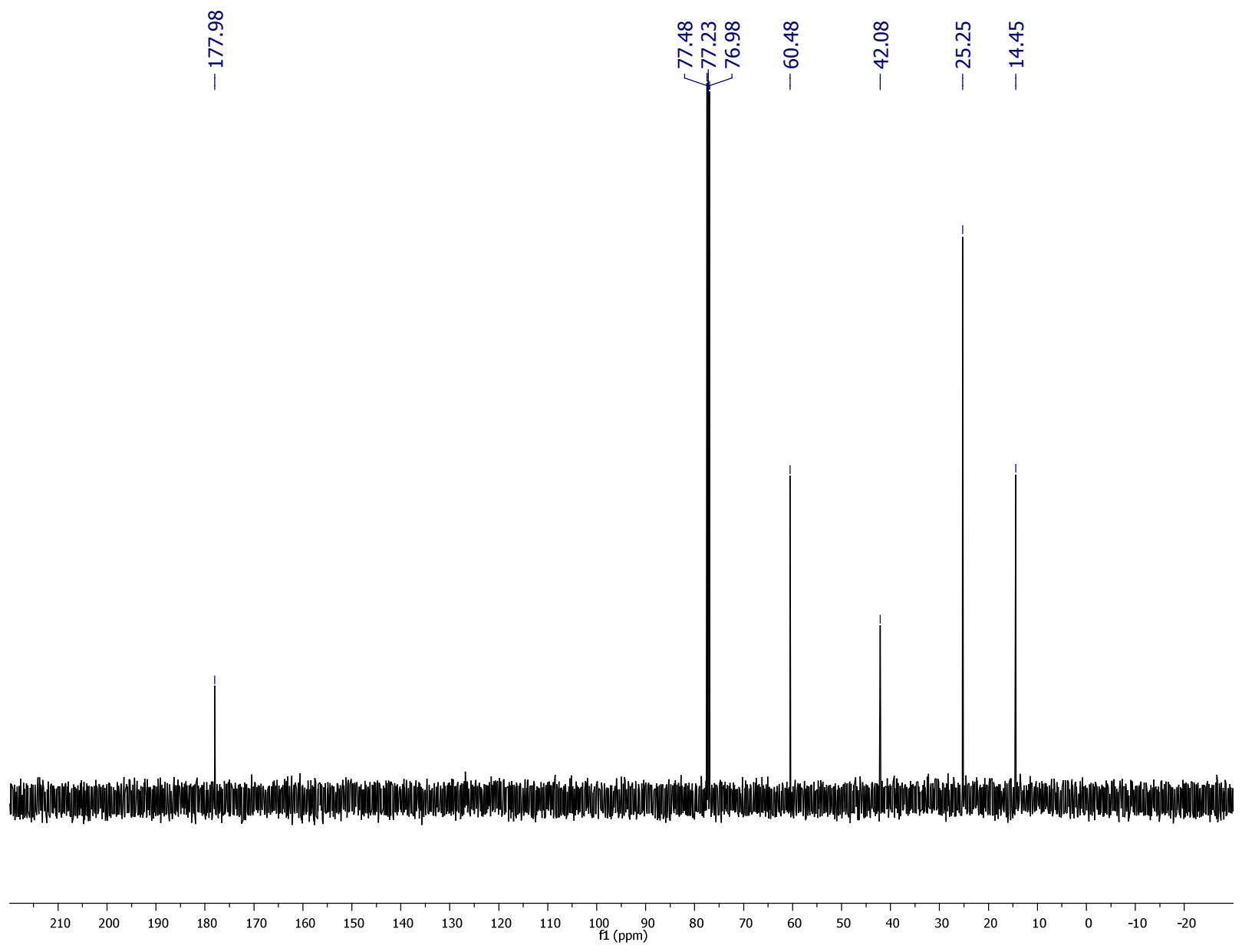

Figure S31. ${ }^{13} \mathrm{C}$-NMR spectrum of ethyl 6-azido-2,2-dimethylhexanoate-3,3,4,4,5,5,6,6- $d_{8}$ 


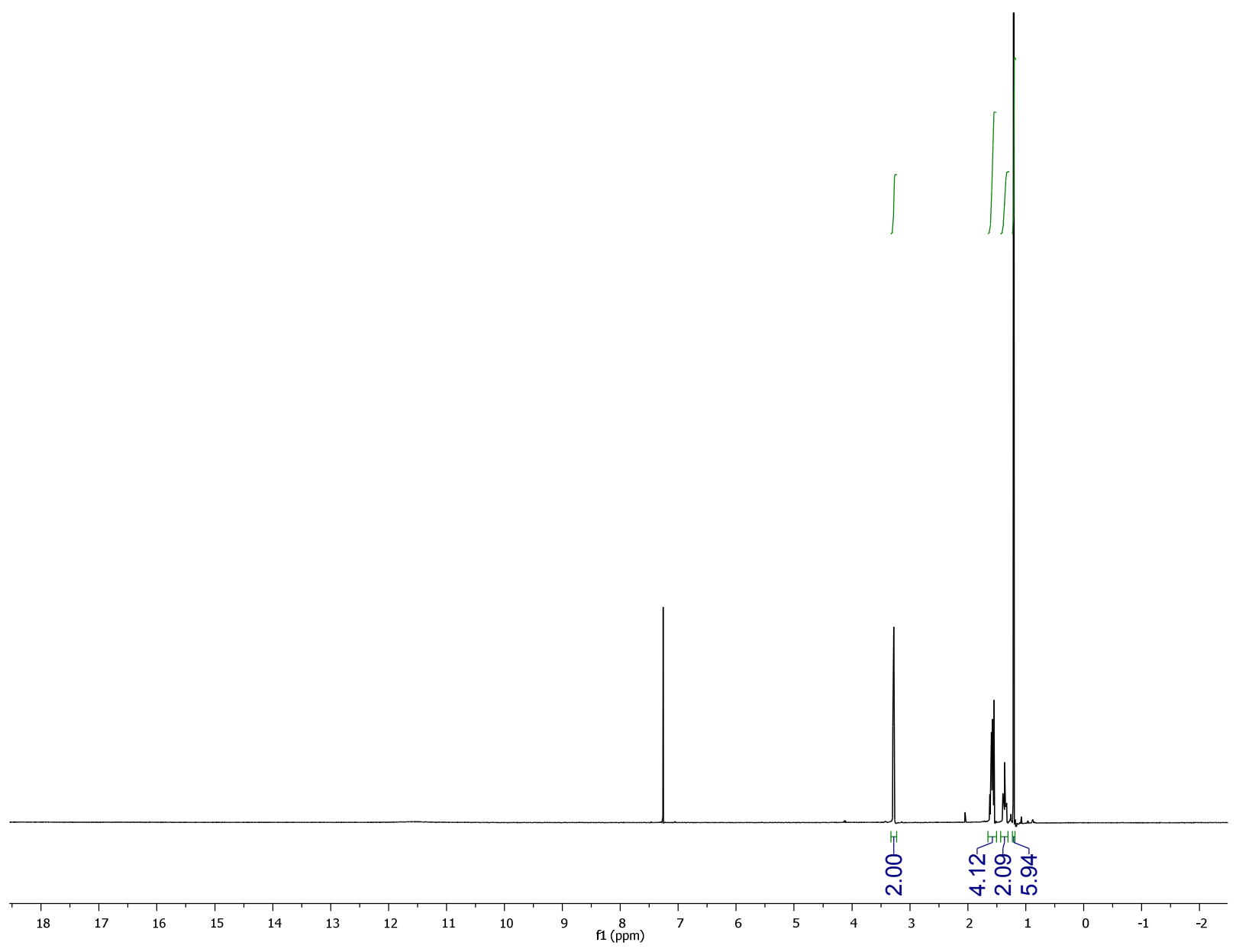

Figure S32. ${ }^{1}$ H-NMR spectrum of 6-azido-2,2-dimethylhexanoic acid 


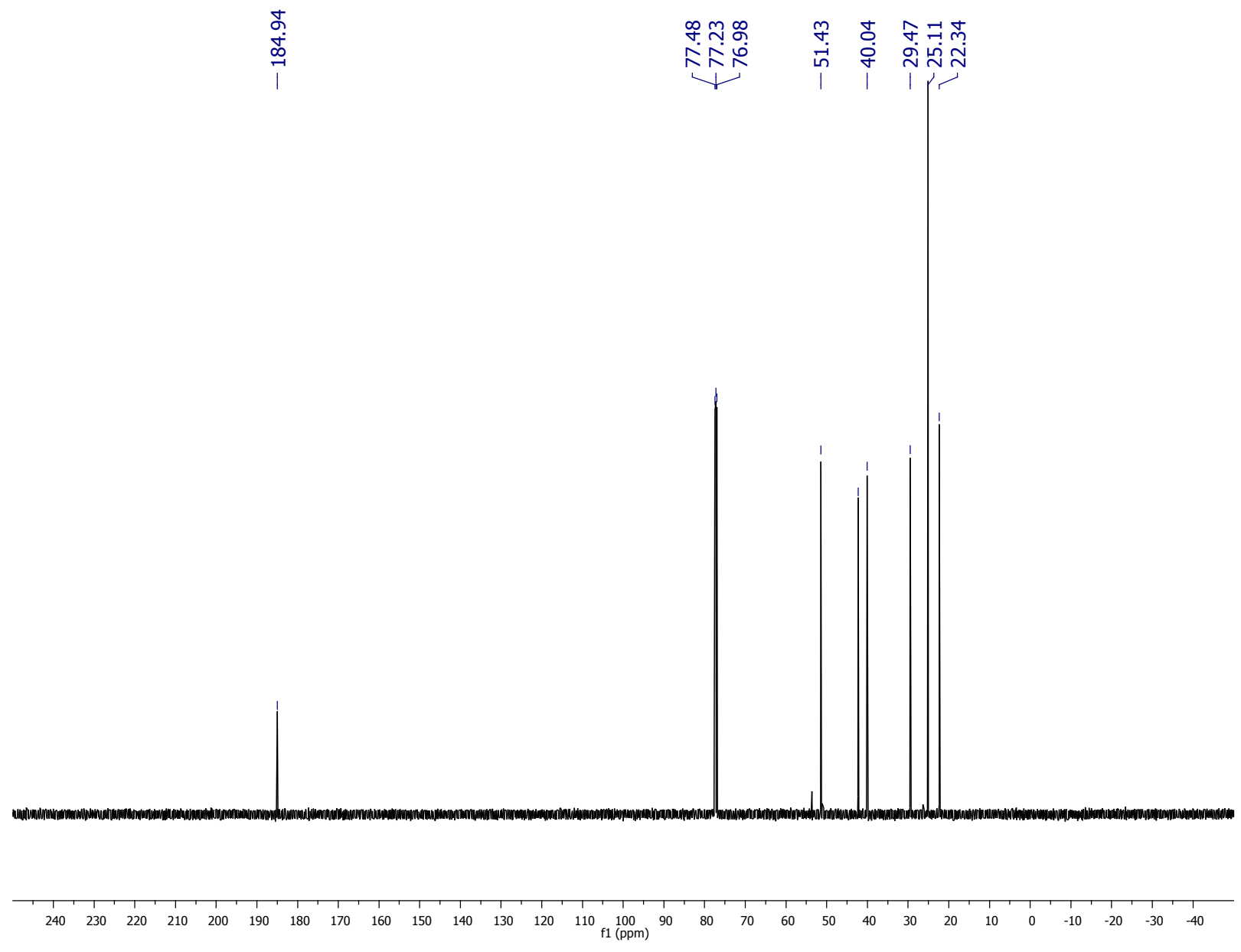

Figure S33. ${ }^{13} \mathrm{C}-\mathrm{NMR}$ spectrum of 6-azido-2,2-dimethylhexanoic acid 


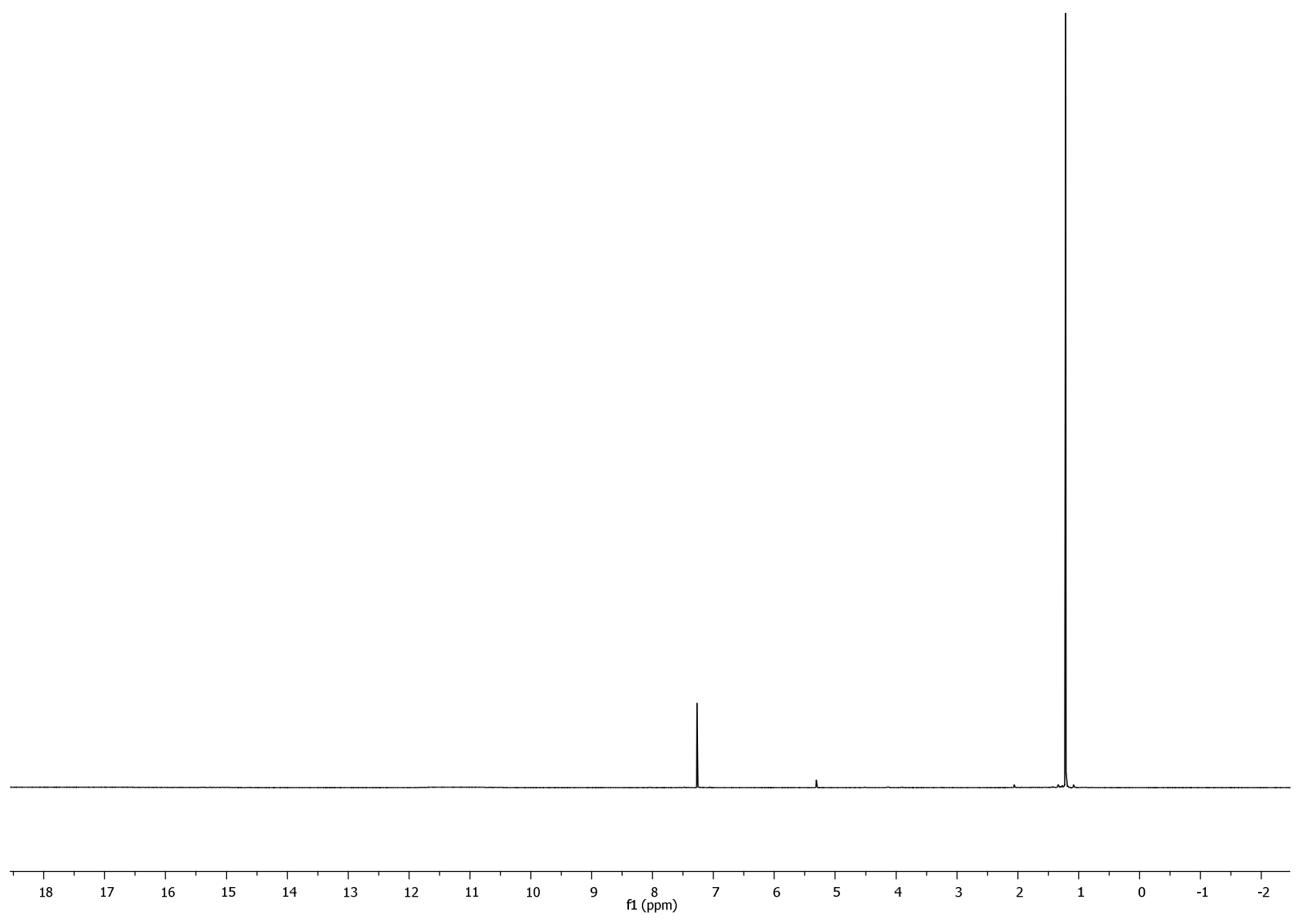

Figure S34. ${ }^{1} \mathrm{H}-\mathrm{NMR}$ spectrum of 6-azido-2,2-dimethylhexanoic-3,3,4,4,5,5,6,6- $d_{8}$ acid 


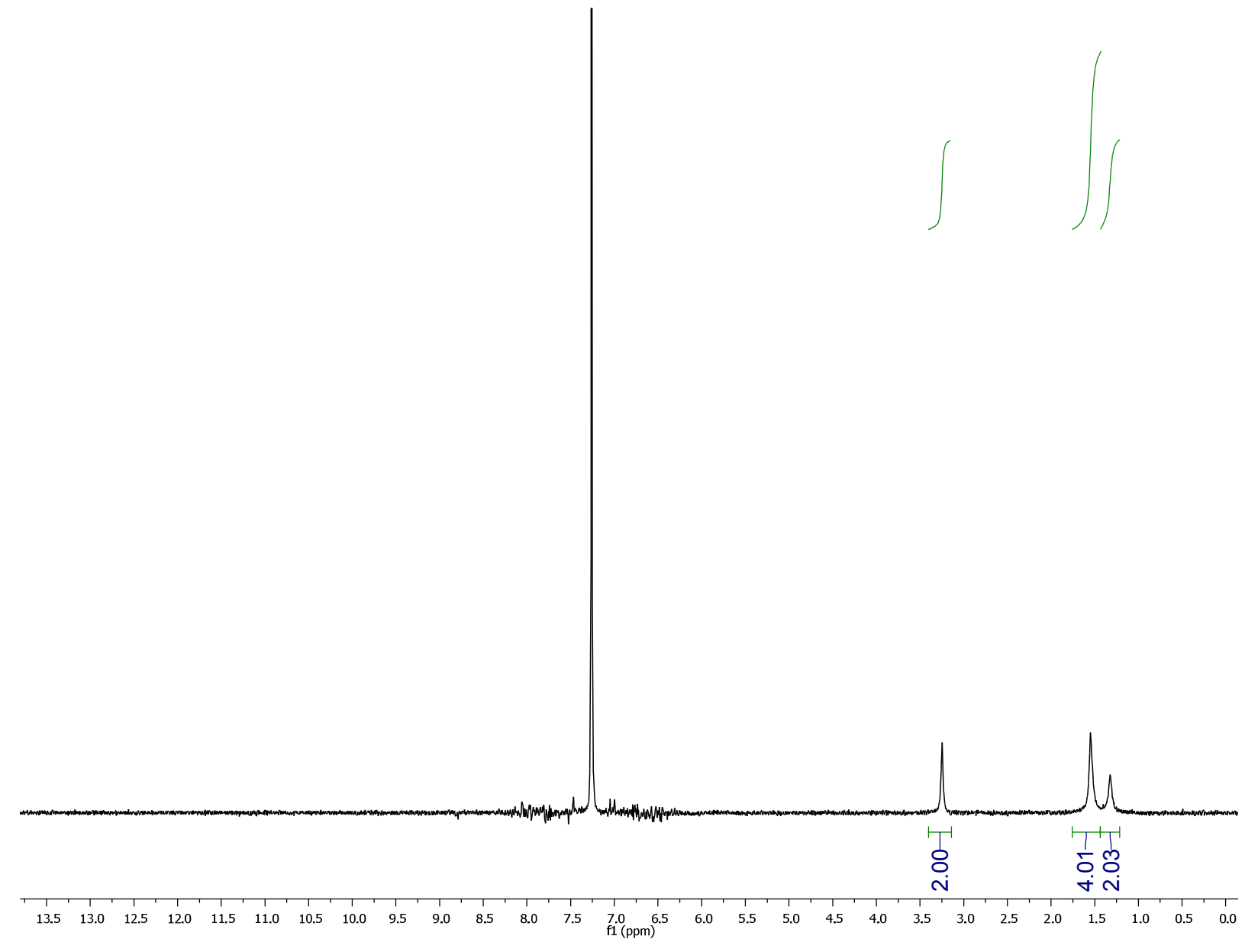

Figure S35. ${ }^{2} \mathrm{H}-\mathrm{NMR}$ spectrum of 6-azido-2,2-dimethylhexanoic-3,3,4,4,5,5,6,6- $d_{8}$ acid 

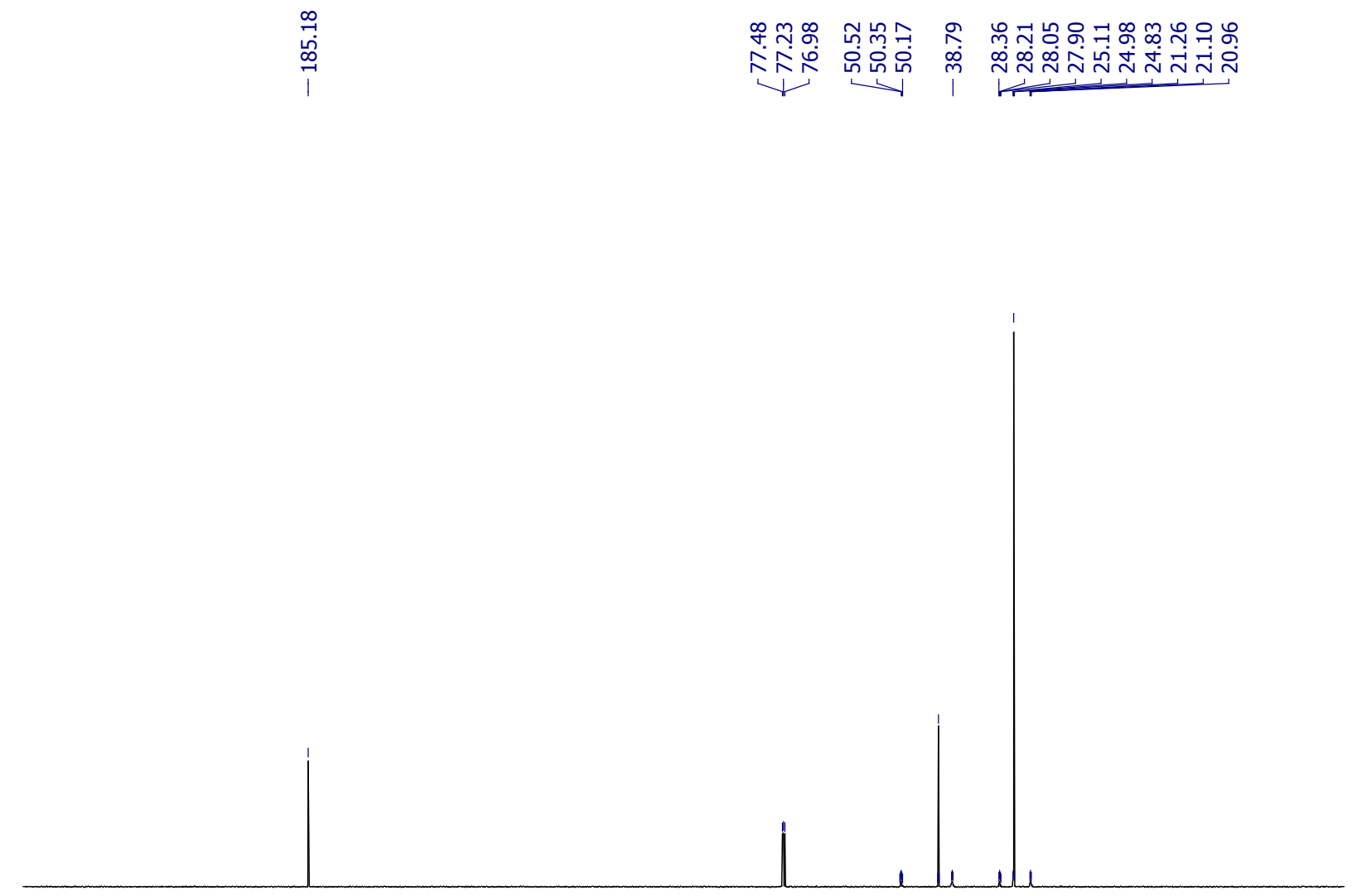

\begin{tabular}{llllllllllllllllllllllllllllllllllll}
\hline 240 & 230 & 220 & 210 & 200 & 190 & 180 & 170 & 160 & 150 & 140 & 130 & 120 & 110 & 100 & 90 & 80 & 70 & 60 & 50 & 40 & 30 & 20 & 10 & 0 & -10 & -20 & -30 & -40 & -50
\end{tabular}

Figure S35. ${ }^{13} \mathrm{C}$-NMR spectrum of 6-azido-2,2-dimethylhexanoic-3,3,4,4,5,5,6,6- $d_{8}$ acid 


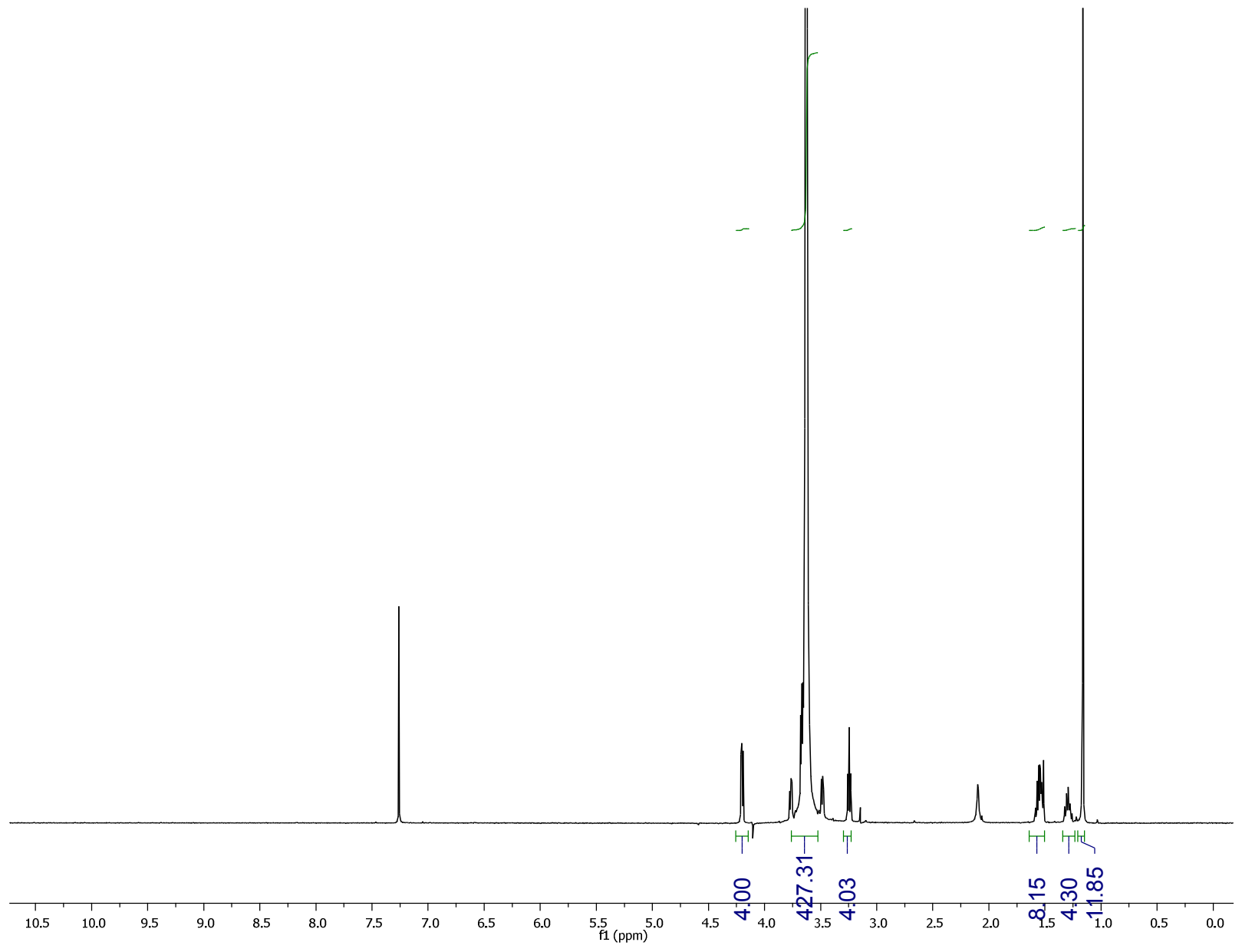

Figure S36. ${ }^{1} \mathrm{H}-\mathrm{NMR}$ spectrum of $\mathrm{A}_{2 \mathrm{H}}$ ' 


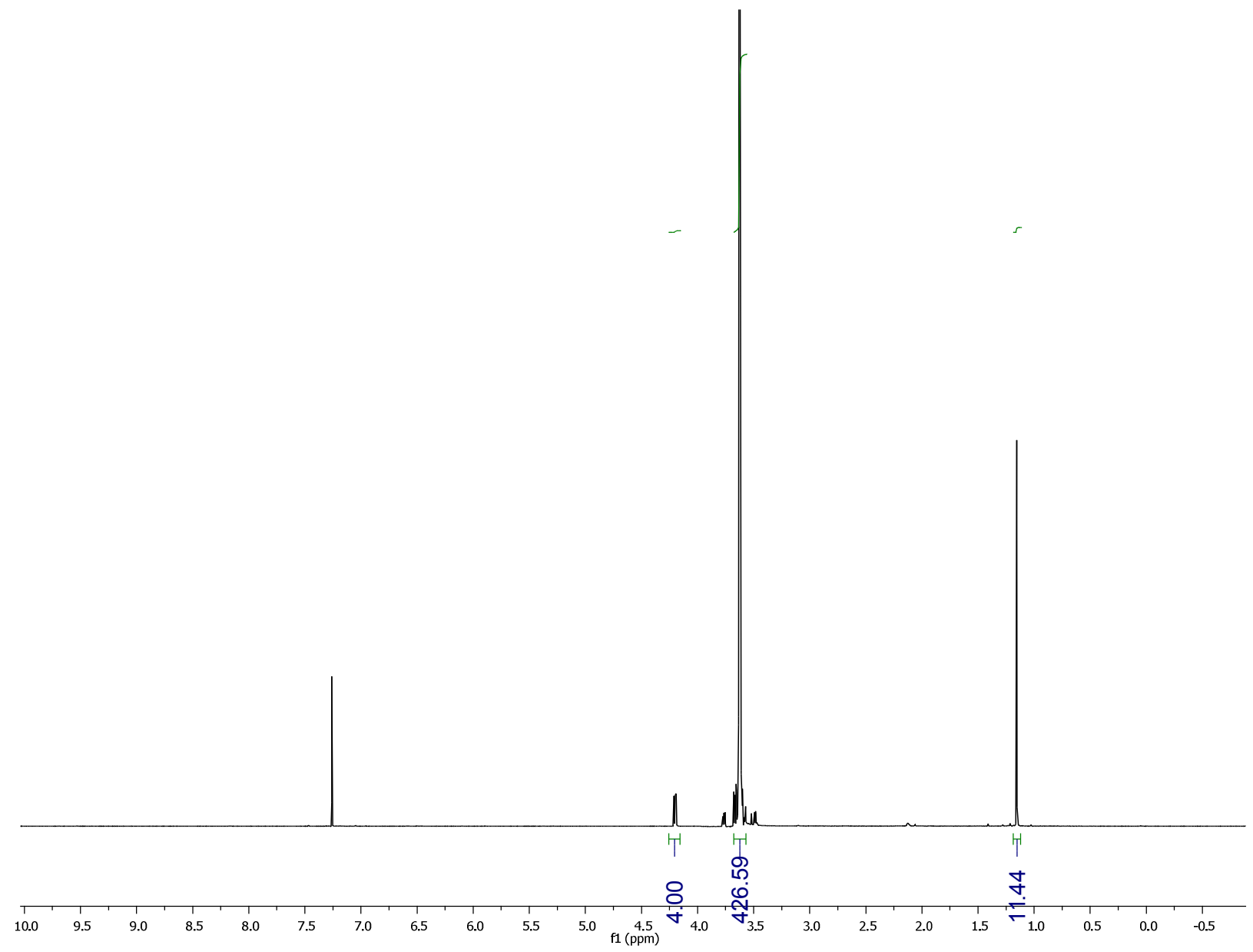

Figure S37. ${ }^{1} \mathrm{H}-\mathrm{NMR}$ spectrum for $\mathrm{A}_{2 \mathrm{D}}$ ' 